\title{
DR-2002-8
}

$\mathrm{DOE} / \mathrm{BC} / 10640-21$

\section{COMPUTER SIMULATION OF RECOVERY OF HEAVY CRUDE OIL USING CARBON DIOXIDE DRIVE OR HUFF-N-PUFF}

\section{Final Report}

Work Performed for the Department of Energy

Under Contract No. DE-AS19-81BC10640

Date Published-November 1983

Colorado State University

Fort Collins, Colorado

\section{U. S. DEPARTMENT OF ENERGY}




\section{DISCLAIMER}

This report was prepared as an account of work sponsored by an agency of the United States Government. Neither the United States Government nor any agency Thereof, nor any of their employees, makes any warranty, express or implied, or assumes any legal liability or responsibility for the accuracy, completeness, or usefulness of any information, apparatus, product, or process disclosed, or represents that its use would not infringe privately owned rights. Reference herein to any specific commercial product, process, or service by trade name, trademark, manufacturer, or otherwise does not necessarily constitute or imply its endorsement, recommendation, or favoring by the United States Government or any agency thereof. The views and opinions of authors expressed herein do not necessarily state or reflect those of the United States Government or any agency thereof. 


\section{DISCLAIMER}

Portions of this document may be illegible in electronic image products. Images are produced from the best available original document. 
This report was prepared as an account of work sponsored by an agency of the United States Government. Neither the United States Government nor any agency thereof, nor any of their employees, makes any warranty, express or implied, or assumes any legal liability or responsibility for the accuracy, completeness, or usefulness of any information, apparatus, product, or process disclosed, or represents that its use would not infringe privately owned rights. Reference herein to any specific commercial product, process, or service by trade name, trademark, manufacturer, or otherwise does not necessarily constitute or imply its endorsement, recommendation, or favoring by the United States Government or any agency thereof. The views and opinions of authors expressed herein do not necessarily state or reflect those of the United States Government or any agency thereof.
DOE/BC/10640-21

Distribution Category UC-92a

\section{COMPUTER SIMULATION OF RECOVERY OF HEAVY CRUDE OIL USING CARBON DIOXIDE DRIVE OR HUFF-N-PUFF}

Final Report

By

Roland Begin

and

David A. Krueger, Principal Investigator

Department of Physics

Colorado State University

Fort Collins, Colorado 80523

Kenneth L. Spence, Technical Project Officer

Bartlesville Energy Technology Center

P.O. Box 1398

Bartlesville, Oklahoma 74005

Work Performed for the Department of Energy

Under Contract No. DE-AS19-81BC10640

Date Published-November 1983
$\mathrm{DOE} / \mathrm{BC} / 10640--21$

DE84 002484 
I. Introduction . . . . . . . . . . . . . . . . 1

II. Overview of Model . . . . . . . . . . . . . 5

III. Mathematical Development of the Model . . . . . . . 11

A. Governing Equations . . . . . . . . . . . . . 11

B. Pressure Equation Derivation ........... . 15

C. Finite Differencing of Equations . . . . . . . . . 19

IV. Solution Method ............... 25

V. Phase Properties . . . . . . . . . . . . . 29

A. Thermodynamic Equilibria . . . . . . . . . . 29

B. Density . . . . . . . . . . . . . 32

C. Viscosity .. . . . . . . . . . . . . . 35

D. Saturation ................ . . 36

E. Compressibility . . . . . ......... 37

F. Relative Permeability . . . . . . . . . . . 39

VI. Sample Runs . . . . . . . . . . . . . 42

VII. Discussion and Conclusions . . . . . . . . . . . 48

VIII. Nomenclature ... . . . . . . . . . . . 51

IX. References ................... 53

X. Appendix . . . . . . . . . . . . . . . 55

A. Sample Input Format . . . . . . . . . . . . 55

B. Sample Output Format . . . . . . . . . . . 58

C. Source Code for CO2CYCL . . . . . . . . . . . 62 
Figure II-1. Model geometry . . . . . . . . . . . 8

Figure III-1. Flow geometry . . . . . . . . . . . 12

Figure III-2, Grid detail . . . . . . . . . . . 20

Figure IV-1. Solution flow chart . . . . . . . . . 28

Figure V-1. Fluid phase behavior . . . . . . . . . 30

Figure V-2. Relative permeability . . . . . . . . 40

Table VI-1. Results of Sample Runs . . . . . . . . . 43

Table VI-2. Gas front location during sample runs . . . . 44 
Acknowledgment

The authors thank F. C. Orr, Jr. for providing a copy of his computer program for simulating one-dimensional convection of four phase, four component mixtures. 


\section{Introduction}

It has been estimated by the U.S. Bureau of Mines that the total amount of heavy oil deposits in this country exceeds 150 billion barrels (bbl). ${ }^{1}$ This resource includes 55.5 billion bbl of oil with an API gravity less than $20^{\circ}$ and 21.3 billion bb1 that lie in shallow reservoirs which are less than 1500 feet deep. Forty percent of the proven heavy crude deposits are in Kansas, Missouri, and Oklahoma in reservoirs that are shallower than 500 feet deep. ${ }^{2}$ Most of the remaining deposits are located in deeper reservoirs located in California and Louisiana. Given the great variety of conditions that can exist in different reservoirs and the importance of the economic and environmental considerations involved in tertiary recovery operations, the development of a number of alternative technologies to recover this oil is crucial.

Many enhanced recovery techniques exist. 3,4 Waterflooding, for example, has been a standard secondary recovery practice for decades. However, by itself it is seldom useful in the recovery of highly viscous crude oils. This is due to the adverse mobility ratio of water to such crudes. In general, a mobility ratio, $\left(\mathrm{K}_{\mathrm{w}} / \mu_{\mathrm{w}}\right) /\left(\mathrm{K}_{\mathrm{o}} / \mu_{\mathrm{o}}\right)$, greater than one is considered unfavorable since water will usually finger through the oil at such ratios resulting in poor oil recovery.

Immiscible gas displacement processes (e.g., using air as the displacing fluid), like waterfloods, have been utilized in recovery operations for many years. Although such processes have even less favorable mobility ratios than do waterfloods, they have the advantage that the injected gas, being lighter than oil or water, will generally form a gas cap, thereby forcing the oil to migrate downdip to a well. 
In contrast to immiscible displacements where one fluid phase displaces another fluid phase without mixing between the phases, in miscible displacements no distinct interface exists between the displaced and displacing fluids. That is, miscibility implies that the two fluids can mix in all proportions. Generally, the recovery of heavy oil requires the application of such miscible displacement processes. Chemical solvents, dry gas, enriched gas, and carbon dioxide are typical displacing agents in miscible floods. Often, to improve the recovery economics, a small quantity of miscible fluid is driven by a large slug of immiscible fluid. Dry gas displacements are generally applicable on1y in reservoirs where pressures are in excess of 2500 psi, whereas enriched gas and chemical solvent displacements are useful down to roughly 1200 psi. 4

Displacement processes that use $\mathrm{CO}_{2}$ as the displacing agent can be classed as either miscible or partially miscible. Complete miscibility of $\mathrm{CO}_{2}$ with oil is not generally achieved unless the reservoir pressure is greater than about $1500 \mathrm{psi}$. This minimum miscibility pressure (MMP) will vary considerably depending upon both the oil composition and the reservoir temperature. The displacement mechanisms most important in $\mathrm{CO}_{2}$ processes are the reduction of the oil viscosity and swelling of the oil. These will be active to some degree even at pressures below the MMP. Various techniques have been tried using $\mathrm{CO}_{2} \cdot$ These include carbonated water-flooding, water-alternated-with-gas (WAG) injection, $\mathrm{CO}_{2}$ mixed with flue exhaust gases, and continuous $\mathrm{CO}_{2}$ injection. Because the solubility of $\mathrm{CO}_{2}$ in oil increases with pressure, the application of $\mathrm{CO}_{2}$ processes have so far been generally limited to relatively deep reservoirs (>2000 feet). 
The recovery of heavy crude from shallow deposits such as those described above presents some unique problems to be investigated. At these depths the maximum pressure that the reservoir can withstand without fracturing is usually less than 500 psi (assuming a pressure gradient of 1 psi/foot of depth). Since the solubility of $\mathrm{CO}_{2}$ in oil increases with pressure this restriction is an important one. This situation could be improved somewhat if the injectivity of the reservoir were increased by hydraulically fracturing the formation. It is plausible to assume that injection of $\mathrm{CO}_{2}$ into such fractures would serve to stimulate: the oil in the near vicinity of the fracture. The resultant increase in swelling and decreased viscosity of the oil phase near the fracture should help displace the oil toward the fracture. As injection of $\mathrm{CO}_{2}$ continues and the oil and water become saturated, a mobile gas phase will develop. The appearance of gas in the pores blocks the flow of oil and water reducing their relative permeabilities drastically. However, assuming a favorable ratio of vertical to horizontal absolute permeability, then since the gas is less dense than the oil it will tend to percolate up through the reservoir eventually forming a secondary gas cap at the top of the formation. This gas cap will then aid in the displacement of oil toward the fracture and the well bore.

Because of the enormously complex nature of the system described above, the present study is limited to an investigation of the behavior of the flows in and near a fracture. The numerical model simulates multicomponent, multiphase, compressible flow through a horizontal twodimensional porous medium which is bounded on one side by a onedimensional fracture. The absolute permeability of the fracture is assumed to be much greater (five orders of magnitude or more) than that 
of the reservoir matrix, resulting in the simplification that flow in the matrix is predominately perpendicular to the fracture face. Flow in the matrix parallel to the fracture is ignored in this model.

The fluid system consists of three components in three phases. Component 1 is the injected fluid, e.g., $\mathrm{CO}_{2}$, and can exist in any of the three phases - gas, oil, and water. Component 2 is the hydrocarbon component and is assumed to be heavy enough so that it exists only in the oil phase. Component 3 is the aqueous component and is restricted to the water phase. All fluid properties, except, viscosity and relative permeability, are assumed to be linear functions of pressure and composition. The temperature of the system is taken as constant and effects due to capillary pressure and gravity are not included.

The mathematical formulation is based on a set of molar continuity equations (one per component), the phase equilibrium condition, and a volume conservation equation. Reduction of this system of equations to a single equation in pressure leads to a sequential (implicit pressureexplicit moles) method of solution. In-step iterations are performed to increase the implicitness of the method. The algorithm includes time step control and a volume balance check.

A flow chart of the computer code as well as the source code and input and output formats are included in the Appendix. Three sample problems are examined. 


\section{Overview of Model}

The fundamental relation describing flow in a porous medium is Darcy's Law which 'simply states that the volumetric flow rate, $\vec{Q}$, through a porous medium is directly proportional to the pressure gradient. For single phase, single component flow this relation has the form:

$$
\overrightarrow{\mathrm{v}}=-(\mathrm{K} / \mu)(\nabla \mathrm{P}-\rho \mathrm{g} \nabla \mathrm{D})
$$

where:

$$
\begin{aligned}
& \begin{array}{l}
\vec{v} \\
=
\end{array} \begin{array}{l}
\vec{Q} / A=\text { the apparent macroscopic velocity (also known as } \\
\text { the superficial or Darcy velocity), }
\end{array} \\
& K=\text { absolute permeability of the medium, } \\
& \mu=\text { viscosity of fluid, } \\
& P=\text { pressure, } \\
& \rho=\text { fluid density, } \\
& g=\text { acceleration due to gravity, } \\
& D=\text { depth, } \\
& A=\text { contact area. }
\end{aligned}
$$

In multiphase, multi-component flow each fluid phase, e.g., gas, oil, and water, is assumed to be individually governed by Darcy's Law' and each component is subject to the constraint of mass conservation. Darcy's Law for some phase $j$ may be written:

$$
\overrightarrow{\mathrm{v}}_{j}=-\left(\mathrm{k}_{\mathrm{rj}} \mathrm{K} / \mu_{j}\right)\left(\nabla \mathrm{P}_{j}-\rho_{j} \mathrm{g \nabla D}\right)
$$


where

$$
\begin{aligned}
& \mathrm{k}_{\mathrm{rj}}=\text { relative permeability of phase } \mathrm{j} \text { (dimensionless and } \\
& 0<k_{r j}<1 \text { ), } \\
& \mu_{j}, \rho_{j}=\text { viscosity and density of phase } j \text {. }
\end{aligned}
$$

In general, the pressures in the phases will not be equal due to the presence of capillary pressure, i.e., the pressure difference across the interface separating two fluid phases. If, however, the capillary pressure is small compared to the externally imposed pressure gradient then the pressure in the different phases are approximately the same and $P_{j} \rightarrow P$.

Conservation of mass of component $i$ can be expressed:

$$
D_{t}\left(\phi \Sigma_{j} x_{i j} \rho_{j} S_{j}\right)=-\nabla \cdot \Sigma_{j} x_{i j} \rho_{j} \vec{v}_{j}
$$

where

$$
\begin{aligned}
& x_{i j}=\text { the mole fraction of component } i \text { in phase } j, \\
& \phi \quad=\text { porosity, } \\
& s_{j}=\text { saturation of phase } j, \\
& D_{t}=\text { the partial derivative operator with respect to } t .
\end{aligned}
$$

In this model, we assume that the system is a horizontal plane and we can therefore neglect gravity in our formulation. We further assume that the capillary pressure is zero. 
There will be an equation like Eq. (II-3) for each component of the system. These equations must be discretized and solved for each grit block in the system (see Sec. III). The geometry of the system and its corresponding discrete representations are illustrated in Fig. II-1.

Finally, we observe that if the permeability of the fracture is much larger than that of the rock matrix, and the we11 is located as indicated in the figure, then although the flow in the fracture will be both parallel and perpendicular to the fracture axis the flow in the matrix will be primarily perpendicular to the fracture. That is, even though we are considering a two-dimensional geometry the flow in each matrix "branch" will be essentia1ly one-dimensional. This results in a substantia1 simplification of the solution algorithm.

The conditions leading to this simplified flow geometry can be made more quantitative. The basic constraint is that the flow in the reservoir matrix perpendicular to the fracture (y-direction) be much greater than that parallel to the fracture (z-direction):

$$
\mathrm{q}_{\mathrm{Ry}}>\mathrm{q}_{\mathrm{Rz}} \text { or } \Delta \mathrm{zD} \mathrm{D}_{\mathrm{R}}\left(\mathrm{P}_{\mathrm{R}}\right)>\Delta \mathrm{yD}_{\mathrm{z}}\left(\mathrm{P}_{\mathrm{R}}\right)
$$

This implies that the pressure gradients in the $z$-direction in both the matrix and the fracture are approximately the same:

$$
\mathrm{D}_{z}\left(\mathrm{P}_{\mathrm{R}}\right) \approx \mathrm{D}_{\mathrm{z}}\left(\mathrm{P}_{\mathrm{F}}\right)
$$

where

$$
\begin{aligned}
& P_{R}=\text { pressure in the rock matrix, } \\
& P_{F}=\text { pressure in the fracture. }
\end{aligned}
$$



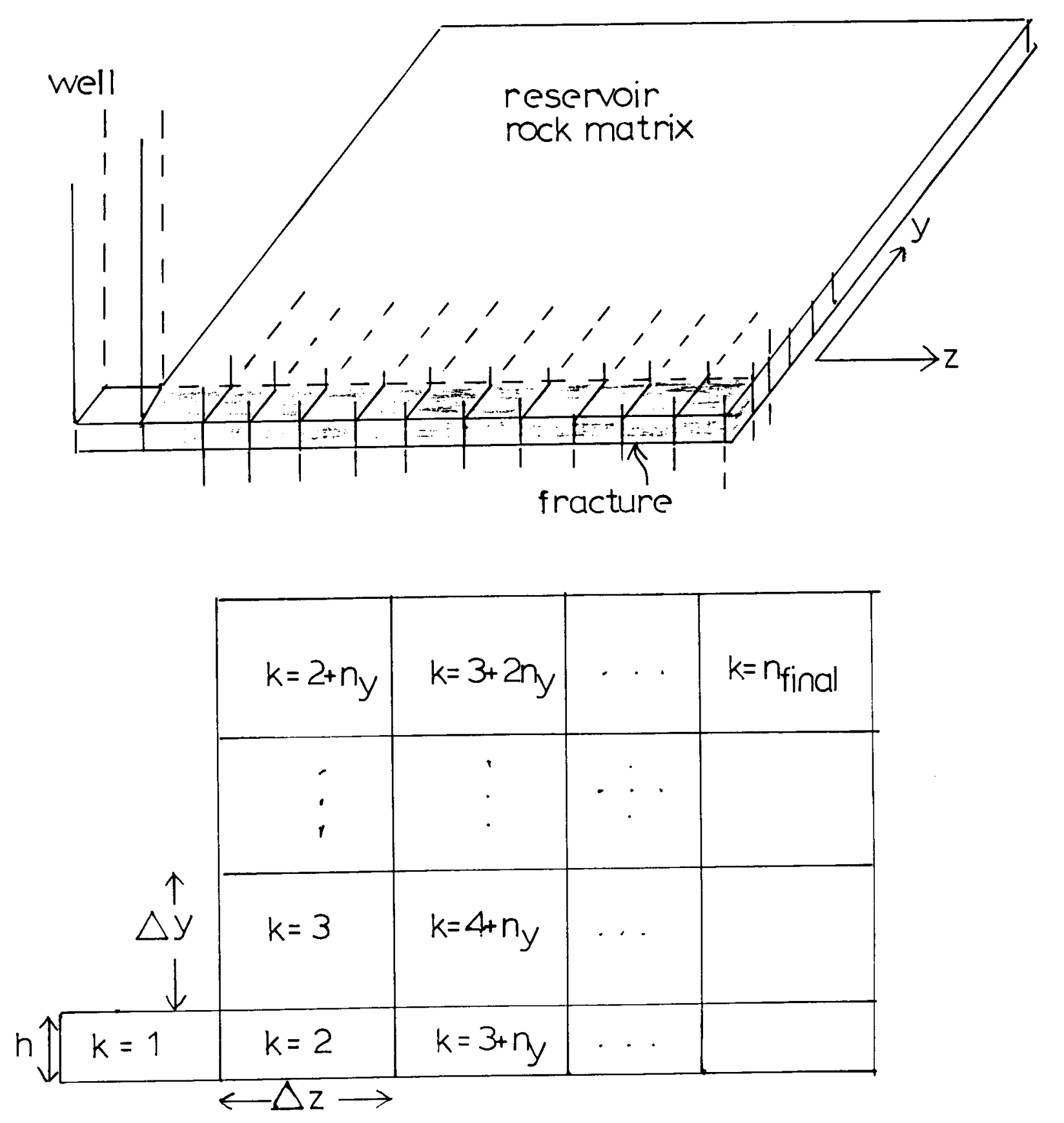

Figure II-1. Model geometry. 
If we also assume that the flow into each matrix branch is roughly equal then we get:

$$
\Delta z\left(K_{R} / \mu\right) D_{y}\left(P_{R}\right) \approx h\left(K_{F} / \mu\right) D_{z}\left(P_{F}\right) / n_{z}
$$

where

$$
\begin{aligned}
& \mathrm{h}=\text { fracture width, } \\
& \mathrm{n}_{\mathrm{z}}=\text { number of grid blocks in fracture. }
\end{aligned}
$$

Combining relations (II-4), (II-5), and (II-6), yield the condition:

$$
\mathrm{h} /\left(\mathrm{n}_{\mathrm{y}} \Delta \mathrm{y}\right)>\mathrm{K}_{\mathrm{R}} / \mathrm{K}_{\mathrm{F}}
$$

where

$$
\mathrm{n}_{\mathrm{y}}=\text { number of grid blocks in matrix branch } .
$$

If the fracture is approximated by two closely spaced parallel plates then its permeability is given by: ${ }^{5}$

$$
\mathrm{K}_{\mathrm{F}} \approx \mathrm{h}^{2} / 12
$$

Thus, the flow condition reduces to:

$$
\mathrm{h}^{3} / 12 \mathrm{~K}_{\mathrm{R}}>\ell_{\mathrm{R}}
$$


If $\mathrm{h} \sim 1 \mathrm{~mm}=10^{-3} \mathrm{~m}$ and $\mathrm{K}_{\mathrm{R}} \sim 10^{2} \mathrm{md}=10^{-9} \mathrm{~cm}^{2}$, then

$$
\mathrm{h}^{3} / 12 \mathrm{~K}_{\mathrm{R}}=10^{5} \mathrm{~cm}>>\ell_{\mathrm{R}}
$$

which is easily satisfied for simulations of flows in laboratory cases. Therefore, for fractures having high permeabilities the simplified flow geometry described above is clearly reasonable.

With the preliminary exposition of the concepts of flow behavior and component mass continuity complete, we are ready to begin the mathematical construction of our model. 


\section{Mathematical Development of the Mode1}

\section{A. Governing Equations}

The development of the numerical model begins with the molar balance of each component in each of the system's grid blocks. The molar continuity of component $i$ in the $k^{\text {th }}$ fracture grid block is given. by:

$$
\begin{aligned}
& {\left[\Delta\left(\Sigma_{j} N_{i j}\right) / \Delta t\right]_{k}=\left[\Sigma_{j} x_{i j}{ }^{\rho}{ }_{j} q_{z j}\right]_{k}-\Delta z / 2} \\
& \quad-\left[\Sigma_{j} x_{i j}{ }^{\rho}{ }_{j} q_{z j}\right]_{k}+\Delta z / 2-\left[\Sigma_{j} x_{i j}{ }^{\rho}{ }_{j} q_{y j}\right]_{k}+h / 2
\end{aligned}
$$

where:

$$
\begin{aligned}
\mathrm{N}_{i j} \quad= & \text { number of moles of component } i \text { in phase } j, \\
x_{i j}= & \text { molar fraction of } i \text { in } j, \\
\rho_{j}= & \text { molar density of phase } j, \\
q_{z j}, q_{y j}= & \text { volumetric flow rates of phase } j \text { along the fracture } \\
& \text { axis (z-direction) and perpendicular to the fracture } \\
& \text { (y-direction). }
\end{aligned}
$$

The flow geometry is indicated in Fig. III-1.

For convenience later in reducing the initial system of equations to a single equation in pressure, we transform the discrete form of the continuity equation (Eq. (1)) into the corresponding differential form:

$$
\left[D_{t}\left(\Sigma_{j} N_{i j}\right]_{k}=-\Delta z\left[D_{z}\left(\Sigma_{j} x_{i j}^{\rho} q_{z j}\right)\right]_{k}-\left[\Sigma_{j} x_{i j} \rho_{j} q_{y j}\right]_{k}+h / 2 \cdot\right. \text { (III-2a) }
$$



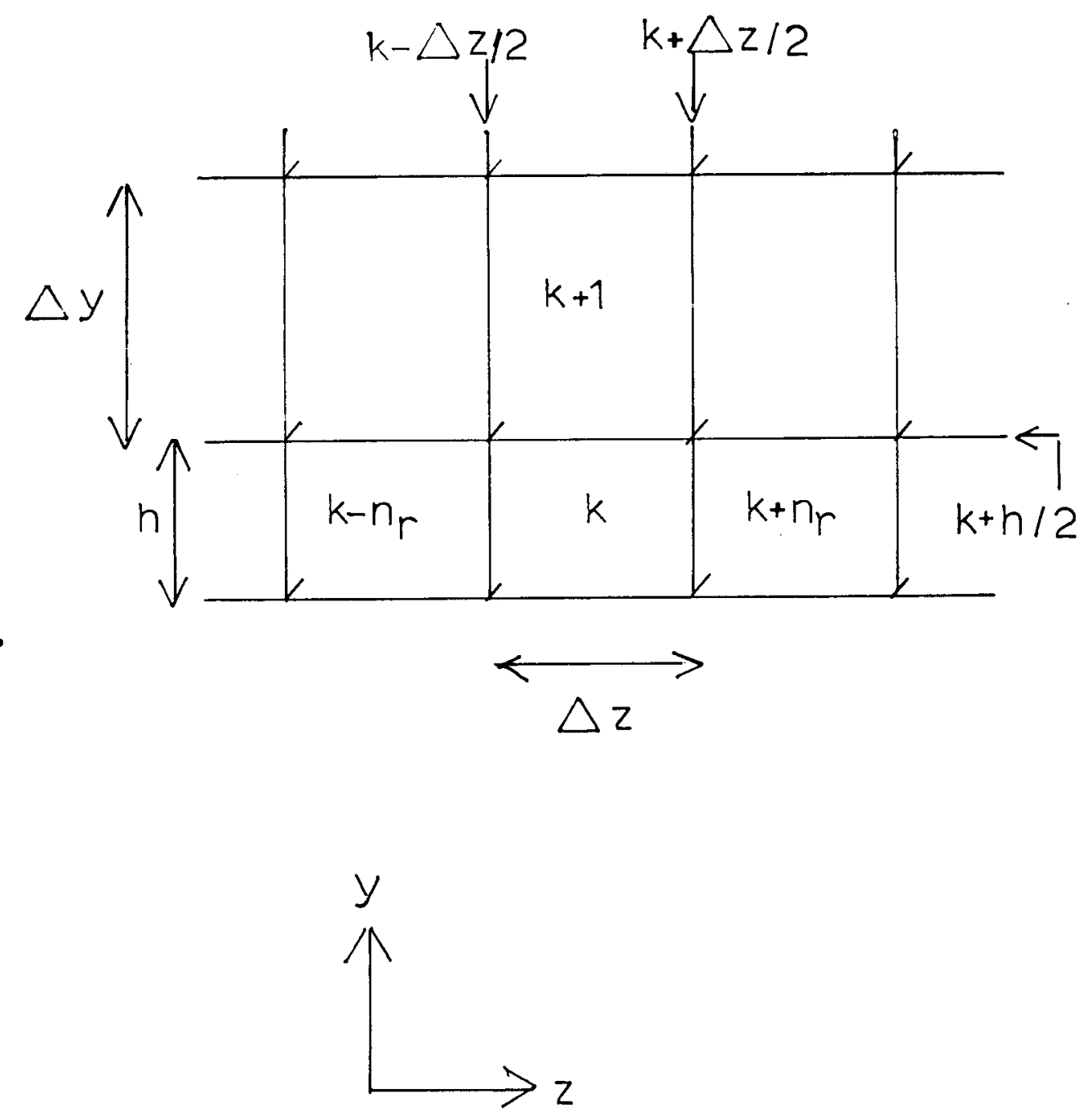

Figure III-1. Flow geometry. 
Here $D_{t}$ and $D_{z}$ are differential operators representing the partial derivative of the argument with respect to the operator subscript.

Similar reasoning leads to an equation of continuity for component $i$ valid for blocks in the reservoir matrix:

$$
\left[D_{t}\left(\Sigma_{j} N_{i j}\right)\right]_{k}=-\Delta y\left[D_{y}\left(\Sigma_{j} x_{i j} \rho_{j} q_{y j}\right)\right]_{k}
$$

There are three continuity equations for each grid block in the system. For example, in the fracture:

$$
\begin{gathered}
\mathrm{CO}_{2}(\mathrm{i}=1): \quad\left[\mathrm{D}_{\mathrm{t}}\left(\mathrm{N}_{11}+\mathrm{N}_{12}+\mathrm{N}_{13}\right)\right]_{k}= \\
-\Delta z\left[\mathrm{D}_{z}\left(\mathrm{~W}_{1 z}\right)\right]_{k}-\left[\mathrm{W}_{1 \mathrm{y}}\right]_{k}+\mathrm{h} / 2 \\
\mathrm{HC}(\mathrm{i}=2): \quad\left[\mathrm{D}_{t}\left(\mathrm{~N}_{22}\right)\right]_{k}=-\Delta z\left[\mathrm{D}_{z}\left(\mathrm{~W}_{2 z}\right)\right]_{k}-\left[\mathrm{W}_{2 \mathrm{y}}\right]_{\mathrm{k}}+\mathrm{h} / 2 \\
\mathrm{H}_{2} \mathrm{O}(\mathrm{i}=3): \quad\left[\mathrm{D}_{t}\left(\mathrm{~N}_{33}\right)\right]_{k}=-\Delta z\left[\mathrm{D}_{z}\left(\mathrm{~W}_{3 z}\right)\right]_{k}-\left[\mathrm{W}_{3 \mathrm{y}}\right]_{k}+\mathrm{h} / 2
\end{gathered}
$$

where:

$$
\begin{aligned}
& w_{1 z}=\rho_{1} q_{1 z}+x_{12} \rho_{2} q_{2 z}+x_{13} \rho_{3} q_{3 z} \\
& w_{2 z}=x_{22} \rho_{2} q_{2 z} \\
& w_{3 z}=x_{33} \rho_{3} q_{3 z}
\end{aligned}
$$

with similar expressions for $W_{1 y}, W_{2 y}$, and $W_{3 y}$. 
For a compressible fluid system we require that the total volume of the fluids be conserved. If the rock matrix is incompressible then the pore volume is constant and the above condition constrains the total fluid volume to be equal to the pore volume at all times:

$$
\left[\mathrm{V}_{\text {pore }}\right]_{\mathrm{k}}=\left[\mathrm{V}_{\text {fluid }}\right]_{\mathrm{k}}=\left[\mathrm{N}_{11} \mathrm{~V}_{11}+\mathrm{N}_{12} \mathrm{~V}_{12}+\mathrm{N}_{13} \mathrm{~V}_{13}+\mathrm{N}_{22} \mathrm{~V}_{22}+\mathrm{N}_{33} \mathrm{~V}_{33}\right]_{\mathrm{k}} \quad(\text { III }-6)
$$

where:

$$
v_{i j}=\text { volume of a mode of component } i \text { in phase } j \text {. }
$$

Finally, the components are distributed among the three phases so as to insure thermodynamic equilibrium. We consider two possible cases: (a) the oil and water phases are not completely saturated with $\mathrm{CO}_{2}$, therefore there is no mobile gas phase present; (b) the oil and water are saturated and a mobile gas phase is present. This implies (see Sec. V-A on phase equilibria) for case (a):

$$
\frac{x_{12}}{x_{13}}=\frac{{ }^{\theta} 12}{{ }_{13}}=n=\text { constant }
$$

where ${ }_{12} \mathrm{P}$ and ${ }_{13} \mathrm{P}$ are the molar solubilities of $\mathrm{CO}_{2}$ in the oil and water, respectively, and for case (b):

$$
\begin{aligned}
& \mathrm{x}_{12}=\theta_{12} \mathrm{P} \\
& \mathrm{x}_{13}=\theta_{13} \mathrm{P}
\end{aligned}
$$


Observe that Eqs. (III-3) to (III-6) and either (III-7a) or (III-7b) can be combined and reduced to a single equation in pressure (see next section). For $\mathrm{N}$ grid blocks there will be $\mathrm{N}$ such equations in pressure which must be solved simultaneously.

A set of semi-empirical equations relating fluid properties, such as density, viscosity, relative permeability, etc., to the pressure and composition of the system completes the mathematical description of the mode1.

\section{B. Pressure Equation Derivation}

As mentioned above, Eqs. (III-3) to (III-7) can be reduced to a single equation in pressure. This equation has the following form in the fracture:

$$
\begin{aligned}
A D_{t}(P)= & -\Delta z\left[D_{z}\left(W_{1 z}\right)+\delta_{2} D_{z}\left(W_{22}\right)\right. \\
& \left.+\delta_{3} D_{z}\left(W_{3 z}\right)\right]-\left[W_{1 y}+\delta_{2} W_{2 y}+\delta_{3} W_{3 y}\right]
\end{aligned}
$$

where $A, \delta_{2}$, and $\delta_{3}$ are time-lagged coefficients which are dependent upon the particular phase equilibrium condition considered.

For case (a), where no mobile gas is present in the grid block, we find that: 


$$
\begin{aligned}
A= & C_{\text {eff }}\left(A^{\prime} / A^{\prime \prime}\right) \\
C_{\text {eff }}= & -\left[N_{11} D_{P}\left(V_{11}\right)+N_{12} D_{P}\left(V_{12}\right)+N_{13} D_{P}\left(V_{13}\right)\right. \\
& \left.+N_{22} D_{P}\left(V_{22}\right)+N_{33^{2}} D_{P}\left(V_{33}\right)\right] \\
A^{\prime}= & \left(N_{13}+N_{33}\right) x_{22}+n\left(N_{12}+N_{22}\right) x_{33} \\
A^{\prime \prime}= & V_{13}\left(N_{13}+N_{33}\right) x_{22}+n V_{12}\left(N_{12}+N_{22}\right) x_{33} \\
\delta_{2}= & {\left[V_{22} A^{\prime}+\eta N_{13}\left(V_{12}-V_{13}\right)\right] / A^{\prime \prime} } \\
\delta_{3}= & {\left[V_{\left.33^{A}-N_{12}\left(V_{12}-V_{13}\right)\right] / A^{\prime \prime}} .\right.}
\end{aligned}
$$

When a mobile gas phase is present we have case (b) and:

$$
\begin{aligned}
A= & \left(C_{\text {eff }}+C^{\prime}\right) / V_{11} \\
C^{\prime}= & \left(V_{11}-V_{12}\right)\left(\mathrm{N}_{12}+\mathrm{N}_{22}\right) \theta_{12} /\left(1-\theta_{12} \mathrm{P}\right) \\
& +\left(\mathrm{V}_{11}-\mathrm{V}_{13}\right)\left(\mathrm{N}_{13}+\mathrm{N}_{33}\right) \theta_{13} /\left(1-\theta_{13} \mathrm{P}\right) \\
\delta_{2}= & {\left[\mathrm{V}_{22}\left(1-\theta_{12} \mathrm{P}\right)+\left(\mathrm{V}_{12}-\mathrm{V}_{11}\right) \theta_{12} \mathrm{P}\right] /\left[\mathrm{V}_{11}\left(1-\theta_{12} \mathrm{P}\right)\right] } \\
\delta_{3}= & {\left[\mathrm{V}_{33}\left(1-\theta_{13} \mathrm{P}\right)+\left(\mathrm{V}_{13}-\mathrm{V}_{11}\right) \theta_{13} \mathrm{P}\right] /\left[\mathrm{V}_{11}\left(1-\theta_{13} \mathrm{P}\right)\right] }
\end{aligned}
$$

Note that in Eqs. (III-8a) and (III-8b) above, $\mathrm{C}_{\text {eff }}$ is the effective compressibility of the fluid system.

Now, using Darcy's Law (neglecting gravity), we can substitute into $\mathrm{Eq} \cdot(\operatorname{III}-8)$ :

$$
q_{j}=\tau v_{j}=-\tau \lambda_{j} \nabla P
$$


where:

$$
\begin{aligned}
\tau= & \text { cross-sectional area perpendicular to flow }\left(\tau_{F}=\right.\text { fracture } \\
& \begin{array}{l}
\text { cross-sectional area, } \tau_{R}=\text { reservoir branch cross- } \\
\text { sectional area })
\end{array} \\
\lambda_{j}= & \text { mobility of phase } j, \\
\lambda_{j z}= & \left(k_{r j} / \mu_{j}\right) k_{\text {frac }}, \\
\lambda_{j y}= & \left(k_{r j} / \mu_{j}\right) k_{\text {res. }} .
\end{aligned}
$$

For the fracture block adjacent to the well block the total volumetric flow rate across the well-fracture interface is a constant value set by the user of the model. Thus, for $k=2$ :

$$
\begin{aligned}
{\left[_{t}(P)\right]_{k}=} & {\left[W_{1 z}+\delta_{2} W_{2 z}+\delta_{3} W_{3 z}\right]_{k-\Delta z / 2} } \\
& +\tau_{F}\left[w_{1 z}+\delta_{2} W_{2 z}+\delta_{3} W_{3 z}\right]_{k+\Delta z / 2} D_{z}(P) \\
& +\tau_{R}\left[w_{1 y}+\delta_{2}{ }^{W} 2 y+\delta_{3}{ }^{W} 3 y\right]_{k+h / 2} D_{y}(P)
\end{aligned}
$$

where:

$$
\begin{aligned}
& \mathrm{w}_{1 z}=\rho_{1}{ }_{1 z}+\mathrm{x}_{12} \rho_{2} \lambda_{2 z}+\mathrm{x}_{13} \rho_{3}{ }_{3 z}, \\
& \mathrm{w}_{2 z}=\mathrm{x}_{22} \rho_{2}{ }^{\lambda} 2 \mathrm{z}, \\
& \mathrm{w}_{3 z}=\mathrm{x}_{33^{\rho} 3^{\lambda} 3 z} .
\end{aligned}
$$

Note that the injection term []$_{k-\Delta z / 2}$ can be written: 


$$
\begin{aligned}
{[] } & =\rho_{1} q_{1 z}+\left(x_{12}+\delta_{2} x_{22}\right) \rho_{2} q_{2 z}+\left(x_{13}+\delta_{3} x_{33}\right) \rho_{3} q_{3 z} \\
& =\left[\rho_{1} f_{1}+\left(x_{12}+\delta_{2} x_{22}\right) \rho_{2} f_{2}+\left(x_{13}+\delta_{3} x_{33}\right) \rho_{3} f_{3}\right] Q
\end{aligned}
$$

where:

$$
\begin{aligned}
& f_{j}=\text { fractional flow of phase } j\left(f_{j}=\lambda_{j} / \Sigma_{j} \lambda_{j}\right), \\
& Q=\text { total volumetric flow rate. }
\end{aligned}
$$

For the remaining fracture blocks the pressure equation is given by:

$$
\begin{aligned}
{\left[A D_{t}(P)\right]_{k} } & =\Delta z \tau_{F}\left[D_{z}\left(w_{1 z} D_{z}(P)\right)+\delta_{2} D_{z}\left(w_{2 z} D_{z}(P)\right)+\delta_{3} D_{z}\left(w_{3 z} D_{z}(P)\right)\right]_{k} \\
& +\tau_{R}\left[\left(w_{1 y}+\delta_{2} w_{2 y}+\delta_{3} w_{3 y}\right) D_{y}(P)\right]_{k+h / 2}
\end{aligned}
$$

Finally, the pressure equation for blocks in the reservoir matrix branches is:

$$
\begin{aligned}
{\left[A D_{t}(P)\right]_{k} } & =\Delta y_{R}\left[D_{y}\left(w_{1 y} D_{y}(P)\right)+\delta_{2} D_{y}\left(w_{2 y} D_{y}(P)\right)\right. \\
& \left.+\delta_{3} D_{y}\left(w_{3 y} D_{y}(P)\right)\right]_{k} .
\end{aligned}
$$

The above pressure equations, Eqs. (III-9), (III-10), and (III-11), along with the continuity equations, Eqs. (III-3), (III-4), and (III-5) are now transformed into finite difference equations for a numerical solution for the pressures and compositions in each grid block. 
C. Finite Differencing of Equations

The differential equations presented above are differenced according to the following approximations:

$$
\begin{aligned}
& {\left[D_{t}(P)\right]_{k} \approx\left(P_{k}^{l+1}-P_{k}^{l}\right) / \Delta t} \\
& {\left[\mathrm{D}_{\mathrm{z}}(\mathrm{P})\right]_{\mathrm{k}+\Delta \mathrm{z} / 2} \approx\left(\mathrm{P}_{\mathrm{k}+\mathrm{n}_{\mathrm{r}}}^{\ell+1}-\mathrm{P}_{\mathrm{k}}^{\ell+1}\right) / \Delta \mathrm{z}} \\
& {\left[D_{y}(P)\right]_{k+\Delta y / 2 \approx\left(P_{k+1}^{l+1}-P_{k}^{\ell+1}\right) / \Delta y}} \\
& {\left[D_{z}(P)\right]_{k-\Delta z / 2} \approx\left(P_{k}^{\ell+1}-P_{k-n_{r}}^{\ell+1}\right) / \Delta z} \\
& {\left[D_{y}(P)\right]_{k-\Delta y / 2} \approx\left(P_{k}^{l+1}-P_{k-1}^{\ell+1}\right) / \Delta y} \\
& D_{z}\left(G D_{z}(P)\right)_{k} \approx\left[G_{+}^{\ell} P_{k+n_{r}}^{l+1}-\left(G_{+}^{\ell}+G_{-}^{l}\right) P_{k}^{l+1}+G_{-}^{\ell} P_{k-n_{r}}^{l+1}\right] /(\Delta z)^{2} \\
& D_{y}\left(G D_{y}(P)\right)_{k} \approx\left[G_{+}^{l} P_{k+1}^{l+1}-\left(G_{+}^{l}+G_{-}^{l}\right) P_{k}^{l+1}+G_{-}^{l} P_{k-1}^{l+1}\right] /(\Delta y)^{2} .
\end{aligned}
$$

The superscripts $\ell$ and $\ell+1$ denote, respectively, the current and advanced time levels. The subscripts refer to either grid block or grid interface location (Fig. III-1 and III-2). The G coefficients are evaluated "upstream" so.if the flow in the figure is left to right then $G_{+} \rightarrow G_{k}$ and $G_{-} \rightarrow G_{k-1}$, whereas if the flow is to the left, $G_{+} \rightarrow G_{k+1}$ and $G_{-} \rightarrow G_{k}$.

We assume that flow into or out of the fracture is governed primarily by the pressure drop in the rock matrix. Therefore the pressure gradient across the fracture-matrix interface is approximated by: 


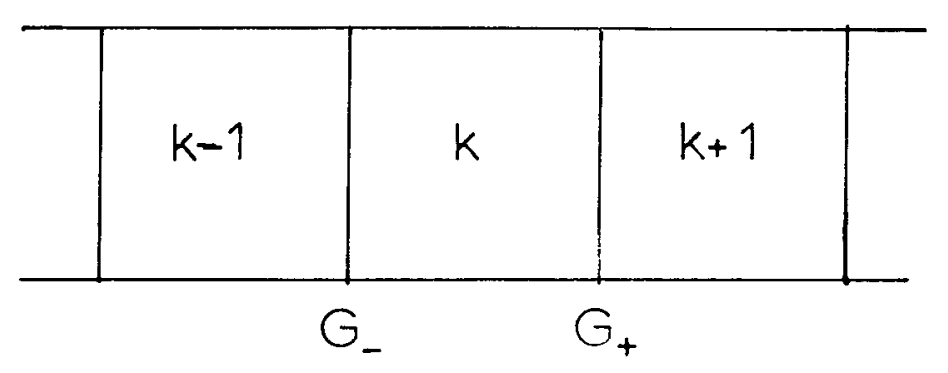

Figure III-2. Grid detail. 


$$
\left[D_{y}(P)\right]_{k+h / 2}=\left(P_{k+1}^{l+1}-P_{k}^{l+1}\right) /(\Delta y / 2) .
$$

Substitution of the above difference approximations into Eq. (III-10) yields a difference equation in pressure valid for fracture blocks not adjacent to the well block:

$$
\alpha_{k}^{l} \mathrm{p}_{\mathrm{k}-\mathrm{n}_{\mathrm{r}}+1}+\beta_{\mathrm{k}}^{\ell} \mathrm{p}_{\mathrm{k}}^{\ell+1}+\gamma_{\mathrm{k}}^{\ell} \mathrm{p}_{\mathrm{k}+\mathrm{n}_{\mathrm{r}}}^{\ell}+\varepsilon_{\mathrm{k}}^{\ell} \mathrm{p}_{\mathrm{k}+1}^{\ell+1}=\theta_{\mathrm{k}}^{\ell}
$$

where:

$$
\begin{aligned}
& \alpha_{k}^{\ell}=r_{z}{ }^{\tau} F_{k-}^{l} \\
& \gamma_{k}^{\ell}=r_{z}^{\tau} F_{k+}^{a_{k}^{l}} \\
& \varepsilon_{k}^{\ell}=r_{y}{ }^{\top} e_{k+}^{\ell} \\
& \beta_{k}^{l}=-\left\{r_{z}{ }_{F}\left(a_{k+}^{l}+a_{k-}^{l}\right)+r_{y} \tau_{R} e_{k+}^{l}+A_{k}^{l}\right\} \\
& \theta_{k}^{\ell}=-A_{k}^{l} P_{k}^{\ell}
\end{aligned}
$$

with:

$$
\begin{aligned}
& a_{k+}^{l}=w_{1 z+}^{l}+\delta_{2}^{l} w_{2 z+}^{l}+\delta_{3}^{l} w_{3 z+}^{l} \\
& a_{k-}^{l}=w_{1 z-}^{l}+\delta_{2}^{l} w_{2 z-}^{l}+\delta_{3}^{l} w_{3 z-}^{l} \\
& e_{k+}^{l}=w_{1 y+}^{l}+\delta_{2}^{l} w_{2 y+}^{l}+\delta_{3}^{l} w_{3 y+}^{l} \\
& r_{z}=\Delta t / \Delta z, \quad r_{y}=2 \Delta t / \Delta y
\end{aligned}
$$

and $A, \delta_{2}, \delta_{3}$ and the $W$ 's were defined earlier. 
The difference equation for the fracture block adjacent to the well is obtained by substituting the difference approximations into Eq. (III-9) yielding:

$$
B_{2}^{\ell} \mathrm{P}_{2}^{\ell+1}+\gamma_{2}^{\ell} \mathrm{P}_{2+\mathrm{n}_{\mathrm{r}}}^{\ell+1}+\varepsilon_{2}^{\ell} \mathrm{P}_{3}^{\ell+1}=\theta_{2}^{\ell}
$$

where $\gamma$ and $\varepsilon$ have the same definitions as in the previous case and:

$$
\begin{aligned}
& B_{2}^{l}=-\left\{r_{z}{ }^{\tau} a_{k}^{l}+{ }^{l}{ }^{\tau} R e_{k+}^{l}+A_{k}^{l}\right\} \\
& \theta_{2}^{l}=-\mathrm{A}_{2}^{l} \mathrm{P}_{2}^{l}-\underline{Q}^{\ell} \\
& \underline{Q}^{l}=\text { number of moles flowing into or out of well block during }
\end{aligned}
$$

Note that during injecion of a single fluid we have:

$$
\underline{Q}^{\ell}=\Delta t\left[\rho_{j}\right]_{k=1}^{\ell} Q_{i n}
$$

where $Q_{\text {in }}$ is the user-defined, total volumetric injection rate.

During the production phase of the huff-n-puff cycle this becomes:

$$
\underline{Q}^{l}=\Delta t\left\{\rho_{1} f_{1}+\left(x_{12}+\sigma_{2} x_{22}\right) \rho_{2} f_{2}+\left(x_{13}+\delta_{3} x_{33}\right) \rho_{3} f_{3}\right\}_{k=2}^{l} Q_{\text {out }}
$$

where $Q_{\text {out }}$ is the volumetric production rate.

Substitution of the appropriate difference approximations into Eq. (III-11) gives the pressure difference equation for matrix grid blocks: 


$$
\alpha_{k}^{l} P_{k-1}^{l+1}+\beta_{k}^{l} P_{k}^{l+1}+\varepsilon_{k}^{\ell} P_{k+1}^{l+1}=\theta_{k}^{\ell}
$$

where:

$$
\begin{aligned}
& \alpha_{k}^{l}=r_{y}{ }^{\top} e_{k-}^{\ell} \\
& \varepsilon_{k}^{\ell}=r_{y} \tau_{R} e_{k+}^{l} \\
& \beta_{k}^{\ell}=-\left[r_{y}{ }^{\tau}{ }\left(e_{k+}^{\ell}+e_{k-}^{\ell}\right)+A_{k}^{\ell}\right] \\
& \theta_{\mathrm{k}}^{\ell}=-\mathrm{A}_{\mathrm{k}}^{\ell} \mathrm{P}_{\mathrm{k}}^{\ell}
\end{aligned}
$$

with:

$$
\begin{aligned}
& \mathrm{e}_{\mathrm{k}+}^{\ell}=\mathrm{w}_{1 \mathrm{y}+}^{\ell}+\delta_{2}^{\ell} \mathrm{w}_{2 \mathrm{y}+}^{\ell}+\delta_{3}^{\ell} \mathrm{w}_{3 \mathrm{y}+}^{\ell} \\
& \mathrm{e}_{\mathrm{k}-}^{\ell}=\mathrm{w}_{1 \mathrm{y}-}^{\ell}+\delta_{2}^{\ell} \mathrm{w}_{2 \mathrm{y}-}^{l}+\delta_{3}^{\ell} \mathrm{w}_{3 \mathrm{y}-}^{\ell}
\end{aligned}
$$

Note that $\mathrm{r}_{\mathrm{y}}=\Delta \mathrm{t} / \Delta \mathrm{y}$ except for the matrix branch grids blocks adjacent to the fracture where $r_{y}=2 \Delta t / \Delta y$. Consistency with the assumption described above on the pressure gradient governing flow between the fracture and the matrix requires that the $w^{\prime} s$ in the relevant equations contain the absolute permeability of the matrix. This requirement includes the case where fluid is moving from the fracture to the matrix and the relative mobility, $\lambda_{j}$, of the fluid is evaluated "upstream" in the fracture block.

Finally, the continuity or composition equations ((III-3), (III-4), $\left(\right.$ III-5)) are differenced explicitly. That is, the flow rates $q_{j}$ in those equations are rewritten as $f_{j} Q$ where the $Q$ 's are calculated from the solutions just obtained to the matrix of pressure equations 
discussed above. Following the numbering order discussed in Sec. II, this pressure matrix equation has the form:

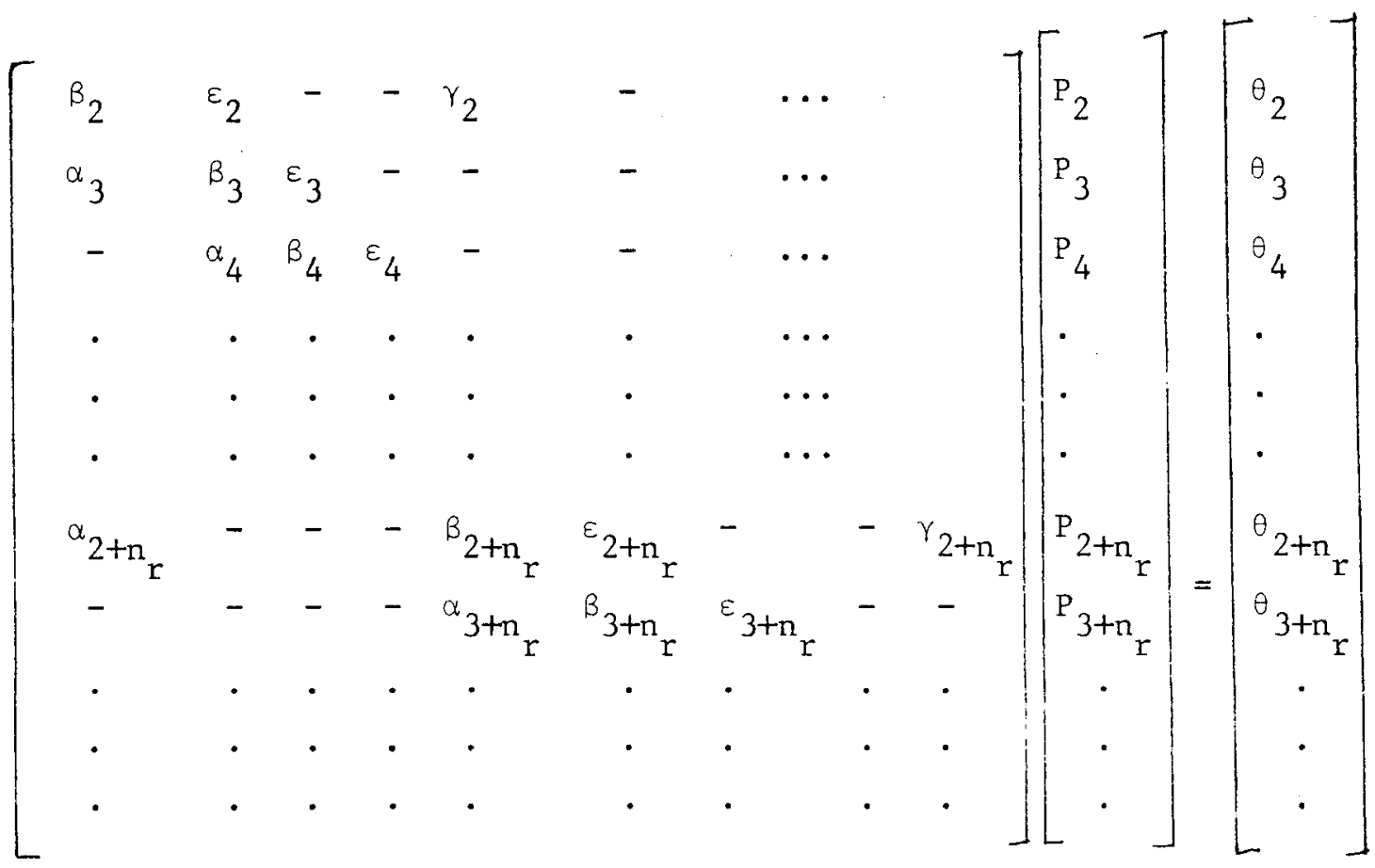

Utilizing the tridiagonal nature of segments of this matrix a modified Gaussian elimination algorithm was used to solve this set of equations. 


\section{Solution Method}

The solution approach employed in this numerical model is sequential. We implicitly solve the matrix of differenced pressure equations and use the solutions to calculate enter-block flow rates. These flow rates are then substituted into the explicitly differenced set of continuity equations to give the overall component composition of each block at the new time level.

To improve the accuracy of the pressure and composition solutions we use an in-step substitution iteration procedure. This consists of using the most recently computed compositions to predict the relative permeabilities and other fluid properties at the advanced time step and then substituting these values back into the coefficients of the pressure matrix and continuity equations and recalculating pressures and compositions. The procedure is repeated until the predicted relative permeatbilities satisfy a pre-set convergence criterion.

There are a number of possible sources of error related to the length of the time step that are inherent in sequential solution algorithms. These include time truncation errors, numerical stability of the solutions, overshooting, and continuity of the solution at the bubble point. We have included several time step controls in the mode]. to reduce the effect of these errors.

The time truncation error is most easily controlled by limiting the magnitude of change of some important variable during any time step. 6 We choose to limit the pressure rise allowed during a step. This is readily accomplished by reducing the step size by a factor DPLIM/DPMAX where DPMAX is the maximum pressure change calculated for a step and DPLIM is the maximum change allowed and is defined by the model user. 
Overshooting occurs when the flow into a block is less than the flow out of a block and the time step is so long that the block is completely emptied and a negative composition results. This occurs most frequently in the presence of a mobile gas phase. When such a condition is present, the step is halved and the entire calculation for that step is repeated.

The numerical stability limitation is due to the explicit calculation of relative permeabilities. Although we use in-step substitution iterations to improve the relative permeability values, convergence of those values will not occur in such an iterative process for any time step that violates the following condition: ${ }^{7}$

$$
2 \Delta t D_{s g}\left(f_{g}\right)\left[\left|q_{y}\right|+\left|q_{z}\right|\right] / v_{p} \leq 1
$$

where

$$
\begin{aligned}
& \mathrm{V}_{\mathrm{p}} \quad=\text { pore volume of a block, } \\
& \mathrm{q}=\text { volumetric flow rate, } \\
& D_{s g}\left(f_{g}\right)=\begin{array}{l}
\text { the change in the fractional flow of gas with } \\
\text { respect to a change in gas saturation during a }
\end{array} \\
& \text { time step, } \\
& \Delta t=\text { length of time step. }
\end{aligned}
$$

At present we set the well flow rates based upon the above stability constraint. However, this is not sufficient to control the size of $D_{s g}\left(f_{g}\right)$ at the bubble point where this derivative can be relatively large. A subroutine which would incorporate the above stability criterion into the model is included in the 1isting of the source code (see Appendix), however, it is currently not completely operational and therefore not being implemented. 
Finally, if during a time step a mobile gas phase appears in some block $k$, then to insure a continuous transition from the immobile gas case to the mobile gas case, the step length must be sufficiently short so that only a very small amount of mobile gas is present at the end of the step. This is necessary because the thermodynamic equilibrium conditions that govern the two cases are quite different. Too long a step could result in a solution which was inconsistent with the equilibrium assumption based on conditions at the beginning of the step. We have included in the model a time step control at the bubble point governing the appearance of a mobile gas phase in a block. This control needs to be generalized to include the possibility of the gas phase disappearing during a step as well.

Finally, a volume balance check is performed during each step by comparing the total fluid volume with the pore volume in each grid block. This provides a rough measure of the accuracy of the solutions obtained. A flow chart of the solution scheme is included in Fig. IV-1. 


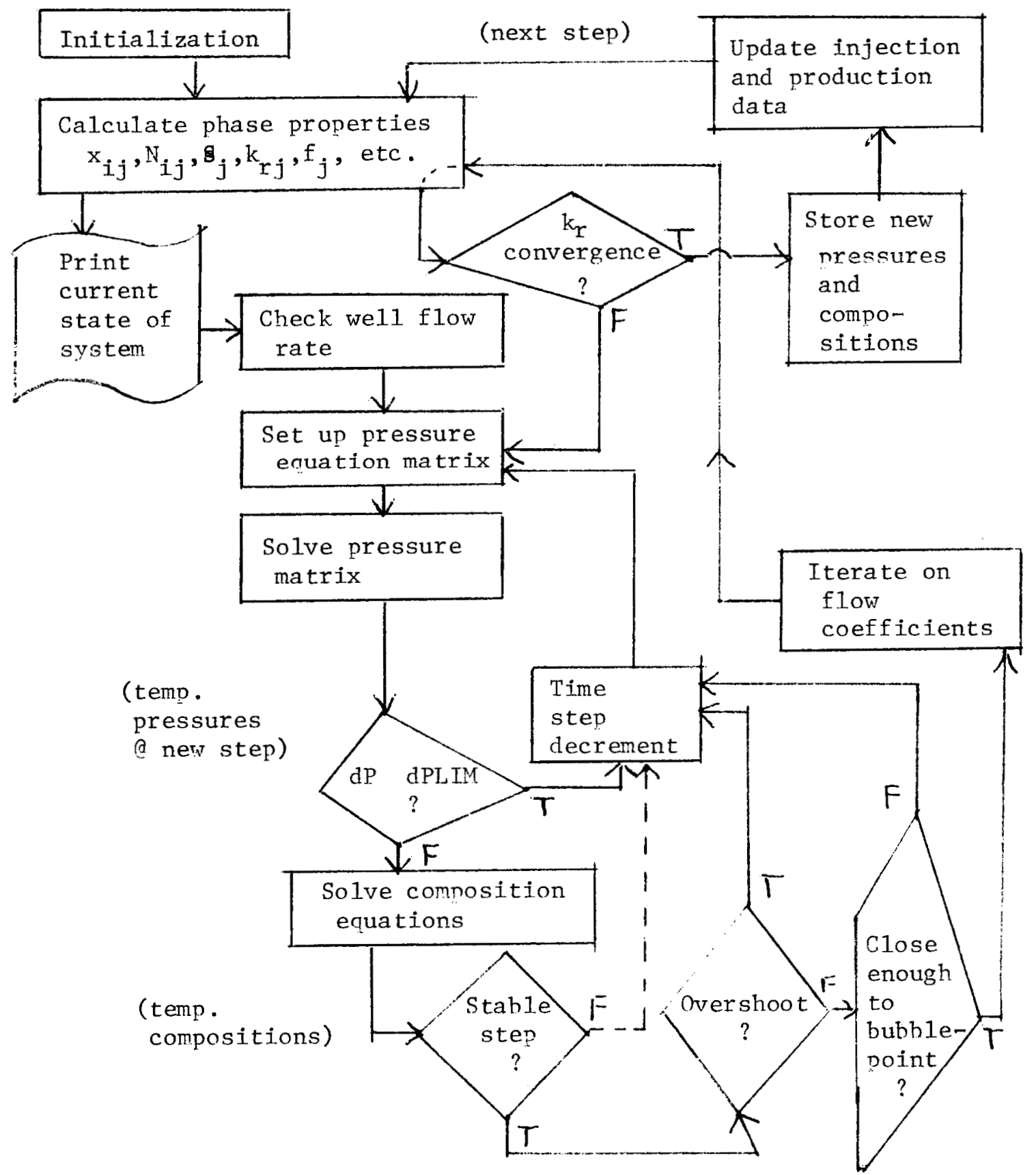

Figure IV-1. Solution flow chart. 


\section{Phase Properties}

\section{A. Thermodynamic Equilibria}

The phase behavior of the system modelled by this simulator involves mass transfer between three phases (gas, oil, water) and may be represented on a ternary phase diagram (see Fig. $\dot{V}-1$ ). Phase equilibrium is subject to the following restrictions:

(1) Of the three components present in the system $\left(\mathrm{CO}_{2}\right.$, hydrocarbons ( $\mathrm{HC}$ ), and $\mathrm{H}_{2} \mathrm{O}$ ), only the transfer of $\mathrm{CO}_{2}$ molecules is assumed to occur between the gas and the two liquid phases.

(2) The carbonated oil and carbonated water solutions are assumed to be "weak".

Assumption (1) implies both immiscibility between the oil and water phases and the absence of any extraction of $\mathrm{HC}$ and $\mathrm{H}_{2} \mathrm{O}$ molecules into a vapor phase. The latter conclusion is reasonable since we are considering for the purposes of this model only "heavy" oils, that is oils of $20^{\circ}$ API gravity and below, which generally contain little or no "1ight" components. Furthermore, this implies that the gas phase is composed of only $\mathrm{CO}_{2}$.

Assumption (2) is justified since the primary focus of the model is to investigate the flow behavior of oil and water in shallow reservoirs, where the relatively low formation fracturing pressure limits the useful. pressure range to about 500 psia and below. At such low pressures the carbonated oil solutions (and, of course, the carbonated water) can be considered to be weak due to the relatively low solubility of $\mathrm{CO}_{2}(<20$ mole $\%$ in oil).

Assumption (2) then leads to two important conclusions: first, Henry's Law states that the solubility of a weak solution of gas in a 


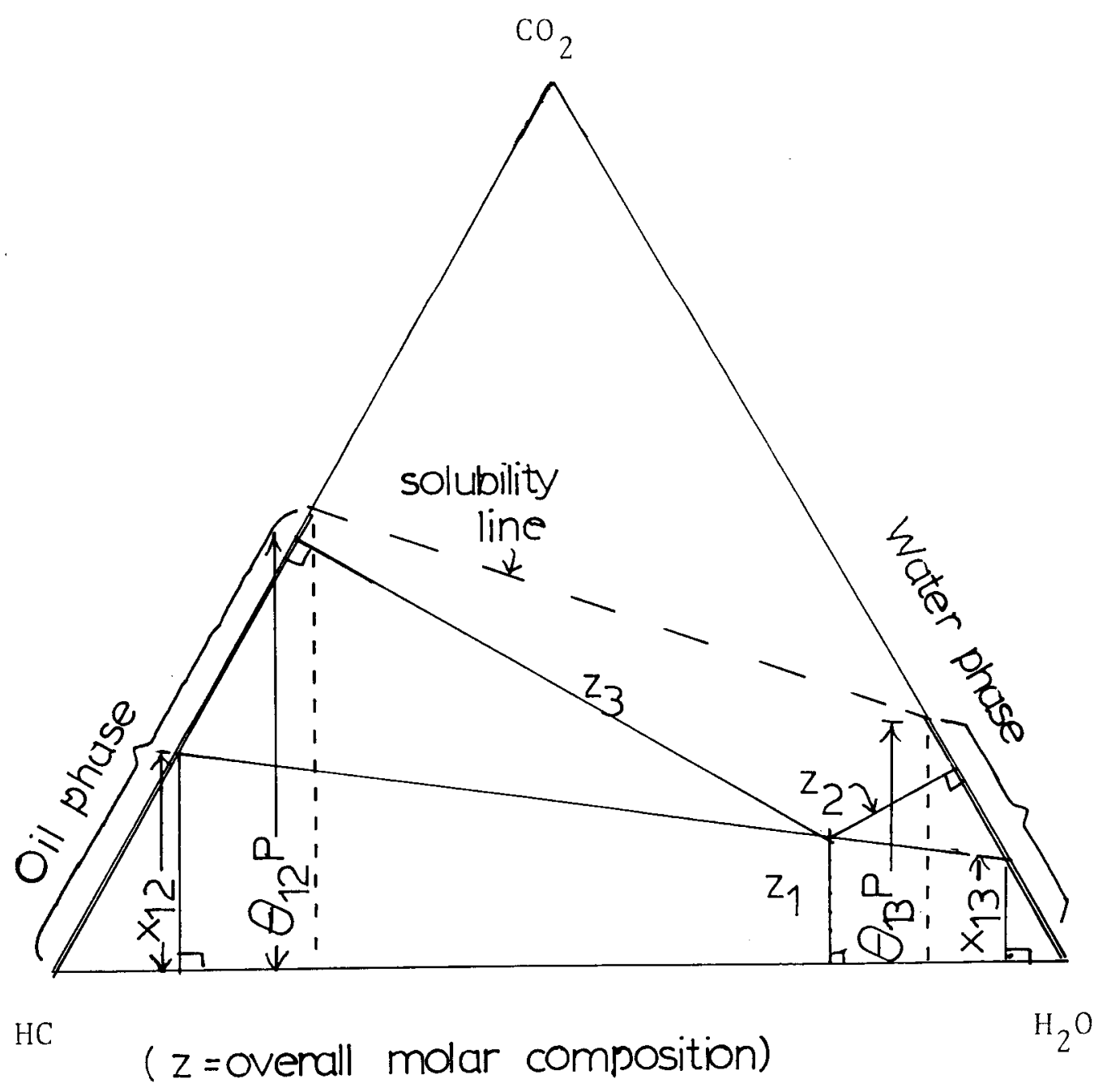

Figure $V-1$. Fluid phase behavior. 
liquid at low pressures is proportional to the gas pressure. ${ }^{8}$ Thus, the solubility of $\mathrm{CO}_{2}$ in the oil and water is approximately linear with pressure. Second, the ratio of the concentrations of a solute in two different solvents (again, assuming "weak" solutions) is constant for a given pressure and temperature (distribution 1aw). ${ }^{8}$ This latter conclusion, coupled with the assumptions of solubility linear with pressure and isothermal conditions, leads to the result that the ratio of the concentrations (and the solubilities) is a constant over the pressure range considered above.

Phase equilibrium calculation:

We determine how injected gas is partitioned among the three phases at equilibrium conditions for a given overall composition characterized by a point on the ternary phase diagram (see Fig. V-1). If the composition point, depicted by $Z$ on the diagram, is above the solubility. line (which is a function of pressure alone) then three mobile phases gas, oil, and water - exist. If the composition point is below the line then only the oil and water are mobile and any gas that is present is either in solution or is immobile residual gas. We will henceforth refer to the latter case, where no mobile gas phase is present, as case $A$ and to the case where mobile gas is present as case B.

For case $A$, the equilibrium condition is given by:

$$
x_{12} / x_{13}=\theta_{12} / \theta_{13}=n
$$

where $\theta_{12} \mathrm{P}$ and ${ }_{13} \mathrm{P}$ are the solubilities of $\mathrm{CO}_{2}$ in oil and water, respectively, as functions of the average pressure, $P$ and $\eta$ is the constant solubility ratio, ${ }_{12} /{ }_{13} \cdot$ 
For case $B$, the condition is simply:

$$
\begin{aligned}
& x_{12}=\theta_{12^{P}} \\
& x_{13}=\theta_{13^{P}}
\end{aligned}
$$

i.e., the mole fractions of $\mathrm{CO}_{2}$ in oil and water are equal to their saturated values.

If $z_{i}$ is the overall mole fraction of component $i$ in the system and the index $i=2,3$ refers to oil and water, respectively, then it can be shown ${ }^{16}$ that the concentration of $\mathrm{CO}_{2}$ in water with no attendant solubility restriction is:

$$
x_{13}=\left\{\left[1+n z_{1}+z_{2}(n-1)\right]-\sqrt{\left.\left[1+n z_{1}+z_{2}(n-1)\right]^{2}-4 z_{1} n\right\} / 2 n} .\right.
$$

If $\mathrm{x}_{13}<\theta_{13} \mathrm{P}$ then the $\mathrm{CO}_{2}$ is all in solution, no mobile gas exists, and the equilibrium condition of case $A$ can be applied to determine $x_{12}$. Then, using the constraint that $x_{12}+x_{22}=x_{13}+x_{33}=1, x_{22}$ and $x_{33}$ can be calculated.

If, however, $x_{13} \geq \theta_{13} P$ then the liquid phases are saturated and $\mathrm{CO}_{2}$ must begin to bubble out of solution. Therefore, the equilibrium condition of case $B$ must be invoked, where then $x_{12}={ }_{12}{ }^{P}$ and $x_{13}=$ ${ }_{13}{ }^{\mathrm{P}}$. Any remaining $\mathrm{CO}_{2}$ must enter a mobile gas phase.

B. Density

Gas phase density is calculated using the compressibility equation of state:

$$
P V=n z R T
$$


where:

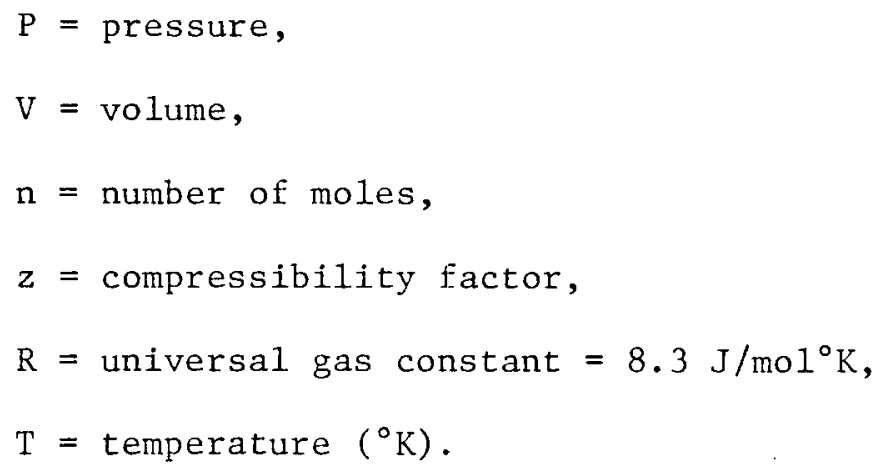

Assuming that $\mathrm{T}=35^{\circ} \mathrm{C}$ then the molar density of the gas is given by:

$$
\rho_{1}=\mathrm{P} / \mathrm{zRT}=2.7 \times 10^{-6} \mathrm{P} / \mathrm{z}
$$

where $\mathrm{P}$ is in psia and $z$ is assumed to be a linear function of pressure for $P<500$ psi. $^{9}$

The calculation of liquid (oil or water) phase densities requires experimental data on the density vs. pressure behavior of the pure liquid and of the $\mathrm{CO}_{2}$ saturated liquid. ${ }^{10-15}$ This information, coupled with the assumption that a molecule of $\mathrm{CO}_{2}$ dissolved in the liquid occupies the same volume in the unsaturated liquid as it does in the saturated liquid allows us to calculate the molar density of the liquid phases via the following relation:

$$
\rho_{j}=\left[x_{i j} V_{i j}+x_{j j} V_{j j}\right]^{-1}
$$

where: 
j denotes the phase $=2$ for oil, $=3$ for water,

$x_{i j}$ is the mole fraction of $\mathrm{CO}_{2}$ in phase $\mathrm{j}$,

$x_{j j}$ is the mole fraction of oil in the oil phase or of water in the water phase,

$V_{i j}$ is the specific molar volume of the component $i$ located
in phase $j$.

The specific volumes of oil and water, $\mathrm{V}_{22}$ and $\mathrm{V}_{33}$, are obtained by inverting the mass density of the respective pure component and multiplying by the appropriate molecular weight. Mole fractions are calculated based on the most recent pressure and composition solutions.

The specific volume of $\mathrm{CO}_{2}$ in oil, $\mathrm{V}_{12}$, is calculated utilizing experimental data on the swelling factor, $f$, of $\mathrm{CO}_{2}$-saturated oil. By definition, the volume of a quantity of saturated oil is equal to the product of the swelling factor, the number of moles of dead oil, and the specific volume of the oil at standard conditions. The swelling factor is assumed to be linear with pressure. $V_{12}$ is then found to be given by:

$$
\mathrm{V}_{12}=\left(1-\theta_{12} \mathrm{P}\right)\left[\mathrm{fV}_{22}(\mathrm{P}=1 \text { atm })-\mathrm{V}_{22}(\mathrm{P})\right] /\left(\theta_{12} \mathrm{P}\right)
$$

The specific volume of $\mathrm{CO}_{2}$ in water requires data on the mass densities of pure and $\mathrm{CO}_{2}$-saturated water at various pressures. We find that:

$$
\mathrm{v}_{13}=\left(1-\theta_{13} \mathrm{P}\right)\left[\mathrm{m}_{3} / \rho_{3}{ }^{\prime}, \text { sat }-\mathrm{V}_{33}\right] /\left(\theta_{13} \mathrm{P}\right)+\mathrm{m}_{1} / \rho_{3}{ }^{\prime} \text {, sat }
$$

where: 


$$
\begin{aligned}
& \mathrm{m}_{1}, \mathrm{~m}_{3}=\text { molecular weights of } \mathrm{CO}_{2} \text { and } \mathrm{H}_{2} \mathrm{O} \\
& \rho_{3}{ }^{\prime}, \text { sat }=\text { mass density of } \mathrm{CO}_{2} \text {-saturated water. }
\end{aligned}
$$

\section{Viscosity}

In this model the viscosities of the $\mathrm{CO}_{2}$ gas phase and the water phase are assumed to be constant. Since the gas is pure and the solubility of $\mathrm{CO}_{2}$ in water is relatively small this assumption is a reasonable approximation to the actual behavior of the system under consideration. On the other hand, the oil phase viscosity is assumed to be a function of both pressure and composition. Over a limited range of , pressure and dissolved gas composition it has been observed that the log of the oil viscosity varies linearly with the pressure and the amount of gas dissolved in the oil. ${ }^{11,12}$ Thus, we approximate the oil viscosity by the following relation:

$$
\log \mu_{2}=\mathrm{AP}+\mathrm{Bx}_{12}+\mathrm{C}
$$

where:

$$
\mu_{2}=\text { oil phase viscosity }(\mathrm{cp})
$$

The constants $\mathrm{A}, \mathrm{B}$, and $\mathrm{C}$ must be determined from experimental data describing the variation of the viscosity of pure and $\mathrm{CO}_{2}$-saturated oil with pressure. A is the slope of the $\log \mu_{2}$ vs. P data for pure oil. $C$ is the intercept of that graph with the $\log \mu_{2}$ axis. B relates the viscosity to the oil composition and is given by $B=\left(A^{\prime}-A\right) / \theta 12$, where 
$\mathrm{A}^{\prime}$ is the slope of the $\mathrm{CO}_{2}$-saturated oil viscosity curve and $\theta_{12}$ is the molar solubility of $\mathrm{CO}_{2}$ in the oil.

The user must determine $\mathrm{A}, \mathrm{A}^{\prime}$, and $\mathrm{C}$ from available experimental data and input these values into the model (see INPUT formats). Note that in general $\mathrm{A}^{\prime}<\mathrm{A}$ and $\mathrm{B}<0$.

D. Saturation

Knowledge of the equilibrium composition of the system and of the specific volumes of the components leads directly to phase saturations.

The total fluid volume is given by:

$$
V_{f}=\sum_{i, j} N_{i j} V_{i j}
$$

Phase saturations are then given by:

$$
S_{j}=\sum_{i} N_{i j} V_{i j} / V_{f}
$$

Thus:

$$
\begin{aligned}
& \text { gas }-\mathrm{s}_{1}=\mathrm{N}_{11} \mathrm{~V}_{11} / \mathrm{V}_{\mathrm{f}} \\
& \text { oil - } \mathrm{s}_{2}=\left(\mathrm{N}_{12} \mathrm{~V}_{12}+\mathrm{N}_{22} \mathrm{~V}_{22}\right) / \mathrm{V}_{\mathrm{f}} \\
& \text { water }-\mathrm{s}_{3}=\left(\mathrm{N}_{13} \mathrm{~V}_{13}+\mathrm{N}_{33} \mathrm{~V}_{33}\right) / \mathrm{V}_{\mathrm{f}}
\end{aligned}
$$

where:

$$
V_{f}=N_{11} V_{11}+N_{12} V_{12}+N_{13} V_{13}+N_{22} V_{22}+N_{33} V_{33}
$$




\section{E. Compressibility}

The effective compressibility of the fluid system is defined by:

$$
\mathrm{C}=\mathrm{C}_{\mathrm{eff}} / \mathrm{V}_{\mathrm{f}}
$$

where:

$$
\begin{aligned}
\mathrm{C}_{\text {eff }}= & -\left[\mathrm{N}_{11} \mathrm{D}_{\mathrm{p}}\left(\mathrm{V}_{11}\right)+\mathrm{N}_{12} \mathrm{D}_{\mathrm{P}}\left(\mathrm{V}_{12}\right)+\mathrm{N}_{13} \mathrm{D}_{\mathrm{P}}\left(\mathrm{V}_{13}\right)+\mathrm{N}_{22} \mathrm{D}_{\mathrm{P}}\left(\mathrm{V}_{22}\right)\right. \\
& \left.+\mathrm{N}_{33} \mathrm{D}_{\mathrm{P}}\left(\mathrm{V}_{33}\right)\right] \\
\mathrm{V}_{\mathrm{f}}= & \text { the total fluid volume. }
\end{aligned}
$$

Assume that $\mathrm{CO}_{2}$ behaves like a compressible ideal gas, i.e., $\mathrm{PV}=\mathrm{nzRT}$ (see Sec. V.B). We expand the volume in a Taylor series:

$$
\mathrm{V}=\mathrm{V}_{\mathrm{o}}+\left[\mathrm{D}_{\mathrm{P}}(\mathrm{V})\right]_{\mathrm{P}_{\mathrm{o}}} \Delta \mathrm{P}+\frac{1}{2}\left[\mathrm{D}_{\mathrm{P}}^{2}(\mathrm{~V})\right]_{\mathrm{P}_{\mathrm{o}}}(\Delta \mathrm{P})^{2}+\cdots
$$

Rearranging:

$$
\mathrm{C}=-\Delta \mathrm{V} /\left(\mathrm{V}_{\mathrm{o}} \Delta \mathrm{P}\right) \stackrel{\simeq}{=}-\left\{\left[\mathrm{D}_{\mathrm{P}}(\mathrm{V})\right]_{\mathrm{P}_{\mathrm{o}}}+\left[\mathrm{D}_{\mathrm{P}}^{2}(\mathrm{~V})\right]_{\mathrm{P}_{\mathrm{o}}} \Delta \mathrm{P} / 2\right\} / \mathrm{V}_{\mathrm{o}}
$$

Applying the first and second derivatives to the above equation of state gives:

$$
C=\left[1-\Delta \mathrm{P} / \mathrm{P}_{\mathrm{o}}\right] /\left(\mathrm{zP}_{\mathrm{o}}\right)
$$

Thus, the first term in the expression for $\mathrm{C}_{\text {eff }}$ can be written:

$$
\mathrm{N}_{11} \mathrm{~V}_{11}\left[1-\Delta \mathrm{P} / \mathrm{P}_{0}\right] /\left(\mathrm{zP}_{\mathrm{o}}\right)
$$

where 


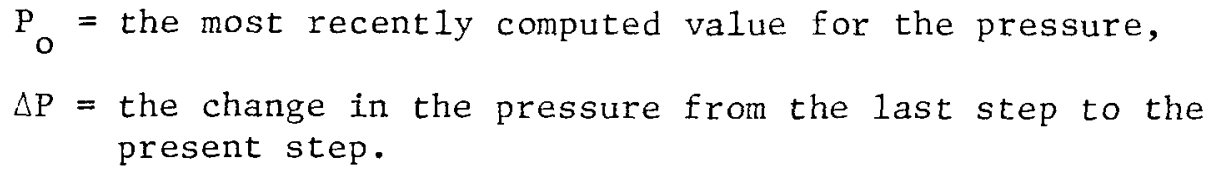

The second and third terms in $C_{\text {eff }}$ involve the compressibility of dissolved gas in oil and water. Referring back to the section on densities it is easily seen that:

$$
-\mathrm{N}_{12} \mathrm{D}_{\mathrm{P}}\left(\mathrm{V}_{12}\right)=\left[\mathrm{a}_{\mathrm{s}} \mathrm{V}_{22}(1)+\left(\mathrm{V}_{22}(1)-\mathrm{V}_{22}(\mathrm{P})\right) /\left(\theta_{12} \mathrm{P}^{2}\right)\right] \mathrm{N}_{12}
$$

where $a_{s}$ is the slope of the swelling factor $f$,

$$
-\mathrm{N}_{13} \mathrm{D}_{\mathrm{P}}\left(\mathrm{v}_{13}\right)=\left[\mathrm{m}_{3} \mathrm{a}_{3}+\left(\mathrm{m}_{1}-\mathrm{m}_{3}\right) \mathrm{a}_{3}^{\mathrm{sat}}\right] /\left(\mathrm{b}_{3}\right)^{2}
$$

where $a_{3}^{\text {sat }}$ and $a_{3}$ are the slopes of mass density of saturated and pure water, respectively, and $b_{3}$ is the density of water at atmospheric pressure.

Finally, the last two terms of $\mathrm{C}_{\text {eff }}$ represent the compressibilities of pure oil and pure water. Noting that:

$$
\begin{aligned}
& \mathrm{v}_{22}=\mathrm{m}_{2} /\left(\mathrm{a}_{2} \mathrm{P}+\mathrm{b}_{2}\right) \\
& \mathrm{v}_{33}=\mathrm{m}_{3} /\left(\mathrm{a}_{3} \mathrm{P}+\mathrm{b}_{3}\right)
\end{aligned}
$$

where $a_{2}, a_{3}$ and $b_{2}, b_{3}$ are, respectively, the slopes and intercepts of the oil and water mass density curves, we get: 


$$
\begin{aligned}
& -\mathrm{N}_{22} \mathrm{D}_{\mathrm{P}}\left(\mathrm{V}_{22}\right)=\mathrm{a}_{2} \mathrm{~N}_{22} \mathrm{~V}_{22}^{2} / \mathrm{m}_{2} \\
& -\mathrm{N}_{33} \mathrm{D}_{\mathrm{P}}\left(\mathrm{V}_{33}\right)=\mathrm{a}_{3} \mathrm{~N}_{33} \mathrm{~V}_{33}^{2} / \mathrm{m}_{3} .
\end{aligned}
$$

\section{F. Relative Permeability}

The three-phase relative permeabilities of gas, oil and water are calculated from either functional representations of two-phase relative permeabilities or from experimental data obtained on two-phase systems. The general form of the two-phase relative permeability curves is shown in Fig. $\mathrm{V}-2$.

In the figure, $k_{r w}$ and $k_{\text {row }}$ are, respectively, the relative permeabilities of water and of oil to water in the oil-water system. In the oil-gas system, $k_{r g}$ and $k_{\text {rog }}$ are the relative permeabilities of gas and of oil to gas. When the water saturation $S_{w}$ is reduced to its connate value $\mathrm{S}_{\mathrm{wc}}$ its relative permeability $\mathrm{k}_{\mathrm{rw}}$ is zero. When $\mathrm{S}_{\mathrm{w}}=$ $1-S_{\text {or }}$, where $S_{\text {or }}$ is the residual oil saturation, $k_{r w}$ reaches its endpoint value $E_{w}$. Similarly, the oil relative permeability $k_{\text {row }}$ reaches its endpoint value $\mathrm{E}_{\mathrm{ow}}$ when $\mathrm{S}_{\mathrm{w}}=\mathrm{S}_{\mathrm{wc}}$ and is zero when $\mathrm{S}_{\mathrm{w}}=1-\mathrm{S}_{\text {or }}$.

In the oil-gas system, $S_{L}$ is the liquid saturation and equals the sum of the oil and water saturations. When $S_{L}=S_{L c}=S_{w c}+S_{o g}$, where $S_{o g}$ is the residual oil to gas, the relative permeability of the gas $k_{\mathrm{rg}}$ is equal to its endpoint value $\mathrm{E}_{\mathrm{g}}$ and is zero when the gas saturation $\mathrm{S}_{\mathrm{g}}$ equals the critical gas saturation $\mathrm{S}_{\mathrm{gc}}$. The oil endpoint of the oilgas curve is $\mathrm{E}_{\mathrm{og}}$ and for consistency should equal $\mathrm{E}_{\text {ow }}$.

The relative permeability of a phase can be considered to be a function of the effective saturation of that phase with the following general form: ${ }^{16,17}$ 

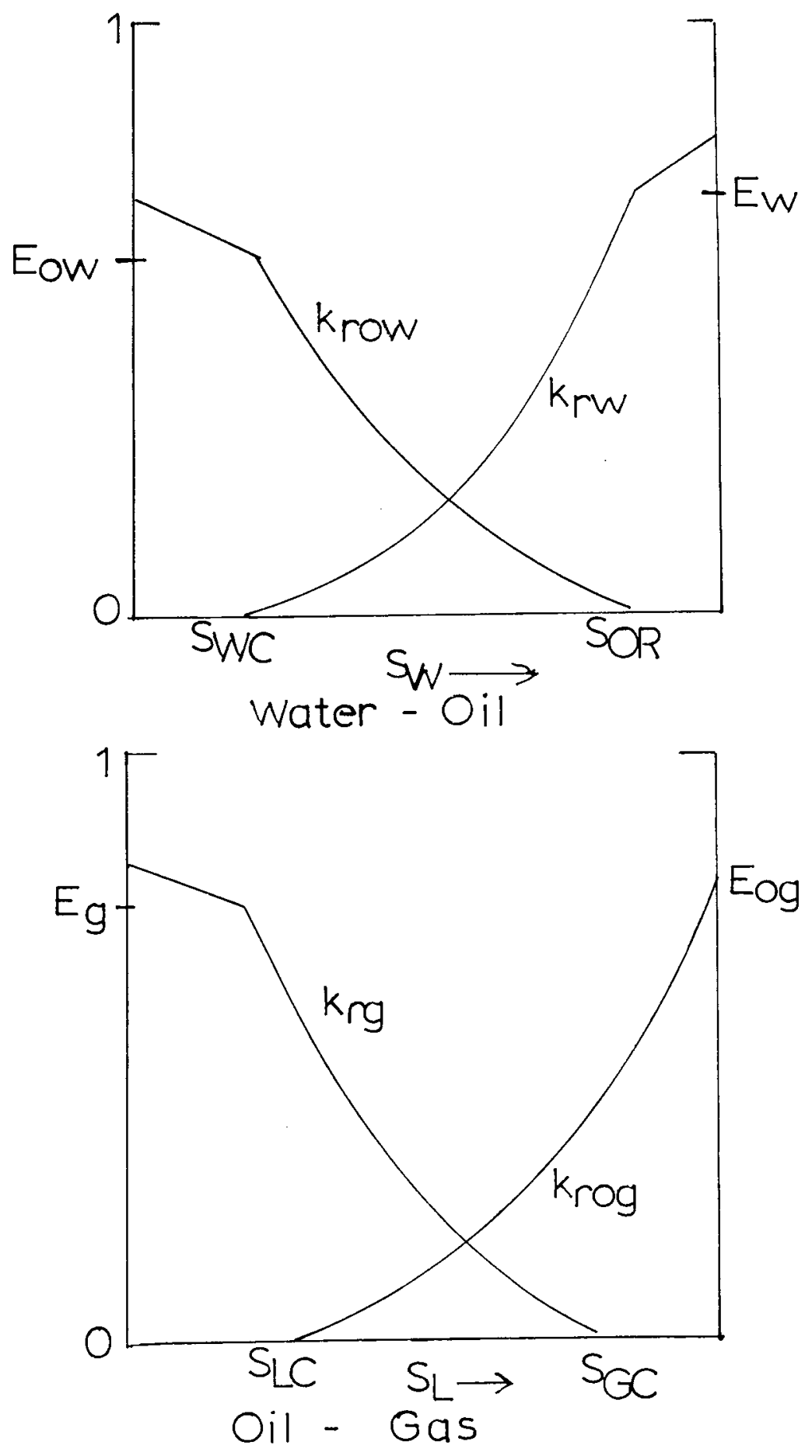

Figure V-2. Relative permeability. 


$$
k_{r j}=E_{j}\left(S_{e f f}\right)^{e}
$$

There are four such functions needed in this model. The endpoint values $\mathrm{E}_{j}$ and the exponents $e_{j}$ are set by the user. In the oil-water system, for $j=w$ the effective saturation $s_{\text {eff }}$ is given by $\left(S_{w}-S_{w c}\right) /$ $\left(1-S_{\text {or }}-S_{w c}\right)$ and for $j=$ ow it is $\left(1-S_{w}-S_{o r}\right) /\left(1-S_{\text {or }}-S_{w c}\right)$. In the oilgas system, for $j=o g, S_{\text {eff }}=\left(S_{L}-S_{L c}\right) /\left(1-S_{L c}\right)$ and for $j=g, S_{\text {eff }}=$ $\left(\mathrm{S}_{\mathrm{g}}-\mathrm{S}_{\mathrm{gc}}\right) /\left(1-\mathrm{S}_{\mathrm{Lc}}-\mathrm{S}_{\mathrm{gc}}\right)$, where $\mathrm{S}_{\mathrm{L}}=1-\mathrm{S}_{\mathrm{g}}$ and $\mathrm{S}_{\mathrm{Lc}}=\mathrm{S}_{\mathrm{wc}}+\mathrm{S}_{\mathrm{og}}$.

Three-phase relative permeabilities are then calculated from the two-phase permeabilities using Stone's second mode $1^{18}$ with a slight modification when $E K_{\text {row }}<1$. The water and gas permeabilities are equal. to their respective two-phase values and the oil permeability is given by:

$$
k_{\text {ro }}=\left(k_{\text {row }}+k_{r w}\right)\left(k_{\text {rog }}+k_{r g}\right) / E_{o g}-\left(k_{r w}+k_{r g}\right)
$$

Note that for $\mathrm{s}_{\mathrm{o}}<\mathrm{s}_{\text {or }}$, $\mathrm{k}_{\text {row }}=0$ and $\mathrm{k}_{\mathrm{rw}}$ is obtained by linearly interpolating between $E_{w}$ and 1 . Similarly, for $S_{w}<S_{w c}, k_{r w}=0$ and $k_{\text {row }}$ is obtained by interpolation and for $\mathrm{S}_{\mathrm{L}}<\mathrm{S}_{\mathrm{LC}}$, $\mathrm{k}_{\mathrm{rog}}=0$ and $\mathrm{k}_{\mathrm{rg}}$ is evaluated by interpolation.

Finally, the relative mobilities $\lambda_{j}$ of the three phases are given by:

$$
\lambda_{j}=k_{r j} / \mu_{j}
$$

and the fractional flow rates $f_{j}$ by

$$
E_{j}=\lambda_{j} / \Sigma_{j} \lambda_{j}
$$




\section{Sample Runs}

Three sample problems were run using this numerical model. In each of these problems the following input parameters were held constant.

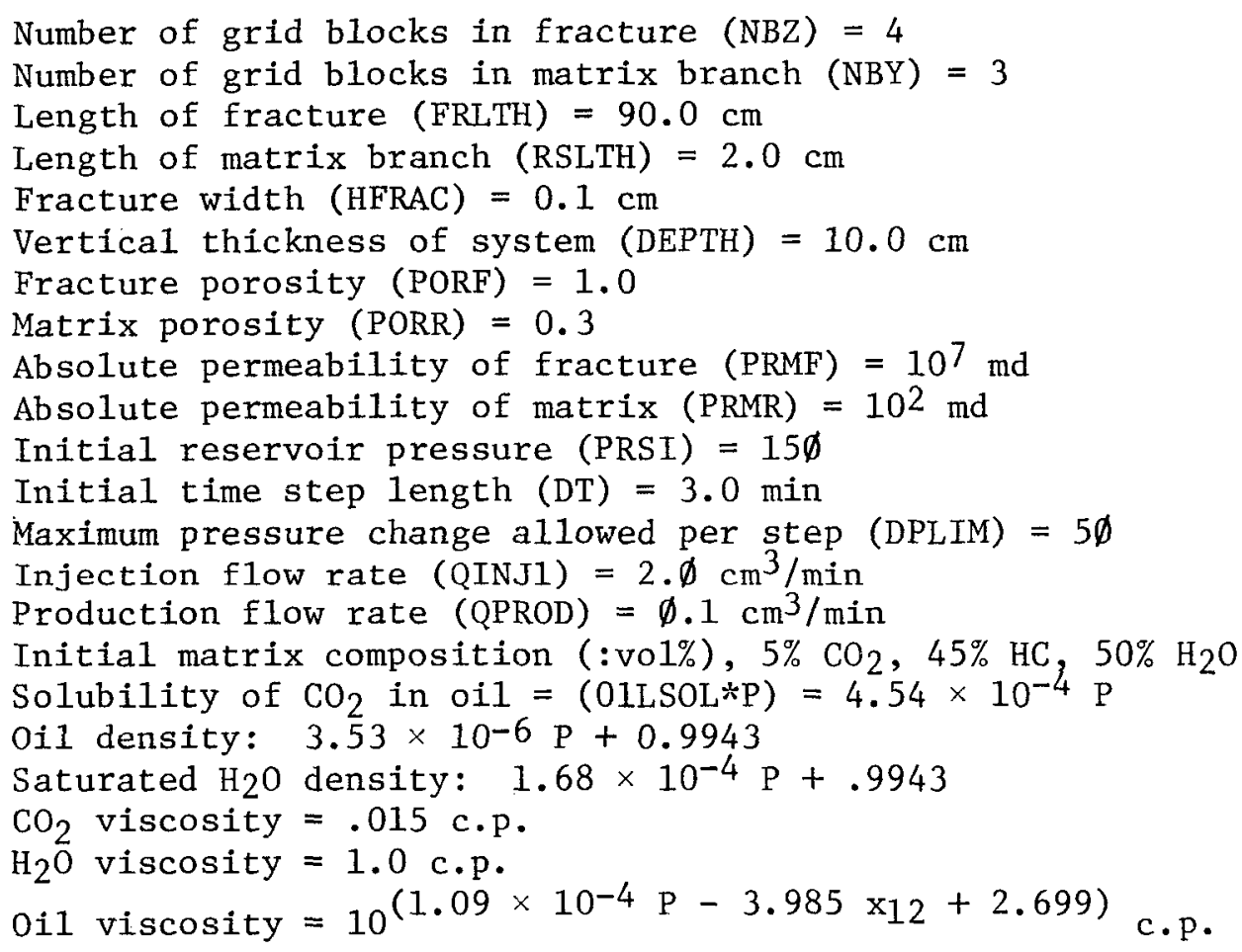

Note: oil densities, solubilities, viscosity data taken from Miller. ${ }^{12}$

For the following runs, well cycling control is pressure limited.

That is, the we11 is switched to injection mode when the pressure drops to some minimum value (in this case $150 \mathrm{psi}$ ) and to production mode when the pressure rises to some maximum value (250 psi for these runs). A brief soak period occurs between the injection and production periods. Table VI-1 contains the accumulated values of moles of $\mathrm{CO}_{2}$ input and moles of $\mathrm{CO}_{2}$, oil, and water output at the end of each injection/ production cycle, for each of the three cases examined. Table VI-2 shows the location of the gas front at the end of each cycle for the three runs made. 
Table VI-1. Results of Sample Runs*

\section{Run 1}

Cycle 1

$\mathrm{CO}_{2}$ injected

$\mathrm{CO}_{2}$ produced

Oil produced

Water produced

Cycle 2

$\mathrm{CO}_{2}$ injected

$\mathrm{CO}_{2}$ produced

oil produced

Water produced

Cycle 3

$\mathrm{CO}_{2}$ injected

$\mathrm{CO}_{2}$ produced

oil produced

Water produced
.0586

.0248

$1.03 \times 10^{-4}$

.163

\section{.143}

.0774

$2.88 \times 10^{-4}$

.455

.215

.133

$4.65 \times 10^{-4}$

.735
Run 2

.0547

.0214

$2.11 \times 10^{-4}$

.587

.106

.0578

$3.36 \times 10^{-4}$

.898

.0546

.0194

$6.38 \times 10^{-4}$

.424

Run 3 
Table VI-2. Gas Front Location During Sample Runs

\begin{tabular}{|c|c|c|c|c|c|c|c|c|c|c|c|c|}
\hline \multirow[b]{2}{*}{ Cycle 1} & \multicolumn{4}{|c|}{ Run 1} & \multicolumn{4}{|c|}{ Run 2} & \multicolumn{4}{|c|}{ Run 3} \\
\hline & $\underline{2}$ & $\underline{6}$ & 10 & 14 & 2 & 6 & 10 & 14 & 2 & $\underline{6}$ & 10 & 14 \\
\hline & 3 & $\overline{7}$ & $\overline{11}$ & 15 & $\underline{3}$ & $\overline{7}$ & $\overline{11}$ & 15 & 3 & $\overline{7}$ & 11 & 15 \\
\hline & $\overline{4}$ & 8 & 12 & 16 & $\overline{4}$ & $\overline{8}$ & 12 & 16 & $\overline{4}$ & 8 & 12 & 16 \\
\hline & 5 & 9 & 13 & 17 & 5 & 9 & 13 & 17 & 5 & 9 & 13 & 17 \\
\hline \multirow[t]{4}{*}{ Cycle 2} & $\underline{2}$ & $\underline{6}$ & 10 & 14 & $\underline{2}$ & $\underline{6}$ & 10 & 14 & $\underline{2}$ & $\underline{6}$ & 10 & 14 \\
\hline & $\overline{3}$ & $\overline{7}$ & $\overline{11}$ & $\overline{15}$ & $\underline{3}$ & $\underline{7}$ & 11 & $\overline{15}$ & $\underline{3}$ & $\underline{7}$ & 11 & 15 \\
\hline & $\overline{4}$ & $\overline{8}$ & $\overline{12}$ & 16 & $\overline{4}$ & $\overline{8}$ & $\overline{12}$ & 16 & $\overline{4}$ & $\overline{8}$ & 12 & 16 \\
\hline & 5 & 9 & 13 & 17 & 5 & 9 & 13 & 17 & 5 & 9 & 13 & 17 \\
\hline \multirow[t]{4}{*}{ Cycle 3} & 2 & $\underline{6}$ & 10 & 14 & $\underline{2}$ & $\underline{6}$ & 10 & 14 & & & & \\
\hline & $\underline{3}$ & $\overline{7}$ & $\overline{11}$ & $\overline{15}$ & 3 & $\overline{7}$ & $\underline{11}$ & $\overline{15}$ & & & & \\
\hline & $\underline{4}$ & $\overline{8}$ & $\overline{12}$ & 16 & $\underline{4}$ & $\underline{8}$ & $\overline{12}$ & 16 & & & & \\
\hline & $\overline{5}$ & 9 & 13 & 17 & $\overline{5}$ & $\overline{9}$ & 13 & 17 & & & & \\
\hline \multirow[t]{4}{*}{ Cycle 4} & & & & & $\underline{2}$ & $\underline{6}$ & 10 & 14 & & & & \\
\hline & & & & & $\underline{3}$ & $\overline{7}$ & $\overline{11}$ & $\overline{15}$ & & & & \\
\hline & & & & & $\overline{4}$ & 8 & $\overrightarrow{12}$ & $\overline{16}$ & & & & \\
\hline & & & & & $\overline{5}$ & $\overline{9}$ & 13 & 17 & & & & \\
\hline
\end{tabular}


Results are given describing the efficiency of the recovery process and the fraction of $\mathrm{CO}_{2}$ trapped in the reservoir for each of the three sample cases. Recovery efficiency is calculated in thousands of standard cubic feet (MSCF) of $\mathrm{CO}_{2}$ injected and not recovered per barrel (bbl) of oil recovered. The fraction of $\mathrm{CO}_{2}$ trapped is a dimensionless quantity calculated from the moles of $\mathrm{CO}_{2}$ injected less the moles of $\mathrm{CO}_{2}$ recovered divided by the moles of $\mathrm{CO}_{2}$ injected.

Run 1

For this case, it was assumed that $\mathrm{CO}_{2}$ was soluble in water, i.e., the molar solubility of $\mathrm{CO}_{2}$ in $\mathrm{H}_{2} \mathrm{O}$ at pressure $\mathrm{P}$ was given by WATSOL $* \mathrm{P} \rightarrow$ $2.1 \times 10^{-5} \mathrm{P}$. Furthermore, the fracture was assumed to initially contain $50 \%$ oil and $50 \%$ water.

Three cycles were run for this case. The recovery factor, $R$, at the completion of the first cycle, which lasted 76.8 minutes, was calculated from the data in Table VI-1 to be $217 \mathrm{MSCF} / \mathrm{bbl}$. The fraction of $\mathrm{CO}_{2}$ trapped, $\mathrm{F}$, was found to be $58 \%$. The second cycle lasted 124.7 minutes, with $\mathrm{R}=150 \mathrm{MSCF} / \mathrm{bb} 1$ and $\mathrm{T}=46 \%$ at the end of the cycle. The third cycle continued for 116.3 minutes, at the end of which $\mathrm{R}=$ $116 \mathrm{MSCF} / \mathrm{bb} 1$ and $\mathrm{T}=38 \%$.

Run 2

Here, $\mathrm{CO}_{2}$ was not allowed to dissolve into the water. This was done by lowering the solubility factor four orders of magnitude from the value used in Run 1 . The initial composition of the fracture was the same as in Run 1. Four cycles were completed.

The first cycle lasted 77.2 minutes, at the end of which $R=104$ MSCF/bb1 and $\mathrm{T}=61 \%$. The second cycle lasted 79.8 minutes, with 
$\mathrm{R}=90.9 \mathrm{MSCF} / \mathrm{bb} 1$ and $\mathrm{T}=37 \%$ at its conclusion. The fourth and final cycle lasted 109.3 minutes. The final recovery factor and fraction of trapped gas were, respectively, $\mathrm{R}=69 . \emptyset \mathrm{MSCF} / \mathrm{bb} 1$ and $\mathrm{T}=3 \emptyset \%$.

Run 3

In this last run, the solubility of $\mathrm{CO}_{2}$ in water was increased to the level used in Run 1 and the initial composition of the fracture was changed to $70 \%$ volume saturation of oil and $30 \%$ volume saturation of water. Only two cycles were run for this case.

The first cycle lasted 66.6 minutes. $\mathrm{R}$ was then found to equal $36.4 \mathrm{MSCF} / \mathrm{bbl}$ and $\mathrm{T}$ to be $65 \%$. At the end of the second cycle, which lasted 128.8 minutes, $\mathrm{R}=47.4 \mathrm{MSCF} / \mathrm{bbI}$ and $\mathrm{T}=49 \%$.

\section{Analysis and Conclusions}

Reduction of the solubility of $\mathrm{CO}_{2}$ in pure water had the expected effect of allowing the $\mathrm{CO}_{2}$ gas to migrate further into the fracture/ matrix system than for the case of $\mathrm{CO}_{2}$ being allowed to dissolve norma11y into pure water. Since reservoir brines generally have varying levels of dissolved salts which act to reduce the $\mathrm{CO}_{2}$ solubility of water the actual $\mathrm{CO}_{2}$ gas migration will be intermediate to that indicated by Runs 1 and 2 .

If the reservoir is assumed to be water-wet then the initial composition of a fracture could well lie between the oil-water volume ratio of 50/50 used in Run 2 and 70/30 used in Run 3. The latter case has clearly the most optimistic projection of $M C F / b b 1$ of the three runs made.

In the first two runs each succeeding injection/production cycle resulted in an improved recovery factor and a lower amount of 
trapped gas. However, in the final run the opposite effect was observed. It would be interesting to investigate the effect of a larger number of cycles per run on the recovery factor and trapped gas fraction.

Optimally, the injection cycle should continue until the reservoir pressure rises close to the fracturing pressure of the rock in order to obtain the maximum stimulation of the oil possible. ${ }^{20}$ Furthermore, the investigation of the effects of cycles of different duration upon the production is clearly an area where more work is needed. 


\section{Discussion and Conclusions}

Previous work has demonstrated the utility of carbon dioxide as an agent in the recovery of heavy crude oil. ${ }^{20}$ Similarly, hydraulic fracturing has been used to increase the injectivity of a reservoir and thereby improve recovery. It is not well understood, however, what effect introducing a fracture into a reservoir would have on a $\mathrm{CO}_{2}$ stimulation process.

We have developed a numerical model for use in the investigation of the compressible flow behavior of injected and reservoir fluids in the vicinity of a high-conductivity fracture. The two-dimensional model includes a rock matrix that is bounded on one side by a linear fracture. Flow into and out of the system is only through a we11 at one end of the fracture. We have neglected gravity and have assumed that there are no variations in the vertical direction. The combination of a high conductivity fracture with a horizontal areal model significantly reduces the computation necessary to describe the evolution of the system because a direct matrix solution of the problem is possible.

We are interested in modeling the behavior of fluids in fractured shallow reservoirs where pressures must be kept small enough ( $<500$ psi) to preserve the competency of the rock. This pressure restriction thus allows us to assume a linear behavior for most fluid properties, thereby making complex equation-of-state calculations unnecessary and further reducing the computational effort.

The model allows up to three fluid phases to exist - gas, oil, and water - and furthermore allows dissolved gas to exist in both the oil and water phases. Well behavior can be either injection, production, or soak, and at the user's option, can be either pressure or time limited. 
This arrangement facilitates the modeling of a huff-n-puff process. The model could, if desired, be readily converted to investigate drive processes as well by placing well block(s) on the other boundaries of the rock matrix.

In our runs we have observed, as expected, that the existence of a fracture increases the portion of the reservoir contacted by the injected $\mathrm{CO}_{2}$. In general we find that the water, being much more mobile than the oil, is displaced away from the fracture while the oil remains near the fracture and is stimulated by the $\mathrm{CO}_{2}$. The degree of stimulation and consequent increase in oil mobility is very clearly dependent on the amount of mobile gas phase present in the system.

A large free gas saturation reduces the efficiency of the recovery process by blocking the pores and inhibiting oil and water flow. Several runs indicate that limiting the presence of free gas in the system is an important factor in improving recovery efficiencies.

One possible way to accomplish this is by alternately injecting water into the system (WAG process) thereby increasing the pressure and forcing free gas into solution with the oil. A few runs were made to investigate the efficacy of such a process. Preliminary indications are that such a process would indeed result in higher oil recoveries than a pure $\mathrm{CO}_{2}$-stimulation treatment. Furthermore, this prediction is supported by various field studies such as the Lick Creek project. 20

We have also looked at how stimulation is affected by the degree of solubility of $\mathrm{CO}_{2}$ in the water. If the reservoir brine has a high dissolved salt content $(>200,000 \mathrm{ppm})$ then the solubility of $\mathrm{CO}_{2}$ in water falls to $20 \%$ that of the pure water case. The model user should 
estimate roughly the salt content of the reservoir brine and adjust the input solubility of $\mathrm{CO}_{2}$ in water accordingly.

We now turn to the numerical features of this model. Although the basic formulation of the model is of the form of an implicit pressureexplicit composition calculation, the inclusion of a scheme for in-step iterations on the coefficients of the pressure-composition terms makes the model more implicit and therefore less subject to stability problems. Recently, however, we have found that limiting the iterations to one or two passes seems to be sufficient to keep the accuracy of the model within reasonable bounds. The automatic volume balance check that is included in the model predicts less than a $5 \%$ volume mismatch for the case of limited iterations.

Time truncation error is controlled by restricting the pressure change allowed during a step. This method of time step control works quite well and could be easily modified to investigate the use of other possible control parameters, such as saturation or fractional flow rates. We have found that time step control at the bubble-point of the system is an important factor in maintaining the desired level of accuracy in the model's predictions. This is due to the existence of different fluid phase equilibrium conditions on the saturated and unsaturated sides of the bubble-point. Different equilibrium conditions imply that slightly different systems of equations govern the flow behavior in the two cases. Therefore, in order to make the transition from unsaturated case to the saturated case as smooth as possible, the time step at the bubble-point must be sufficiently small so that only a very small amount of gas phase is present at the end of the time step in which the gas first appears. We implemented an algorithm which 
appears to adequately satisfy this criterion. The algorithm has been generalized to include the effect of gas disappearing in the system.

The formats of the input data required and the results output from the model are detailed in the Appendices. Note that the source code, with the exception of the PROGRAM statement, is ANSI standard FORTRAN 77.

\section{Nomenclature}

$\mathrm{C}_{\text {eff }}$ - effective compressibility

$f_{j} \quad-$ fractional flow of phase $j$

g - gravitational acceleration

h - fracture width $(\mathrm{cm})$

i - - subscript index denoting component

j - subscript index denoting phase

k $\quad-$ grid block index

$k_{r j} \quad-$ relative permeability of phase $j$

$\mathrm{K}_{\mathrm{F}} ; \mathrm{K}_{\mathrm{R}}$ - absolute permeability of (fracture; rock matrix) (millidarcies)

$\ell_{F} ; l_{R} \quad-$ length of (fracture;matrix branch) $(\mathrm{cm})$

$\mathrm{n}_{\mathrm{z}} ; \mathrm{n}_{\mathrm{y}}$ - number of grid blocks along (fracture:z; matrix branch:y)

$\mathrm{N}_{i j} \quad$ - number of moles of component $i$ in phase $j$

$\mathrm{P}_{\mathrm{k}} \quad$ - - average pressure in grid block $\mathrm{k}$ (psi)

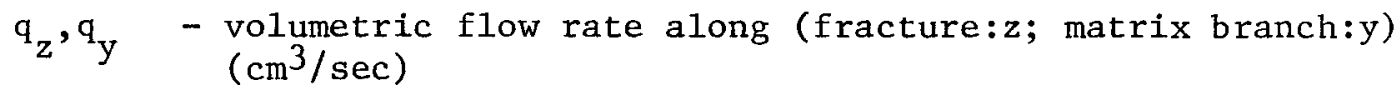

$r_{z}, r_{y}-$ mesh ratio $(\Delta t / \Delta z ; \Delta t / \Delta y)$

$\mathrm{S}_{j} \quad$ - saturation of phase $j$

$\Delta t \quad-$ length of time step (sec)

$v_{i j} \quad-$ specific molar volume of component $i$ in phase $j$

$\mathrm{W}_{i z}, \mathrm{~W}_{i z}$ - pressure equation coefficients containing mobility terms 


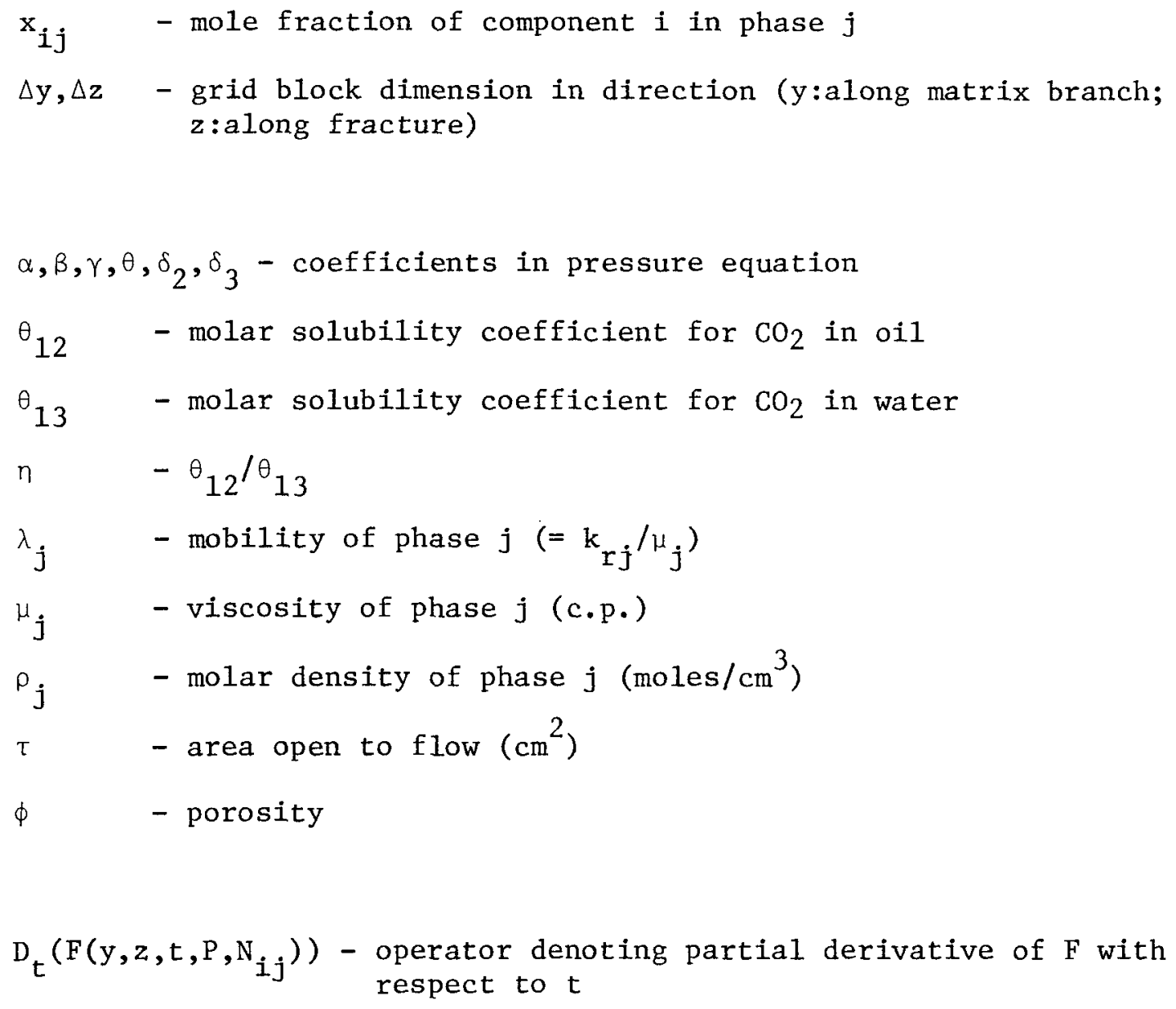


IX. References

1. U.S. Bureau of Mines: Heavy Crude Oil Resource, Reserve, and Potentia1 Production in the United States, IC 8352, 1967.

2. Ball Associates, Ltd.: Surface and Shallow Oil-Impregnated Rocks and Shallow Oil Fields in the United States, Bu-Mines Monograph 12 $(1965)$.

3. Petroleum Training and Technical Services: Technical Review of Enhanced Oil Recovery Literature - Final Report, DOE/ER/10086-T1 (April 1980).

4. Smith, C. R.: Mechanics of Secondary Oil Recovery, Kreiger Publishing Co., Huntington, New York (1975).

5. Lamb, H.: Hydrodynamics, Cambridge University Press (1932).

6. Goodrich, J. H. and Watts, R.: Target Reservoirs for $\mathrm{CO}_{2}$ Miscible Flooding - Final Report, DOE/MC/08341-17 (October 1980).

7. Todd, N. R., O'Dell, P. M., and Hirasaki, G. J.: "Methods for Increased Accuracy in Numerical Reservoir Simulators," Soc. Pet. Eng. J. (December 1972) 515-530.

8. Peaceman, D. W.: Fundamentals of Numerical Reservoir Simulation, E1sevier Scientific Publishing Co., Amsterdam (1977).

9. Landau, L. D. and Lifshitz, E. M.: Statistical Physics, Pergamon Press, Ltd., Oxford, England (1980).

10. Crawford, H. R., Neil1, G. H., Bucy, B. J., and Crawford, P. B.: "Carbon Dioxide - A Multipurpose Additive for Effective We11 Stimulation," J. Pet. Tech. (March 1963) 237-242.

11. Walker, J. R. and Dunlop, D. D.: "Physical Properties of Carbonated Oil," J. Pet. Tech. (August 1963) 873-876.

12. Miller, J. S. and Jones, R. A.: "A Laboratory Study to Determine Physical Characteristics of Heavy Oil After $\mathrm{CO}_{2}$ Saturation," SPE/DOE 9789 (1981).

13. Simon, R. and Graue, D. J.: "Generalized Correlations for Predicting Solubility, Swelling, and Viscosity Behavior of $\mathrm{CO}_{2}$-Crude $0 i 1$ Systems," J. Pet. Tech. (January 1965) 102-106.

14. Dodds, W. S., Stutzman, L. F., and Sollami, B. J.: "Carbon Dioxide Solubility in Water," Ind. and Eng. Chem. (1956) 1 92-95.

15. Parkinson, W. J. and DeNevers, N.: "Partial Molar Volume of Carbon Dioxide in Water Solutions," I and EC Fundamentals (November 1969) 709-713. 
16. Orr, F. M.: "Simulation of the One-Dimensional Convection of Four Phase, Four Component Mixtures," DOE/ET/12082-8 (June 1980).

17. Crichlow, H. B.: Modern Reservoir Engineering - A Simulation Approach, "Prentice-Hall, Inc., Englewood Cliffs, New Jersey (1977).

18. Stone, H. L.: "Estimation of Three-Phase Relative Permeability and Residual $0 i 1$ Data," J. Can. Pet. Tech. (1973) 12 53-61.

19. Patton, J. T., Coats, K. H., and Spence, K.: "Carbon Dioxide Well Stimulation: Part 1 - A Parametric Study," J. Pet. Tech. (August 1982) 1798-1804.

20. Reid, T. B. and Robinson, H. J.: "Lick Creek Meakin Sand Unit Immiscible $\mathrm{CO}_{2}$ /Waterflood Project," J.Pet. Tech. (September 1981) 1723-1729. 


\section{Appendix}

A. Sample Input Format

$$
-- \text { CO } 2 \text { CYCL }-
$$

(HUF N' PUF) CO2 DISPLACING 17 DEg.WILMINGTON OIL IN FRAC'D. RES. • NUMBER OF GRID BLOCKS

$$
\begin{aligned}
& \text { IN FRACTURE = } 4 \\
& \text { IN RESERVOIR BRANCH = } 3
\end{aligned}
$$

TIME STEP LENGTH $=3.000$ SECONDS

NUMBER OF TIME STEPS $=200$

PRESSURE CHANGE LIMIT PER TIME STEP $=\quad 50.0000$ PSI

BUBBLE-EDGE TOLERANCE ON MOLE FRACTION OF CO2 IN OIL = .0010

MAXIMUM NUMBER OF CONVERGENCE ITERATIONS ALLOWED

RESERVOIR GRID SCHEME

$----\rightarrow \mathrm{Z}$

-

$\cdot$

$\dot{\mathrm{V}}^{\mathrm{Y}}$

1

$\begin{array}{llll}2 & 6 & 10 & 14 \\ 3 & 7 & 11 & 15 \\ 4 & 8 & 12 & 16 \\ 5 & 9 & 13 & 17\end{array}$

LENGTH OF FRACTURE (CM) = 90.0000

LENGTH OF RESERVOIR BRANCH $(\mathrm{CM})=$

WIDTH OF FRACTURE (CM) = .1000

DEPTH OF SYSTEM $(\mathrm{CM})=10.0000$

2.0000

FRACTURE X-SECTIONAL AREA (SQ.CM.) = 1.0000

RES. BRANCH X-SECTIONAL AREA (SQ.CM.) $=225.0000$

$\begin{array}{rr}\text { ASSUMED POROSITY IN RESERVOIR }= & : 3000 \\ \text { IN FRACTURE }= & i .0000\end{array}$

PERMEABILITY IN FRACTURE (MD) $=.1000 \mathrm{E}+08$

PERMEABILITY IN RESERVOIR (MD) $=100.0000$

INITIAL RESERVOIR PRESSURE (PSI) = 150.0000 
CO2 INJECTION FLOW RATE (CC/SEC) = PRODUCTION FLOW RATE
2.0000

.1000

FUNCTIONAL FORM OF FLUID DENSITIES

$\begin{array}{lc}\text { BLACK OIL : } & .3530 \mathrm{E}-05 \times \mathrm{P}+.9450 \mathrm{E}+00 \\ \text { SAT-D. OIL SWELLING FACTOR: } & .1000 \mathrm{E}-03 \times \mathrm{P}+1 \text {. } \\ \text { PURE H2O: } & .3000 \mathrm{E}-05 \times \mathrm{P}+.9943 \mathrm{E}+00 \\ \text { SAT-D. H2O: } & .1680 \mathrm{E}-04 \times \mathrm{P}+.9943 \mathrm{E}+00\end{array}$

SLOPE OF GAS COMPRESSIBILITY FACTOR $=-.3500 \mathrm{E}-03$

SOLUBILITY COEFFCIENTS

$\begin{array}{ll}\text { OIL }- & .4540 \mathrm{E}-03 \\ \text { WATER - } & .2100 \mathrm{E}-04\end{array}$

VISCOSITY OF OIL $=$

$$
10 * *(.1090 E-03 * P-.3985 E+01 * X 12+.2699 E+01) \text { C.P. }
$$

(WHERE XI2 IS THE MOLE FRACTION OF CO2 IN OIL)

VIS. $\mathrm{CO} 2=\quad .0150 \quad$ VIS. $\mathrm{H} 20=0.1 .0000 \quad$ (CP)

MOLEC. WGTS. (GMS/MOL) - CO2: 44.0000 OIL: 200.0000 H2O: 18.0000

RELATIVE PERMEABILITY DATA

$\begin{array}{lll}\text { SWC }=.100 & \text { EKRO }=1.000 & \text { EO }=2.00 \\ \text { SOR }=.200 & E K R W=1.000 & E W=2.00 \\ \text { SOG }=.200 & \text { EKROG }=1.000 & \text { EOG }=2.00 \\ \text { SGC }=.050 & E K R G=1.000 & E G=2.00\end{array}$

MESH RATIO FOR PRESSURE EQUATION

IN FRACTURE $=.1333 \mathrm{E}+00$

IN RESERVOIR $=.4500 \mathrm{E}+01$ 
INITIAL COMPOSITION IN MATRIX (VOLUME FRACTIONS)

$$
\begin{array}{lll}
.0500 & .4500 & .5000 \\
& & \\
.0000 & \text { IN FRACTURE }
\end{array}
$$

INJECTION COMPOSITION (VOLUME FRACTIONS)

$$
1.0000 \quad .0000 \quad .0000
$$

$$
\begin{aligned}
& \text { HUF-N-PUF WELL MODE SEQUENCE } \\
& \text { MODE }: \begin{aligned}
1 & =\text { CO2 INJECT ION } \\
2 & =\text { WATER INJECT ION } \\
-1 & =\text { PRODUCT ION } \\
+10 & =\text { POST-INJECT ION SOAK } \\
-10 & =\text { POST-PRODUCT ION SOAK }
\end{aligned}
\end{aligned}
$$

$$
\begin{array}{lllllllllllllllll}
1 & 10 & -1 & -10 & 1 & 10 & -1 & -10 & 1 & 10 & -1 & -10 & 1 & 10 & -1 & -10 \\
1 & 10 & -1 & -10 & 1 & 10 & -1 & -10 & 1 & 10 & -1 & -10 & 1 & 10 & -1 & -10 \\
1 & 10 & -1 & -10 & 1 & 10 & -1 & -10 & & & & & & &
\end{array}
$$

MAX. PRESSURE BUILD-UP ALLOWED DURING INJECTION CYCLE: 250.0000

MIN. PRESSURE ALLOWED: 150.0000

PRESSURE DIFFERENCE REQUIRED TO END SOAK CYCLE: .0500

PRINT KEYS

$$
\operatorname{IPRNT}=5 \quad \text { IP }(1)=1 \quad \text { IP }(2)=1 \quad \text { IP }(3)=0 \quad \text { IP }(4)=
$$


B. Sample Output Format

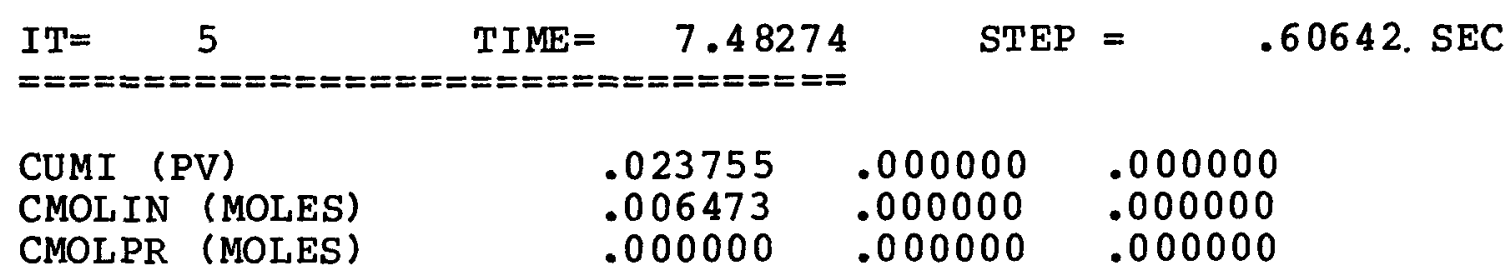

WELL MODE: $\quad$ CO2 INJECTION CYCLE : 1

\begin{abstract}
TSTRT - INITIAL STEP $($ SEC $)=.3000 E+01$
TDPCHG(I) - TIME STEP AFTER TRUNCATION ADJUST.

TOVERF - TIME STEP AFTER OVERSHOOT ADJUST. (FRAC.)

TOVERR - TIME STEP AFTER OVERSHOOT ADJUST. (RES.)

TBUBBL - TIME STEP AFTER BUBBLE EDGE ADJUST. $.6064 \mathrm{E}+00$

IMOB - PASSES THROUGH SUBR. MOBITR $=9$

TIME SPENT IN SUBR. IMPEM $=.2358 \mathrm{E}-01$ SECONDS.

TIME SPENT IN SUBR. PHASE $=.1343 \mathrm{E}-02$ SECONDS.
\end{abstract}

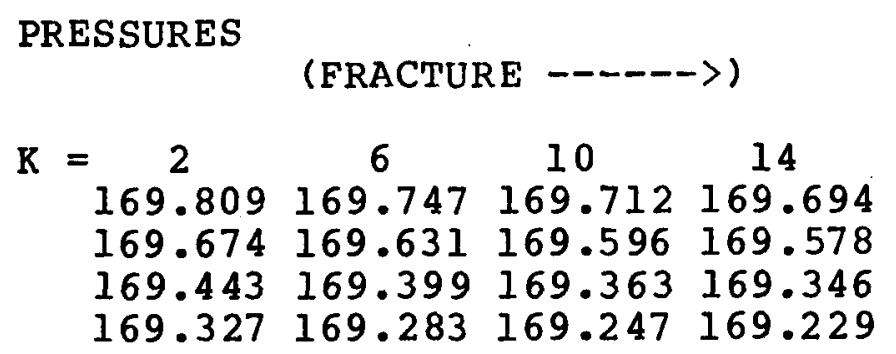




$\begin{array}{ccc}K & Q Z & Q Y \\ 1 & .2000 \mathrm{E}+01 & \\ 2 & .1111 \mathrm{E}+01 & .3678 \mathrm{E}+00 \\ 3 & .0000 \mathrm{E}+00 & .1778 \mathrm{E}+00 \\ 4 & .0000 \mathrm{E}+00 & .8916 \mathrm{E}-01 \\ 5 & .0000 \mathrm{E}+00 & .0000 \mathrm{E}+00 \\ 6 & .5347 \mathrm{E}+00 & .2664 \mathrm{E}+00 \\ 7 & .0000 \mathrm{E}+00 & .1785 \mathrm{E}+00 \\ 8 & .0000 \mathrm{E}+00 & .8950 \mathrm{E}-01 \\ 9 & .0000 \mathrm{E}+00 & .0000 \mathrm{E}+00 \\ 10 & .2675 \mathrm{E}+00 & .2668 \mathrm{E}+00 \\ 11 & .0000 \mathrm{E}+00 & .1787 \mathrm{E}+00 \\ 12 & .0000 \mathrm{E}+00 & .8961 \mathrm{E}-01 \\ 13 & .0000 \mathrm{E}+00 & .0000 \mathrm{E}+00 \\ 14 & .0000 \mathrm{E}+00 & .2670 \mathrm{E}+00 \\ 15 & .0000 \mathrm{E}+00 & .1788 \mathrm{E}+00 \\ 16 & .0000 \mathrm{E}+00 & .8966 \mathrm{E}-01 \\ 17 & .0000 \mathrm{E}+00 & .0000 \mathrm{E}+00\end{array}$

K

1

2
3

4

5

6

7

8
9

10

11

12

13

14

15

16

17
N1 3

$.1473 \mathrm{E}-02$

$.7147 \mathrm{E}-04$

$.1078 \mathrm{E}-06$

. $6181 \mathrm{E}-10$

$.1955 \mathrm{E}-03$

.9019 E-06

$.1003 \mathrm{E}-08$

$.7874 \mathrm{E}-12$

$.1669 \mathrm{E}-05$

$.5735 \mathrm{E}-08$

$.8592 \mathrm{E}-11$

$.8279 E-15$

$.5311 \mathrm{E}-08$

$.2431 E-10$

$.2235 \mathrm{E}-13$

$.8279 \mathrm{E}-15$
N3 3

$.4292 \mathrm{E}+00$
$.1259 \mathrm{E}+01$
$.1260 \mathrm{E}+01$
$.1260 \mathrm{E}+01$
$.6203 \mathrm{E}+00$
$.1260 \mathrm{E}+01$
$.1260 \mathrm{E}+01$
$.1260 \mathrm{E}+01$
$.6218 \mathrm{E}+00$
$.1260 \mathrm{E}+01$
$.1260 \mathrm{E}+01$
$.1259 \mathrm{E}+01$
$.6218 \mathrm{E}+00$
$.1260 \mathrm{E}+01$
$.1260 \mathrm{E}+01$
$.1259 \mathrm{E}+01$
N1 1

$.0000 \mathrm{E}+00$

$.9617 \mathrm{E}-03$

$.9617 \mathrm{E}-03$

$.9617 \mathrm{E}-03$

$.0000 \mathrm{E}+00$

$.9617 \mathrm{E}-03$

$.9617 \mathrm{E}-03$

$.9617 \mathrm{E}-03$

$.0000 \mathrm{E}+00$

$.9617 \mathrm{E}-03$

$.9617 \mathrm{E}-03$

$.9617 \mathrm{E}-03$

$.0000 \mathrm{E}+00$

$.9617 \mathrm{E}-03$

$.9617 \mathrm{E}-03$

.9617 E-03
N1 2

N22
$.5312 \mathrm{E}-01$

$.9575 \mathrm{E}-01$

$.9574 \mathrm{E}-\mathrm{Cl}$

$.9574 \mathrm{E}-\mathrm{Ol}$

$.5321 \mathrm{E}-\mathrm{Cl}$

$.9574 \mathrm{E}-\mathrm{Cl}$

$.9574 \mathrm{E}-\mathrm{Cl}$

$.9574 \mathrm{E}-01$

$.5319 \mathrm{E}-\mathrm{Cl}$

$.9574 \mathrm{E}-01$

$.9574 \mathrm{E}-01 \mathrm{I}$

$.9574 \mathrm{E}-01$

$.5319 E-01$

$.9574 \mathrm{E}-01$

$.9574 \mathrm{E}-01$

$.9574 \mathrm{E}-01$
CMPEF F

$.1017 \mathrm{E}-04$

$.2714 \mathrm{E}-03$

$.2720 \mathrm{E}-03$

$.2723 \mathrm{E}-03$

$.3871 \mathrm{E}-05$

$.2714 \mathrm{E}-03$

$.2721 \mathrm{E}-03$

$.2724 \mathrm{E}-03$

$.3379 \mathrm{E}-05$

$.2715 \mathrm{E}-03$

$.2722 \mathrm{E}-03$

$.2725 \mathrm{E}-03$

$.3374 \mathrm{E}-05$

. 2716E-03

$.2722 \mathrm{E}-03$

$.2726 \mathrm{E}-03$
$.1924 \mathrm{E}+02$
$.4502 \mathrm{E}+02$
$.4502 \mathrm{E}+02$
$.4502 \mathrm{E}+02$
$.2250 \mathrm{E}+02$
$.4502 \mathrm{E}+02$
$.4502 \mathrm{E}+02$
$.4502 \mathrm{E}+02$
$.2250 \mathrm{E}+02$
$.4502 \mathrm{E}+02$
$.4502 \mathrm{E}+02$
$.4502 \mathrm{E}+02$
$.2250 \mathrm{E}+02$
$.4502 \mathrm{E}+02$
$.4502 \mathrm{E}+02$
$.4502 \mathrm{E}+02$

$-.1450 \mathrm{E}+00$

$.4324 \mathrm{E}-03$

$.4126 \mathrm{E}-03$

$.4025 \mathrm{E}-03$

$-.2697 \mathrm{E}-05$

$.4286 \mathrm{E}-03$

$.4084 \mathrm{E}-03$

$.3984 \mathrm{E}-03$

$-.9086 \mathrm{E}-08$

$.4256 \mathrm{E}-03$

$.4055 \mathrm{E}-03$

$.3955 \mathrm{E}-03$

$.2050 \mathrm{E}-09$

$.4241 \mathrm{E}-03$

$.4040 \mathrm{E}-03$

$.3941 \mathrm{E}-03$ 


$\begin{array}{cccccc}\mathrm{K} & \mathrm{VlI} & \mathrm{V} 12 & \mathrm{~V} 22 & \mathrm{~V} 13 & \mathrm{V33} \\ 2 & .2051 \mathrm{E}+04 & .4449 \mathrm{E}+02 & .2115 \mathrm{E}+03 & .3224 \mathrm{E}+02 & .1809 \mathrm{E}+02 \\ 3 & .2053 \mathrm{E}+04 & .4449 \mathrm{E}+02 & .2115 \mathrm{E}+03 & .3224 \mathrm{E}+02 & .1809 \mathrm{E}+02 \\ 4 & .2056 \mathrm{E}+04 & .4450 \mathrm{E}+02 & .2115 \mathrm{E}+03 & .3224 \mathrm{E}+02 & .1809 \mathrm{E}+02 \\ 5 & .2058 \mathrm{E}+04 & .4450 \mathrm{E}+02 & .2115 \mathrm{E}+03 & .3224 \mathrm{E}+02 & .1809 \mathrm{E}+02 \\ 6 & .2052 \mathrm{E}+04 & .4449 \mathrm{E}+02 & .2115 \mathrm{E}+03 & .3224 \mathrm{E}+02 & .1809 \mathrm{E}+02 \\ 7 & .2054 \mathrm{E}+04 & .4449 \mathrm{E}+02 & .2115 \mathrm{E}+03 & .3224 \mathrm{E}+02 & .1809 \mathrm{E}+02 \\ 8 & .2057 \mathrm{E}+04 & .4450 \mathrm{E}+02 & .2115 \mathrm{E}+03 & .3224 \mathrm{E}+02 & .1809 \mathrm{E}+02 \\ 9 & .2058 \mathrm{E}+04 & .4450 \mathrm{E}+02 & .2115 \mathrm{E}+03 & .3224 \mathrm{E}+02 & .1809 \mathrm{E}+02 \\ 10 & .2053 \mathrm{E}+04 & .4449 \mathrm{E}+02 & .2115 \mathrm{E}+03 & .3224 \mathrm{E}+02 & .1809 \mathrm{E}+02 \\ 11 & .2054 \mathrm{E}+04 & .4449 \mathrm{E}+02 & .2115 \mathrm{E}+03 & .3224 \mathrm{E}+02 & .1809 \mathrm{E}+02 \\ 12 & .2057 \mathrm{E}+04 & .4450 \mathrm{E}+02 & .2115 \mathrm{E}+03 & .3224 \mathrm{E}+02 & .1809 \mathrm{E}+02 \\ 13 & .2059 \mathrm{E}+04 & .4450 \mathrm{E}+02 & .2115 \mathrm{E}+03 & .3224 \mathrm{E}+02 & .1809 \mathrm{E}+02 \\ 14 & .2053 \mathrm{E}+04 & .4449 \mathrm{E}+02 & .2115 \mathrm{E}+03 & .3224 \mathrm{E}+02 & .1809 \mathrm{E}+02 \\ 15 & .2054 \mathrm{E}+04 & .4449 \mathrm{E}+02 & .2115 \mathrm{E}+03 & .3224 \mathrm{E}+02 & .11809 \mathrm{E}+02 \\ 16 & .2057 \mathrm{E}+04 & .4450 \mathrm{E}+02 & .2115 \mathrm{E}+03 & .3224 \mathrm{E}+02 & .1809 \mathrm{E}+02 \\ 17 & .2059 \mathrm{E}+04 & .4450 \mathrm{E}+02 & .2115 \mathrm{E}+03 & .3224 \mathrm{E}+02 & .1809 \mathrm{E}+02\end{array}$

$\begin{array}{lll}\mathrm{K} & \text { RHOMOL }(1) & \text { RHOMOL }(2) \\ 2 & .4875 \mathrm{E}-03 & .5021 \mathrm{E}-02 \\ 3 & .4870 \mathrm{E}-03 & .4733 \mathrm{E}-02 \\ 4 & .4863 \mathrm{E}-03 & .4728 \mathrm{E}-02 \\ 5 & .4860 \mathrm{E}-03 & .4728 \mathrm{E}-02 \\ 6 & .4873 \mathrm{E}-03 & .4754 \mathrm{E}-02 \\ 7 & .4869 \mathrm{E}-03 & .4728 \mathrm{E}-02 \\ 8 & .4862 \mathrm{E}-03 & .4728 \mathrm{E}-02 \\ 9 & .4858 \mathrm{E}-03 & .4728 \mathrm{E}-02 \\ 10 & .4872 \mathrm{E}-03 & .4728 \mathrm{E}-02 \\ 11 & .4868 \mathrm{E}-03 & .4728 \mathrm{E}-02 \\ 12 & .4861 \mathrm{E}-03 & .4728 \mathrm{E}-02 \\ 13 & .4857 \mathrm{E}-03 & .4728 \mathrm{E}-02 \\ 14 & .4871 \mathrm{E}-03 & .4728 \mathrm{E}-02 \\ 15 & .4868 \mathrm{E}-03 & .4728 \mathrm{E}-02 \\ 16 & .4860 \mathrm{E}-03 & .4728 \mathrm{E}-02 \\ 17 & .4857 \mathrm{E}-03 & .4728 \mathrm{E}-02\end{array}$

RHOMOL (3)

$.5512 \mathrm{E}-01$

$.5526 \mathrm{E}-01$

$.5527 \mathrm{E}-01$

$.5527 \mathrm{E}-01$

$.5525 \mathrm{E}-01$

$.5527 \mathrm{E}-01$

$.5527 \mathrm{E}-01$

$.5527 \mathrm{E}-01$

$.5527 \mathrm{E}-01$

$.5527 \mathrm{E}-01$

$.5527 \mathrm{E}-01$

$.5527 \mathrm{E}-01$

$.5527 \mathrm{E}-01$

$.5527 \mathrm{E}-01$

$.5527 \mathrm{E}-01$

$.5527 \mathrm{E}-01$

$\begin{array}{ccc}F 1 & F 2 & F 3 \\ .00000 & .00549 & .99451 \\ .00000 & .00066 & .99934 \\ .00000 & .00065 & .99935 \\ .00000 & .00065 & .99935 \\ .00000 & .00204 & .99796 \\ .00000 & .00065 & .99935 \\ .00000 & .00065 & .99935 \\ .00000 & .00065 & .99935 \\ .00000 & .00191 & .99809 \\ .00000 & .00065 & .99935 \\ .00000 & .00065 & .99935 \\ .00000 & .00065 & .99935 \\ .00000 & .00191 & .99809 \\ .00000 & .00065 & .99935 \\ .00000 & .00065 & .99935 \\ .00000 & .00065 & .999935\end{array}$

S2 .59384 .44996 .44979 .44979 .50091 .44981 .44979 .44979 .49997 .44980 .44979 .44979 .49996 .44981 .44979 .44979

\begin{abstract}
S3 .40616 .50618 .50629 .50625 .49909 .50632 .50627 .50624 .50003 .50631 .50626

.50622

.50004

.50631

.50626 .50622
\end{abstract}

$\begin{array}{ll}x(1,2) & x(1,3) \\ .073956 & .003421 \\ .001227 & .000057 \\ .000002 & .000000 \\ .000000 & .000000 \\ .006811 & .000315 \\ .000015 & .000001 \\ .000000 & .000000 \\ .000000 & .000000 \\ .000058 & .000003 \\ .000000 & .000000 \\ .000000 & .000000 \\ .000000 & .000000 \\ .000000 & .000000 \\ .000000 & .000000 \\ .000000 & .000000 \\ .000000 & .000000\end{array}$

TMOB .40840 .33692 .33709 .33703 .50011 .33715 .33707 .33701 .50099 .33713 .33705 .33699 .50099 .33712 .33704 .33698 


\begin{tabular}{llllllll} 
& \multicolumn{1}{l}{$\mathrm{S} 2$} & $\mathrm{X1}$ & $\mathrm{X} 2$ & $\mathrm{X} 3$ & $\mathrm{RHO}$ & $\mathrm{VIS}$ & $\mathrm{KR}$ \\
2 & .5938 & .0740 & .9260 & .0000 & .9463 & 264.7446 & .5938 \\
3 & .4500 & .0012 & .9988 & .0000 & .9456 & 515.9482 & .1139 \\
4 & .4498 & .0000 & 1.0000 & .0000 & .9456 & 521.7494 & .1137 \\
5 & .4498 & .0000 & 1.0000 & .0000 & .9456 & 521.7430 & .1137 \\
6 & .5009 & .0068 & .9932 & .0000 & .9457 & 490.1874 & .5009 \\
7 & .4498 & .0000 & 1.0000 & .0000 & .9456 & 521.7088 & .1137 \\
8 & .4498 & .0000 & 1.0000 & .0000 & .9456 & 521.7524 & .1137 \\
9 & .4498 & .0000 & 1.0000 & .0000 & .9456 & 521.7372 & .1137 \\
10 & .5000 & .0001 & .9999 & .0000 & .9456 & 521.5157 & .5000 \\
11 & .4498 & .0000 & 1.0000 & .0000 & .9456 & 521.7777 & .1137 \\
12 & .4498 & .0000 & 1.0000 & .0000 & .9456 & 521.7478 & .1137 \\
13 & .4498 & .0000 & 1.0000 & .0000 & .9456 & 521.7325 & .1137 \\
14 & .5000 & .0000 & 1.0000 & .0000 & .9456 & 521.7902 & .5000 \\
15 & .4498 & .0000 & 1.0000 & .0000 & .9456 & 521.7759 & .1137 \\
16 & .4498 & .0000 & 1.0000 & .0000 & .9456 & 521.7454 & .1137 \\
17 & .4498 & .0000 & 1.0000 & .0000 & .9456 & 521.7302 & .1137
\end{tabular}



C. Source Code for CO2CYCL

PROGRAM CO2 ( TAPEl=INPUT, TAPE4=OUTPUT )

C
C
C
$C$
$C$
$C$
$C$
$C$
$C$
$C$
$C$
$C$
$C$
$C$
$C$

\author{
TWO DIMENSIONAL SIMULATION \\ OF \\ THREE PHASE, THREE COMPONENT \\ FLOW \\ IN $A$ \\ FRACTURED POROUS MEDIUM
}

WRITTEN BY: ROLAND BEGIN

DEPARTMENT OF PHYSICS

COLORADO STATE UNIVERSTTY

FORT COLLINS, COLORADO 80521

LAST REVISION: MAY 15, 1983

\title{
PARAMETER ( ISZ=52)
}

COMMON / COUNT / IT, ITMAX, ITCNT, ICNVRG, IBUBBL, IDPCHG, IOVERF,

- IOVERR, ISTABL , I MOB , I MOBI , I PRNT, NOUNIT , MXCNVRG

COMMON / TIMES / TPHASE,TIMPEM, TDPCHG (100),TSTRT, TOVERE (100),

-

C

DATA NOUNIT / $4 /$ TOVERR (100), TBUBBL (100), XJUMP

\section{VARIABLE DEFINITIONS.}

VBLK (K) - VOLUME OF GRID BLOCK

$C(I, K)$ - VOLUME FRACTION OF COMPONENT I IN BLOCK $K$.

$C N(I, K)$ - MOLES OF COMPONENT I IN BLOCK $K$

CNGC $(K)$ - MOLES OF RESIDUAL GAS IN IN BLOCK $K$ (IMMOBILE AND INSOLUBLE IN OIL AND WATER PHASES)

$X(I, J, K)-$ MOLE FRACTION OF COMPONENT I IN PHASE $J$ IN BLOCK K.

$S(J, K)$ - SATURATION OF PHASE $J$ IN BLOCK $K$.

$F(J, K)$ - FRACTIONAL FLOW OF PHASE J IN BLOCK K.

WT (I) - MOLECULAR WGT. OF COMPONENT I (GM / MOLE)

RHO $(J, K)$ - DENSITY OF PHASE J IN BLOCK $K$ (GM / CC)

RHOMOL $(J, K)$ - MOLAR DENSITY OF PHASE $J$ IN BLOCK $K$ (MOL/CC) VISO $(K)$ - VISCOSITY OF OIL PHASE IN BLOCK $K$ (CP)

VISG - VISCOSITY OF GAS PHASE

VISW - VISCOSITY OF WATER PHASE

$\operatorname{AKR}(J, K)$ - RELATIVE PERMEABILITY OF PHASE J IN BLOCK K.

PRSAV $(K)$ - AVERAGE PRESSURE IN BLOCK $K$ (PSI)

$\mathrm{QZ}(\mathrm{K})$ - VOLUMETRIC FLOW RATE IN FRACTURE (CC/SEC)

QY (K) - VOLUMETRIC FLOW RATE IN ROCK MATRIX

(PERPENDI CULAR TO FRACTURE) 


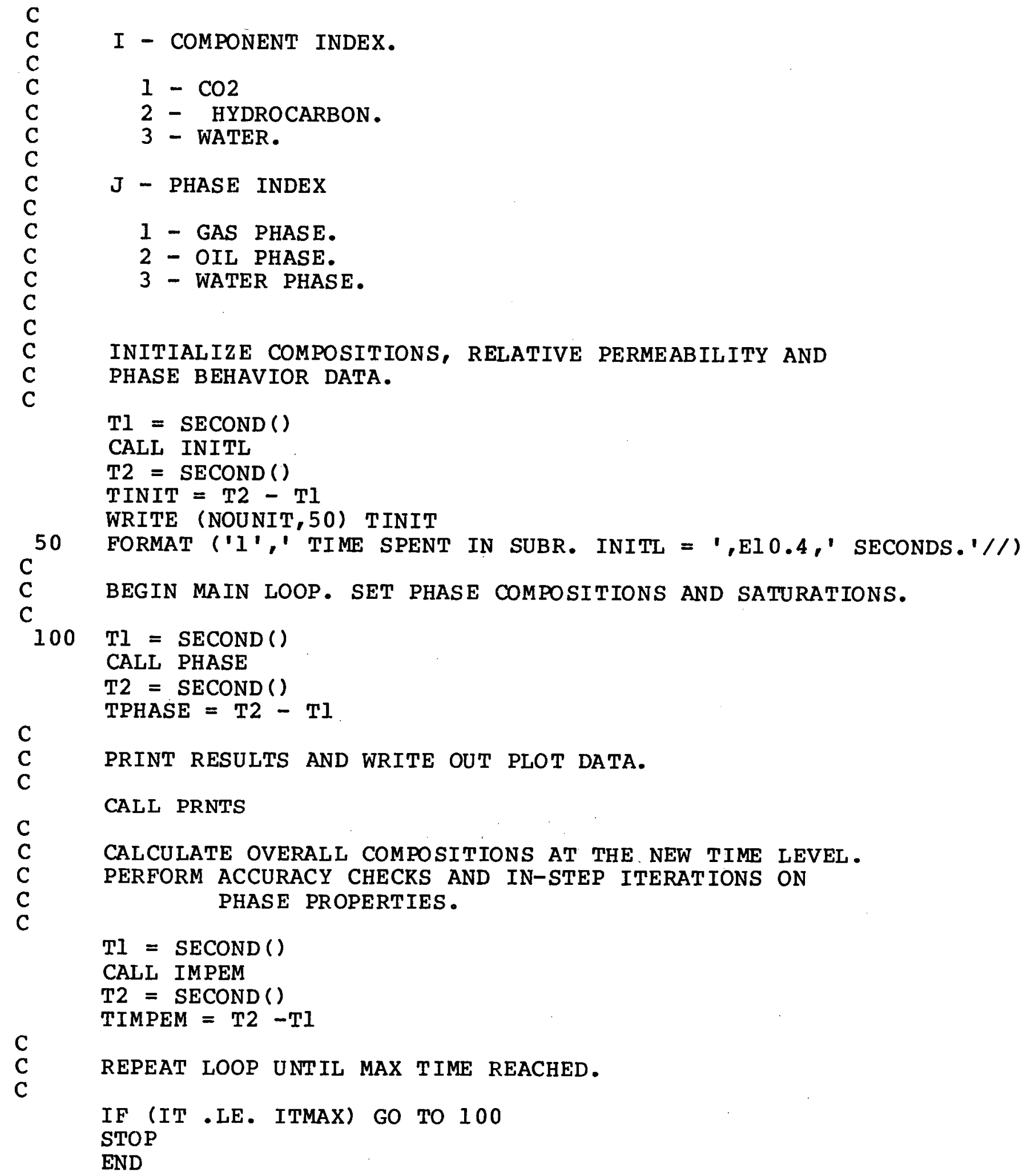




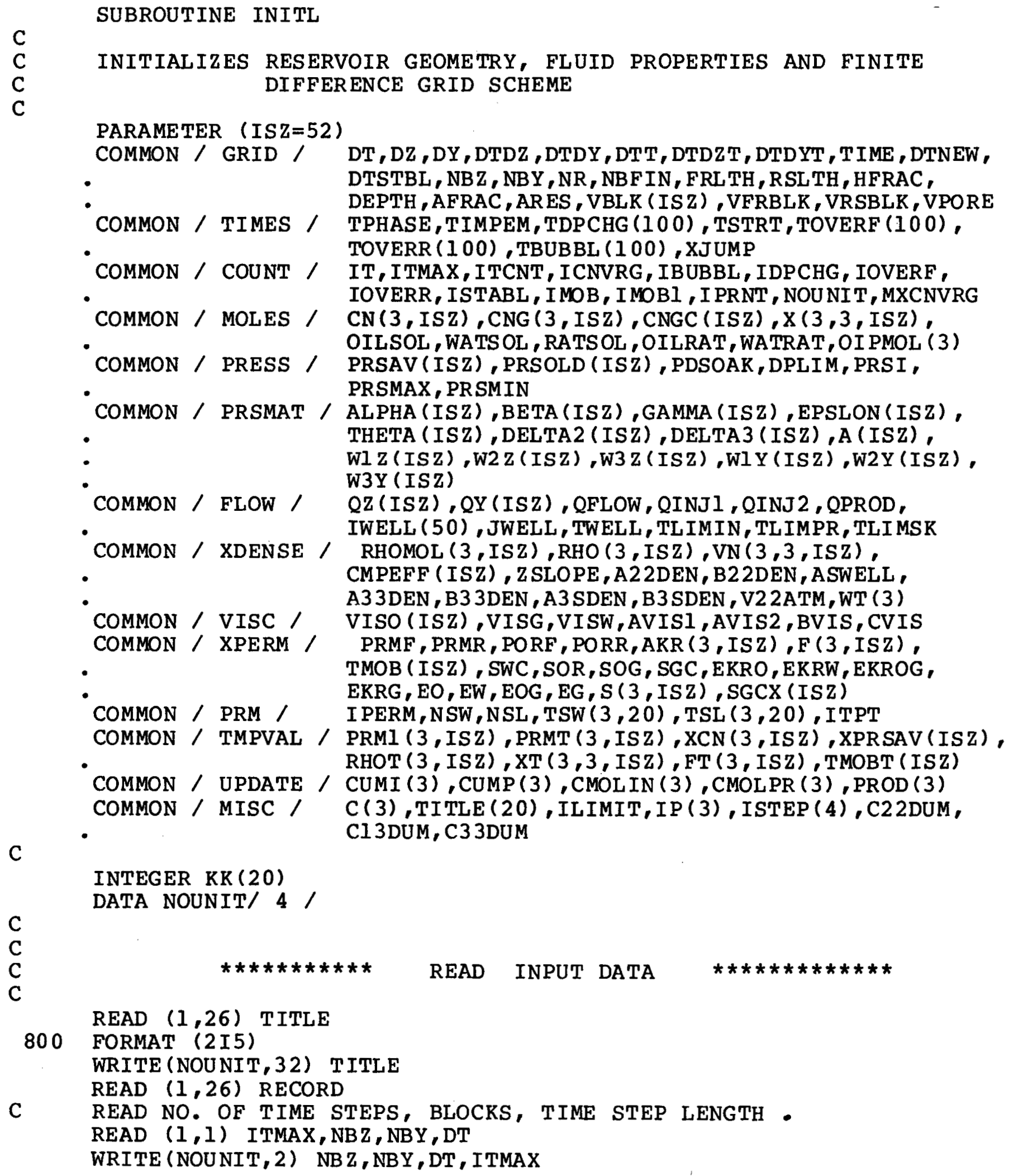


C

READ $(1,26)$ RECORD

READ LIMITING PRESSURE CHANGE

READ $(1,809)$ DPLIM

READ $(1,26)$ RECORD

READ $(1,809)$ XJUMP

WRITE (NOUNIT, 802 ) DPLIM

802 FORMAT ( $2 \mathrm{X}$, 'PRESSURE CHANGE LIMIT PER TIME STEP = 'F10.4, 1 ' PSI')

WRITE (NOUNIT,801) XJUMP

801 FORMAT (/2X,'BUBBLE-EDGE TOLERANCE ON MOLE FRACTION OF CO2 ',

- IN OIL $=$ 'F10.4/)

READ $(1,26)$ RECORD

READ $(1,9) \quad$ MXCNVRG

WRITE (NOUNIT,803) MXCNVRG

803 FORMAT (2X,' MAXIMUM NUMBER OF CONVERGENCE ITERATIONS ALLOWED',

C $5 X, I 5 /)$

\section{$\mathrm{DZ}=1 . / \mathrm{FLOAT}(\mathrm{NBZ})$ \\ $\mathrm{DTDZ}=\mathrm{DT} / \mathrm{DZ}$}

IF (NBY.EQ.0) GO TO 888

$\mathrm{DY}=1 . / \mathrm{FLOAT}(\mathrm{NBY})$

GO TO 889

888 DY $=1$.

889 CONTINUE

$\mathrm{DTDY}=\mathrm{DT} / \mathrm{DY}$

$T I M E=0$.

TWELL $=0$

DTNEW $=1$.

$\mathrm{NR}=\mathrm{NBY}+1$

C

$\mathrm{NBFIN}=\mathrm{NR} * \mathrm{NBZ}+1$

WRITE (NOUNIT, 50)

50

1

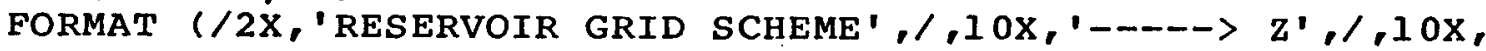

$\mathrm{NBZPI}=\mathrm{NBZ}+\dot{i}$

DO $51 \mathrm{KF}=1, \mathrm{NBZPI}$

51

$K K(K F)=2+(K F-I) * N R$

52

WRITE (NOUNIT, 52) (KK (I), I=1, NBZ)

FORMAT $\left(4 \mathrm{X},{ }^{\prime} \mathrm{I}, 20 \mathrm{I} 5\right)$

IF (NBY.EQ.0) GO TO 56

DO $53 \mathrm{~J}=1$, NBY

DO $54 \quad I=1, N B Z$

54 $K K(I)=K K(I)+1$

WRITE (NOUNIT, 55) (KK (I), I=1, NBZ)

FORMAT $(5 \mathrm{X}, 20 \mathrm{I5})$

C

55

C

$56 \quad I T=0$

ITCNT $=0$

ISTABL $=0$

$I M O B=0$

ICNVRG $=0$

IBUBBL $=0$ 
C
C
C
C

READ DATA FOR PRESSURE EQUATION

READ $(1,26)$ RECORD

READ $(1,26)$ RECORD

809

READ (1,809) FRLTH, RSLTH, HFRAC, DEPTH , PORR, PORF

FORMAT (6F10.4)

AFRAC $=$ HFRAC $*$ DEPTH

ARES $=\mathrm{DZ}$ * FRLTH * DEPTH

READ $(1,26)$ RECORD

READ ( 1,811$)$ A2 2DEN, B2 2DEN, ASWELL , A3 3DEN , B3 3DEN , A3SDEN, 1

811

FORMAT (8E1 0.4)

READ $(1,26)$ RECORD

READ $(1,26)$ RECORD

C

READ $(1,810)$ PRSI, PRMF, PRMR

810 FORMAT $(4 \mathrm{E} 10.4)$

$$
\text { VFRBLK = FRLTH * DZ * AFRAC * PORF }
$$

VRSBLK $=$ RSLTH * DY * ARES * PORR

WRITE (NOUNIT, 82 0) FRL,TH, RSLTH, HFRAC , DEPTH , AFRAC, ARES , PORR, PORF, 1 PRMF, PRMR, PRSI

820 FORMAT (/// 2X,'LENGTH OF FRACTURE $(\mathrm{CM})=1, \mathrm{~F} 10.4$, 1

1

$/ 2 \mathrm{X}$, 'LENGTH OF RESERVOIR BRANCH $(\mathrm{CM})=1, \mathrm{~F} 10.4$,

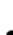

/2X,'WIDTH OF FRACTURE (CM) $=$ ',F10.4, $/ 2 X$, DEPTH OF SYSTEM $(C M)=1$, Fl 0.4 ,

$/ / 2 \mathrm{X}$, 'FRACTURE X-SECT IONAL AREA (SQ.CM.) = ',Fl0.4, $/ 2 \mathrm{X}, '$ 'RES. BRANCH X-SECT IONAL AREA (SQ.CM.) $=1, \mathrm{Fl} 0.4$, $1 / 2 \mathrm{X}$, 'ASSUMED POROSITY IN RESERVOIR $=1$, F10.4, $12 \mathrm{x}, 1$ IN FRACTURE $=$ ', F10.4,

$/ / 2 \mathrm{X}$, 'PERMEABILITY IN FRACTURE (MD) $=1$, EI 0.4, $/ 2 \mathrm{X}$, ' PERMEABILITY IN RESERVOIR (MD) $=$ ', F10.4,

C $/ / / 2 \mathrm{X}$, ' INITIAL RESERVOIR PRESSURE (PSI) $=1$, FI0.4)

READ $(1,26)$ RECORD

READ $(1,810)$ QINJ1, QINJ2, QPROD

WRITE (NOUNIT, 823) QINJ1, QINJ2, QPROD

823

FORMAT $(/ / 2 \mathrm{X}, ' \mathrm{CO} 2$ INJECTION FLOW RAT

C 1

$/ 2 X$, ' WATER INJECT ION FLOW RATE $/ 2 \mathrm{X}$, ' PRODUCTION FLOW RATE

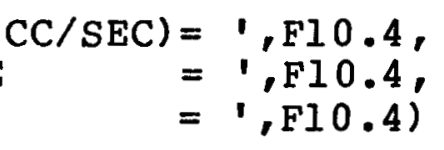

WRITE (NOUNIT, 825) A2 2DEN, B2 2DEN, ASWELL, A3 3DEN, B3 3DEN, 1

825 1 A3SDEN, B3SDEN

C 4

FORMAT (///2X,'FUNCTIONAL FORM OF FLUID DENSITIES', $/ /$, T10,'BLACK OIL : ',T30,El0.4,' X P + ',El0.4,/, T10,'SAT-D. OIL SWELLING FACTOR: ',T40,E10.4,' X P + 1.' ,$/, T 10$, 'PURE H2O :',T30,El0.4,' X P + ',El0.4,/, T10,'SAT-D. H2O:',T30,E10.4,' X P + ',El0.4/) 


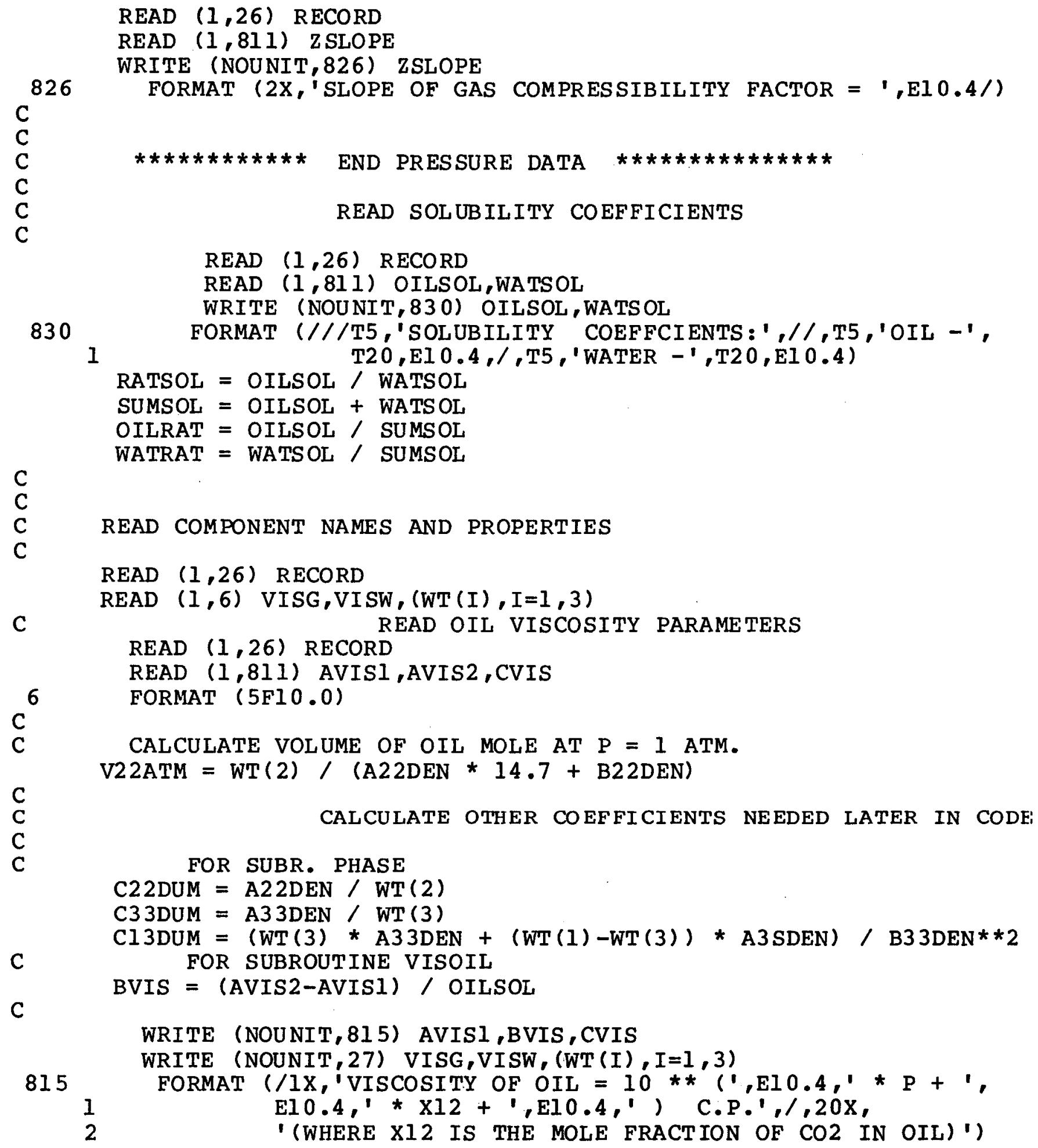


C
C
C

READ RELATIVE PERMEABILITY DATA.

$\operatorname{READ}(1,9)$ I PERM, NSW, NSL

IF (I PERM .EQ. O) GO TO 45

DO $30 \quad I=1, N S W$

$\operatorname{READ}(1,3) \quad(T S W(L, I), L=1,3)$

30 CONT INUE

DO $35 \mathrm{I}=1, \mathrm{NSL}$

$\operatorname{READ}(1,3) \quad(T S L(L, I), L=1,3)$

35 CONT INUE

$E K R W=T S W(2, N S W)$

WRITE (NOUNIT, 17)

WRITE (NOUNIT, 18$) \quad(L, \operatorname{TSW}(1, L), \operatorname{TSW}(2, L), \operatorname{TSW}(3, L), L=1, N S W)$

WRITE (NOUNIT, 19)

WRITE (NOU NIT, 18$) \quad(L, \operatorname{TSL}(1, L), \operatorname{TSL}(2, L), \operatorname{TSL}(3, L), L=1, N S L)$

45 READ $(1,26) \quad$ RECORD

READ $(1,26)$ RECORD

READ $(1,3)$ SWC, SOR, SOG, SGC, EKRO, EKRW, ERROG, ERRG, EO, EW,

IEOG , EG

WRITE (NOUNIT, 5) SWC , EKRO, EO, SOR, EKRW, EW, SOG , EKROG, EOG, SGC, EKRG, EG IF (EKRO .NE. EKROG) WRITE (NOUNIT, 36)

$\mathrm{C}$

48 CONTINUE

C

C

C

C

C

C

110

$Q Z(K)=0$

C

$Q Y(K)=0$

C

INITIALIZE MESH RATIO

$\mathrm{DTDZ}=\mathrm{DTDZ} / \mathrm{FRLTH}$

DTDY $=$ DTDY / RSLTH

$\mathrm{DTT}=\mathrm{DT}$

$\mathrm{DTDZT}=\mathrm{DTDZ}$

DTDYT $=$ DTDY

C

816

WRITE (NOUNIT, 816) DTDZ,DTDY

1

FORMAT (//1X,'MESH RATIO FOR PRESSURE EQUATION:',/,

C

2

IOX,' IN FRACTURE $=$ ',El $0.4,1$,

I0X,'IN RESERVOIR $=$ ', El0.4)

C INITIALIZE PRESSURES AND PERMEABILITIES

DO $130 \mathrm{~K}=2$, NBFIN

$\operatorname{PRSAV}(\mathrm{K})=\mathrm{PRSI}$

PRSOLD $(K)=$ PRSI

130

DO $130 \mathrm{~J}=1,3$

$\operatorname{AKR}(J, K)=0$ 
C
C
C
C

C

C

C

C

$$
\begin{aligned}
& \operatorname{RHOMOL}(1,2)=2.7 \mathrm{E}-6 * \operatorname{PRSI} /(1++\mathrm{ZSLOPE} * \mathrm{PRSI}) \\
& \operatorname{RHOMOL}(2,2)=(\mathrm{A} 22 \mathrm{DEN} * \operatorname{PRSI}+\mathrm{B} 22 \mathrm{DEN}) / \mathrm{WT}(2) \\
& \operatorname{RHOMOL}(2,1)=\operatorname{RHOMOL}(2,2) \\
& \operatorname{RHOMOL}(3,2)=(\mathrm{A} 33 \mathrm{DEN} * \operatorname{PRSI}+\mathrm{B} 33 \mathrm{DEN}) / \mathrm{WT}(3)
\end{aligned}
$$

READ INITIAL COMPOSITIONS (VOLUME FRACTIONS).

$\operatorname{READ}(1,26) \quad \mathrm{RECORD}$

$\operatorname{READ}(1,14) \quad(\mathrm{C}(\mathrm{I}), I=1,3)$

READ RESERVOIR MATRIX COPOSITIONS

CNIRS $=\mathrm{C}(1) *$ RHOMOL $(1,2) *$ VRSBLK

CN2RS $=C(2) *$ RHOMOL $(2,2) *$ VRSBLK

CN3RS $=\mathrm{C}(3) *$ RHOMOL $(3,2) *$ VRSBLK

C

WRITE (NOUNIT, 13) (C (I), I=1,3)

C

$\operatorname{READ}(1,26) \quad \mathrm{RECORD}$

READ FRACTURE COMPOSITIONS

$\operatorname{READ}(1,14) \quad(\mathrm{C}(\mathrm{I}), I=1,3)$

CNIFR $=\mathrm{C}(1) * \operatorname{RHOMOL}(1,2) * \operatorname{VFRBLK}$

CN2FR $=C(2) *$ RHOMOL $(2,2) *$ VFRBLK

$\mathrm{CN} 3 F R=\mathrm{C}(3) * \operatorname{RHOMOL}(3,2) *$ VFRBLK

C

WRITE (NOUNIT, 15) (C (I), $I=1,3$ )

CALCULATE MOLES OF RESIDUAL GAS PRESENT

CNGCFR $=0$

CNGCRS $=$ SGC $* \operatorname{RHOMOL}(1,2) *$ VRSBLK

$\mathrm{KB}=2$

DO $128 \mathrm{KF}=1, \mathrm{NBZ}$

$\mathrm{KBDUM}=\mathrm{KB}+\mathrm{NBY}$

DO $125 \mathrm{~K}=\mathrm{KB}$, KBDUM

DO $122 \mathrm{I}=1,3$

122

DO $122 \mathrm{~J}=1,3$

$X(I, J, K)=0$

$X(1,1, K)=1$.

$\operatorname{CNG}(2, K)=0$

$\operatorname{CNG}(3, K)=0$

IF (K.GT.KB) GO TO 124

$\mathrm{CN}(1, \mathrm{~K})=\mathrm{CN} I \mathrm{FR}$

$\mathrm{CN}(2, \mathrm{~K})=\mathrm{CN} 2 \mathrm{FR}$

$\mathrm{CN}(3, \mathrm{~K})=\mathrm{CN} 3 \mathrm{FR}$

$\operatorname{CNGC}(\mathrm{K})=$ CNGCFR

$\operatorname{VBLK}(K)=\operatorname{VFRBLK}$

124

GO TO 125

$\mathrm{CN}(I, \mathrm{~K})=\mathrm{CNIRS}$

$\mathrm{CN}(2, K)=\mathrm{CN} 2 \mathrm{RS}$

$\mathrm{CN}(3, K)=\mathrm{CN} 3 \mathrm{RS}$

CNGC $(K)=$ CNGCRS

$\operatorname{VBLK}(\mathrm{K})=$ VRSBLK

125 CONTINUE 


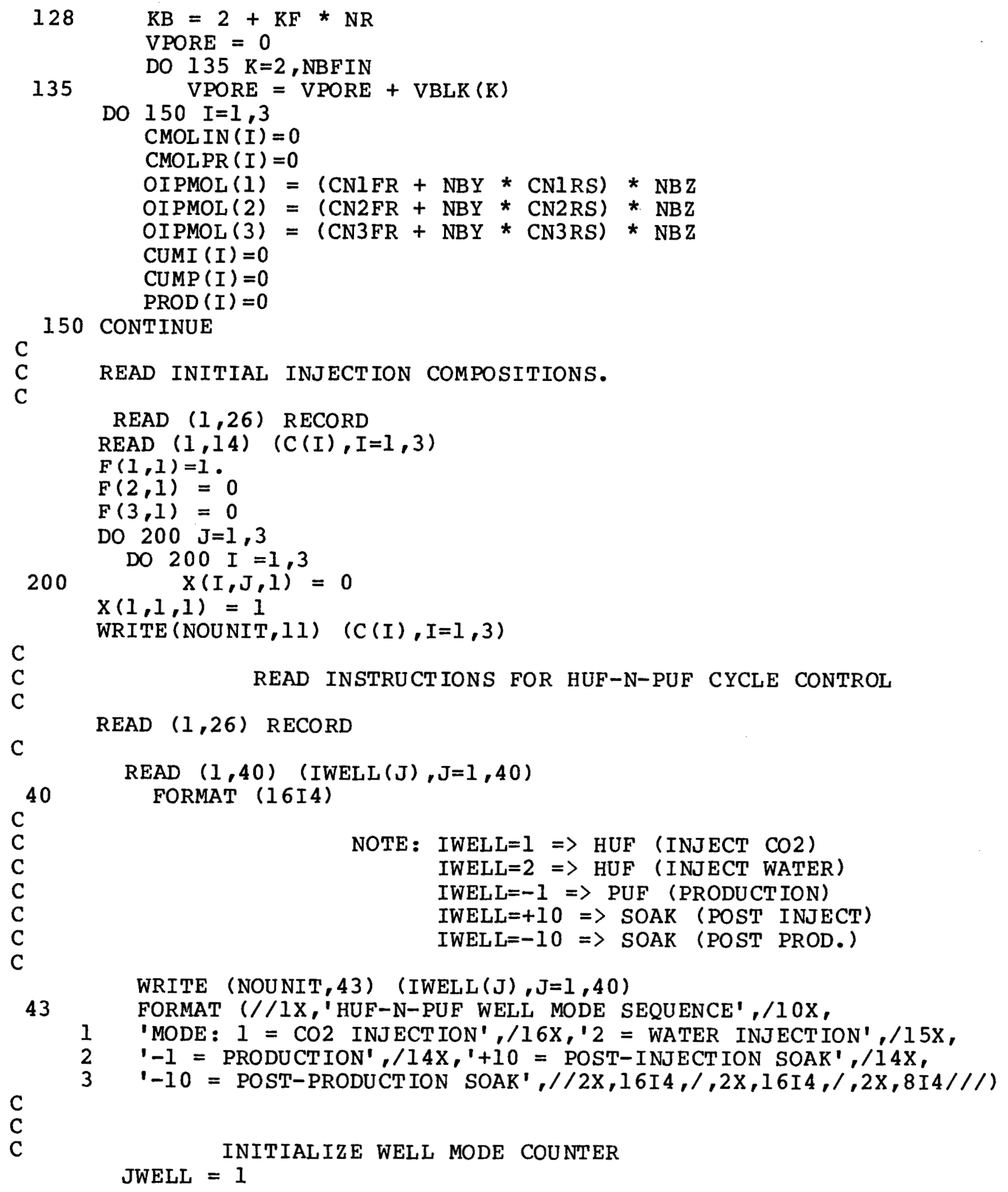


READ PARAMETERS DEFINING WELL MODE CHANGES

$\operatorname{READ}(1,26)$ RECORD

READ $(1,9)$ ILIMIT

$\operatorname{READ}(1,26)$ RECORD

IF (ILIMIT.EQ.I) THEN

READ $(1,41)$ PRSMAX, PRSMIN, PDSOAK

WRITE (NOUNIT, 46) PRSMAX, PRSMIN, PDSOAK

ELSE IF (ILIMIT.EQ.2) THEN

READ $(1,41)$ TLIMIN, TL IMPR, TLIMSK

WRITE (NOUNIT, 47) TLIM IN, TL IMPR, TLIMSK

FORMAT ( $1 \mathrm{X}$, 'MAX. PRESSURE BUILD-UP ALLOWED DURING ', ' INJECTION CYCLE: ' ,FI0 $0,1 / /, 2 \mathrm{X}, 1 \mathrm{MIN}$. PRESSURE', ' ALLOWED: ',F10.4,//,2X,' PRESSURE DIFFERENCE ', 'REQUIRED TO END SOAK CYCLE: ',FI0.4//) FORMAT ( $2 \mathrm{x}$, 'INJECTION CYCLE LIMITED TO ', Fi0.4, ' SEC.',$/$, $2 \mathrm{X}$, ' PRODUCT ION CYCLE LIMITED TO ',F10.4,' SEC.', $/, 2 \mathrm{X}, '$ SOAK CYCLE LIMITED TO ',F 10.4, 'SEC. $/ / /)$

IF (IWELL (1).EQ.I) QZ(1) = QINJI

IF (IWELL(1).EQ.2) QZ(1) = QINJ2

$\mathrm{C}$

C

C

READ PRINT KEYS.

READ $(1,26)$ RECORD

READ $(1,9)$ I PRNT, (IP (J), J $=1,3)$

WRITE (NOUNIT, 1 2) I PRNT, ( I P (J), J $=1,3$ ) RETURN

1 FORMAT ( 3 I5 , 2F10.0)

2 FORMAT (' NUMBER OF GRID BLOCKS: ', /,I 0X,' IN FRACTURE $=1,15,1$, 1

2

3 I OX,' IN RESERVOIR BRANCH $=1,15, / \%$,

3 FORMAT (4F10.0/4F 10.0/4F10.0)

' TIME STEP LENGTH = ,F6.3,' SECONDS $/ /$

5 FORMAT (//' RELATIVE PERMEABILITY DATA: $1 / / 5 \mathrm{X}$, 1 ' $\mathrm{SWC}=1, \mathrm{~F} 5.3,10 \mathrm{X},{ }^{\prime} \mathrm{EKRO}=1, \mathrm{~F} 5.3,10 \mathrm{X}, \mathrm{I}^{\mathrm{EO}}=1, \mathrm{~F} 6.2 / 5 \mathrm{X}$, 2 ' $\mathrm{SOR}=1, \mathrm{~F} 5.3,10 \mathrm{X},{ }^{\prime} \mathrm{ERRW}=1, \mathrm{~F} 5.3,10 \mathrm{X}, \mathrm{EW}=1, \mathrm{~F} 6.2 / 5 \mathrm{X}$,

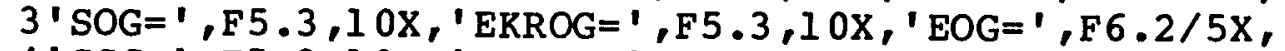
4 ' $\mathrm{SGC}=1, \mathrm{~F} 5.3,10 \mathrm{X}, ' \mathrm{EKRG}=1, \mathrm{~F} 5.3,10 \mathrm{X}, 1 \mathrm{EG}=1, \mathrm{~F} 6.2 /)$

9 FORMAT (15I5)

11 FORMAT ( $/ 1$ INJECTION COMPOSITION (VOL UME FRACTIONS): $1 / / 5 \mathrm{X}, 3 \mathrm{~F} 10.4 /$ )

12 FORMAT (/' PRINT KEYS: ' //5X,' I PRNT=', I $2,3 \mathrm{X}, '$ IP $(1)=1, \mathrm{I} 1,3 \mathrm{X}$,

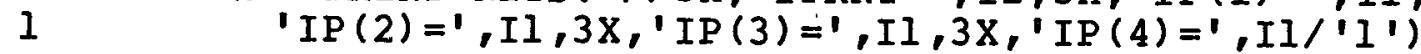

13 FORMAT (/' INITIAL COMPOSITION IN MATRIX (VOLUME FRACTIONS): ', 1

14 FORMAT (7F10.0)

15 FORMAT (

IN FRACTURE : ',$(, 5 \mathrm{X}, 3 \mathrm{~F} 10.4)$ 
17 FORMAT (//1X,'OIL-WATER RELATIVE PERMEABILITIES: '// I5X, 1

18 FORMAT $(20(/ 5 \mathrm{X}, \mathrm{I3}, 3 \mathrm{~F} 10.3))$

19 FORMAT (//IX,'GAS-OIL RELATIVE PERMEABILITIES: '//15X, 1

21 FORMAT (//IX, 'PLOT KEYS:'//6X,'IPLT=',I2,3X,'ISAT=',I2,3X,

1

22 FORMAT (2A4)

23 FORMAT (//1X,'SATURATION AND COMPOSITION PROFILES STORED IN FILE 1

24 FORMAT (//IX,'BLOCK OVERALL COMPOSITIONS STORED IN FILE ',2A4, 1

25 FORMAT (//1X,'FLOWING COMPOSITIONS STORED IN FILE ',2A4,

$+\quad$ FOR BLOCKS: $1 / / 5 \mathrm{X}, 10 \mathrm{I5})$

26 FORMAT (20A4)

27 FORMAT (///IX,'VIS. CO2 = 'Fl0.4,5X,'VIS. $\mathrm{H} 20=1, \mathrm{~F} 10.4,4 \mathrm{X}$,

1 ( (CP) $, / /, 1 \mathrm{X},{ }^{\prime} \mathrm{MOLEC}$. WGTS. (GMS/MOL) - $\mathrm{CO} 2$ : ',F10.4,3X,

2

'OIL: ',F10.4,3X,'H2O: ',F10.4)

31 FORMAT (IX,I3,3FI0.4)

32 FORMAT

36 FORMAT

37 FORMAT

$(1 / / 26 \mathrm{X}, 1-\ldots$ - C O 2 C Y C L - - - ///1X,20A4/)

( $/ 1 x, 1---\infty$ WARNING : EKROG NOT EQUAL TO EKRO -

END 
C
C
C
C
C
C

\author{
SUBROUTINE PHASE
}

THIS SUBROUTINE WILL CALCULATE MOLE FRACTIONS OF COMPONENTS PRESENT IN THE VARIOUS PHASES AND THE VOLUME SATURATIONS OF THOSE PHASES.

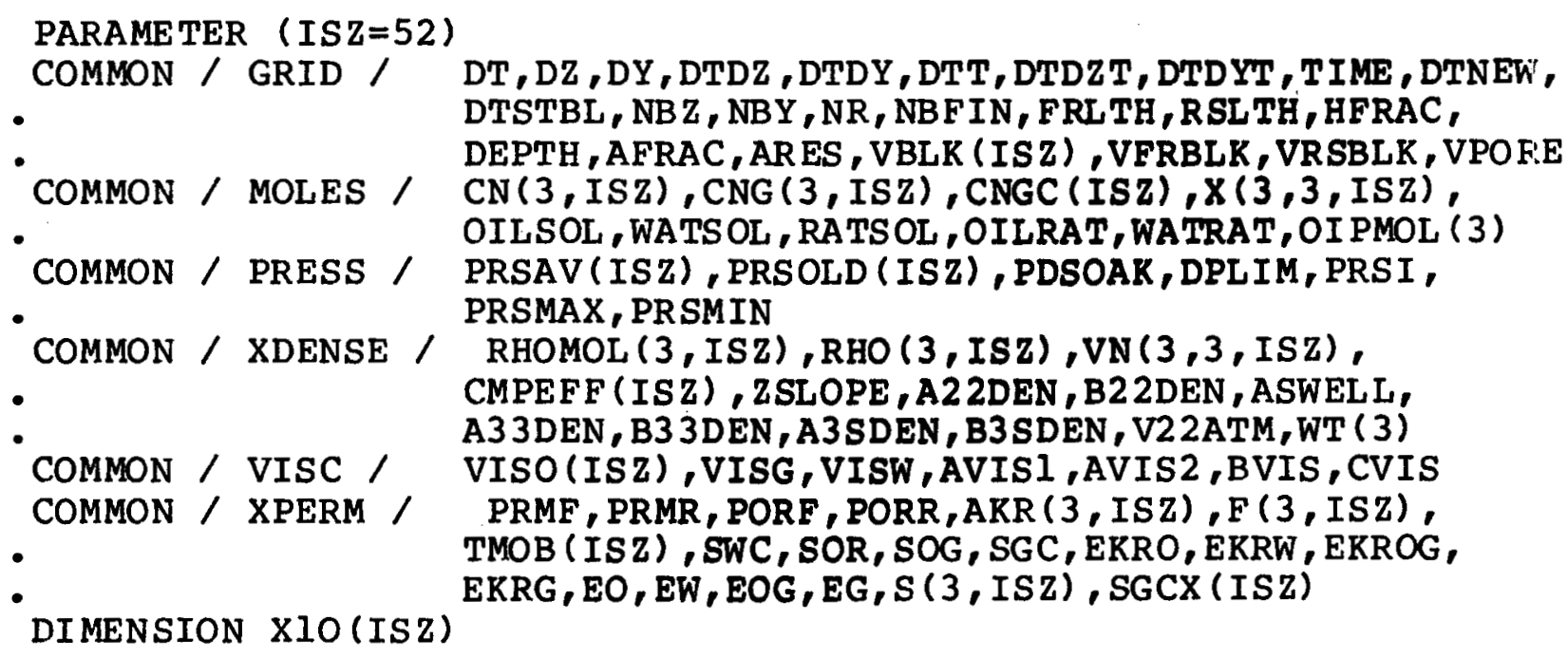

CALCULATE MOLE FRACTIONS OF CO2 IN OIL AND WATER

CALL EQULIB (CNGC, CN, PRSAV, CNG, $X, X 1 O)$

CALCULATE PHASE DEN SITIES

CALCULATE EFFECTIVE COMPRESSIBILITY

(NOTE: EFF. COMP $•=$ CMPEFF/P.V.)

CALL CMPRES (CNG, CN, PRSAV, CMPEFF, VN)

CALCULATE PHASE SATURATIONS

CALL SCALC (CNG, CN, VN, SGCX, S, CNGC)

\title{
CALCULATE RELATIVE PERMEABILITIES AND FRACT IONAL FLOW FUNCTIONS
}

CALL PERM (S,VISO,SGCX,AKR, F, TMOB) RHOMOL $(1,1)=\operatorname{RHOMOL}(1,2)$

RHOMOL $(3,1)=($ A33DEN * PRSAV $(2)+$ B33DEN $) / W T(3)$

RETURN

END 
C

SUBROUTINE EQULIB (CNGCX, CNX, P, CNGX, XX, XIO)

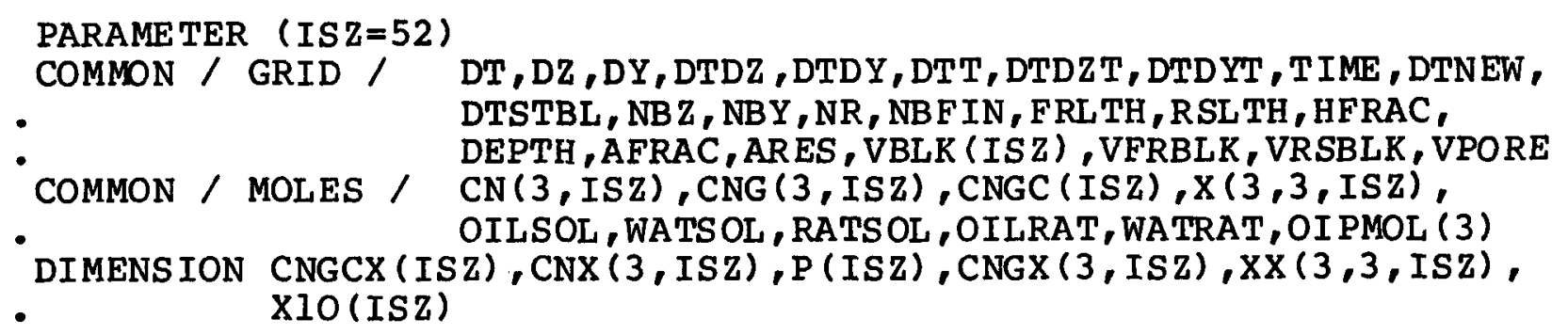

C

C

C

C

\section{PHASE EQUILIBRIUM CALCULATION}

DO $100 \mathrm{~K}=2$, NBFIN

PARTITION COMPONENTS INTO PHASES

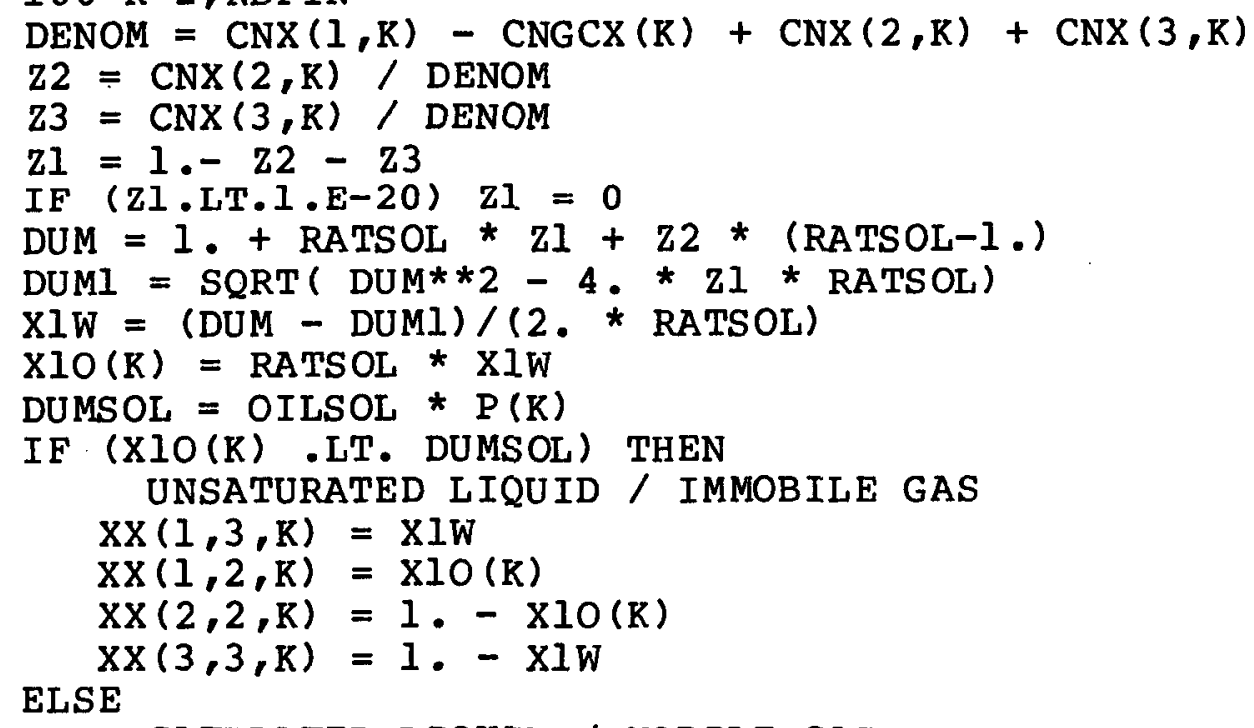




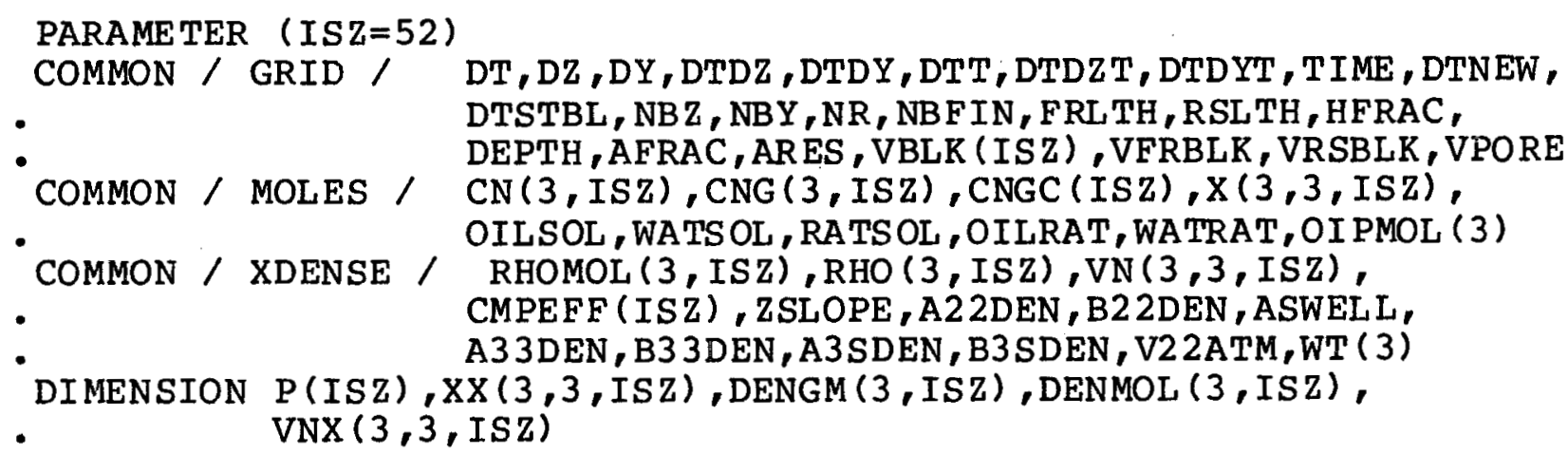


C

SUBROUTINE CMPRES (CNGX, CNX, P, CMP, VNX)

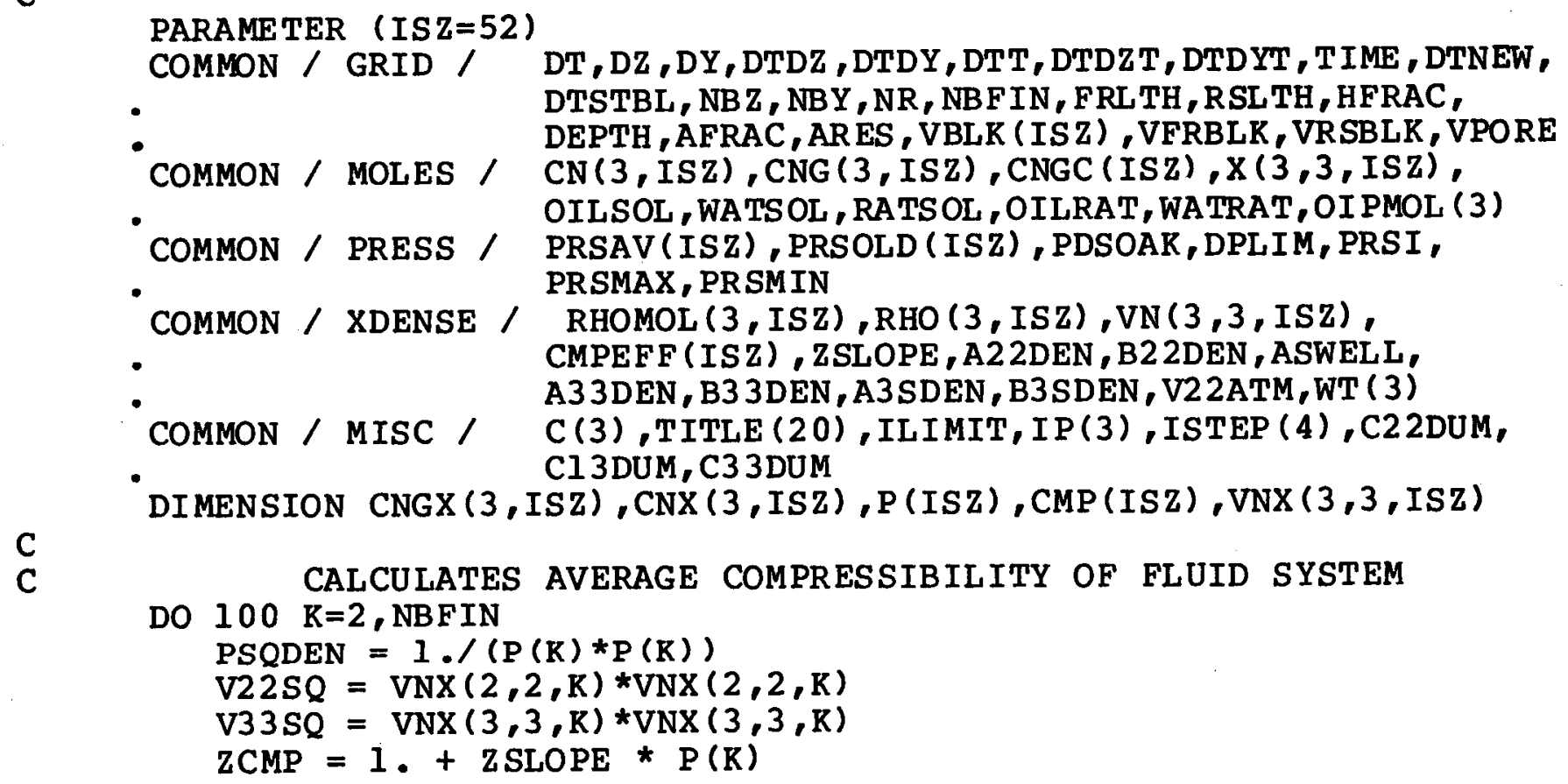

C

1

$\operatorname{Cll}=\operatorname{CNGX}(1, K) * \operatorname{VNX}(1,1, K) /(\mathrm{ZCMP} * \mathrm{P}(\mathrm{K})) *(1-(\mathrm{P}(\mathrm{K})-\operatorname{PRSOLD}(\mathrm{K})) /$ (

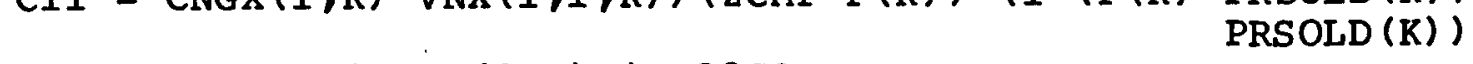

C
$\mathrm{Cl} 3=\operatorname{CNGX}(3, \mathrm{~K}) * \operatorname{Cl} 3 \mathrm{DUM}$

* PSQDEN / OILSOL)

100

$\mathrm{CMP}(\mathrm{K})=\mathrm{Cl1}+\mathrm{C} 22+\mathrm{C} 33+\mathrm{Cl} 2+\mathrm{Cl} 3$

CONT INUE

RETURN

END 
C

SUBROUTINE SCALC (CNGX, CNX, VNX, XSGC, SX, CNGCX)

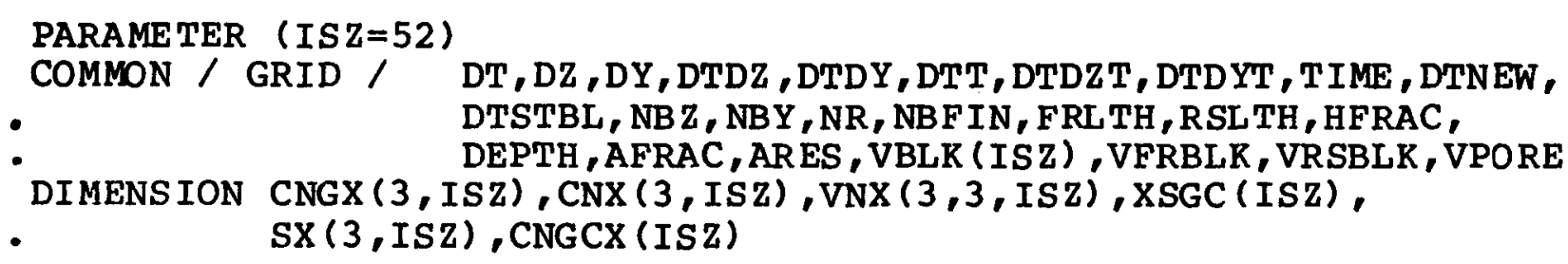
$\operatorname{SX}(3, \mathrm{ISZ}), \mathrm{CNGCX}(\mathrm{ISZ})$

C

C

C

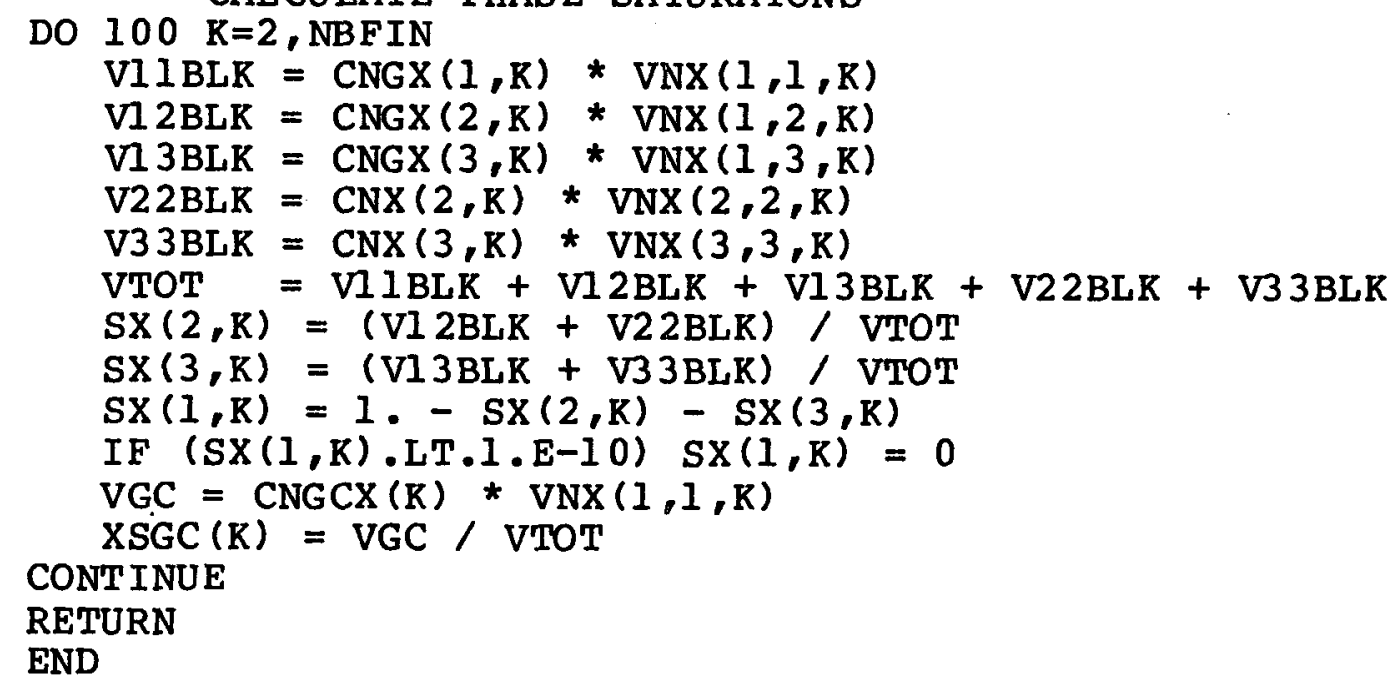




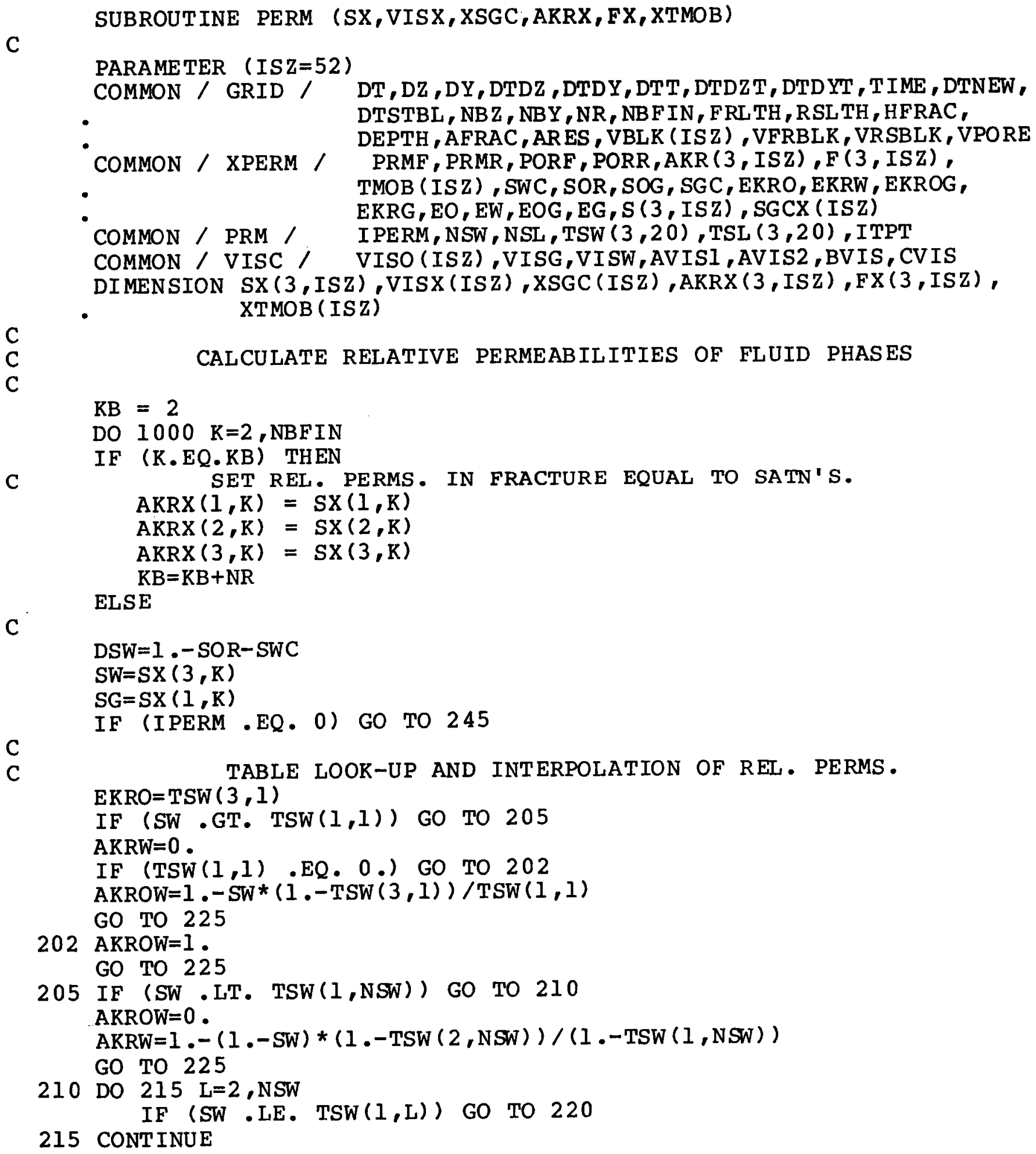


$220 \mathrm{LMI}=\mathrm{L}-1$

$\operatorname{DTSW}=\mathrm{TSW}(1, \mathrm{~L})-\mathrm{TSW}(1, \mathrm{LMI})$

$\mathrm{DSW}=\mathrm{SW}-\mathrm{TSW}(1, \mathrm{LMI})$

$A K R W=T S W(2, L M I)+D S W *(T S W(2, L)-T S W(2, \operatorname{LMI})) / D T S W$

$A R R O W=T S W(3, L M I)+D S W *(T S W(3, L)-T S W(3, L M I)) / D T S W$

$225 \mathrm{SL}=1 .-\mathrm{SG}$

IF (SL .GT. TSL $(1,1))$ GO TO 230

$A K R O G=0$.

AKRG $=1 .-S L$ * $(1,-\operatorname{TSL}(3,1)) / \operatorname{TSL}(1,1)$

GO TO 600

230 IF (SL . LT. TSL $(1$, NSL)) GO TO 235

$A K R G=0$.

AKROG $=$ TSL $(2$, NSL $)+($ SL-TSL $(1$, NSL $)) *(1,-T S L(2$, NSL $)) /(1,-T S L(1, N S L))$ GO TO 600

235 DO $240 \quad L=2$, NSL

IF (SL . LE. TSL $(I, L)$ ) GO TO 242

240 CONTINUE

$242 \mathrm{LMl}=\mathrm{L}-1$

DTSL $=$ TSL $(1, L)-T S L(1, L M I)$

$\mathrm{DSL}=\mathrm{SL}-\mathrm{TSL}(1, \mathrm{LMI})$

$A K R O G=T S L(2, L M I)+D S L$ * $(T S L(2, L)-T S L(2, L M I)) / D T S L$

$A K R G=T S L(3, L M I)+D S L$ * $(T S L(3, L)-T S L(3, L M I)) / D T S L$

C GO TO 600

C

C

C

245 IF (SW .GE. SWC) GO TO 250

CALCULATE OIL-WATER RELATIVE PERMEABILITIES

$A K R W=0$.

AKROW $=1 .-S W *(1,-E K R O) / S W C$

GO TO 400

250 IF (SW . LE. 1.-SOR) GO TO 300

$A K R O W=0$.

$A K R W=1 .-(1 .-S W) *(1 .-E K R W) / S O R$

GO TO 400

$300 \quad A K R W=E K R W *((S W-S W C) / D S W) * * E W$

$A K R O W=E K R O *((1 .-S W-S O R) / D S W) * * E O$ 


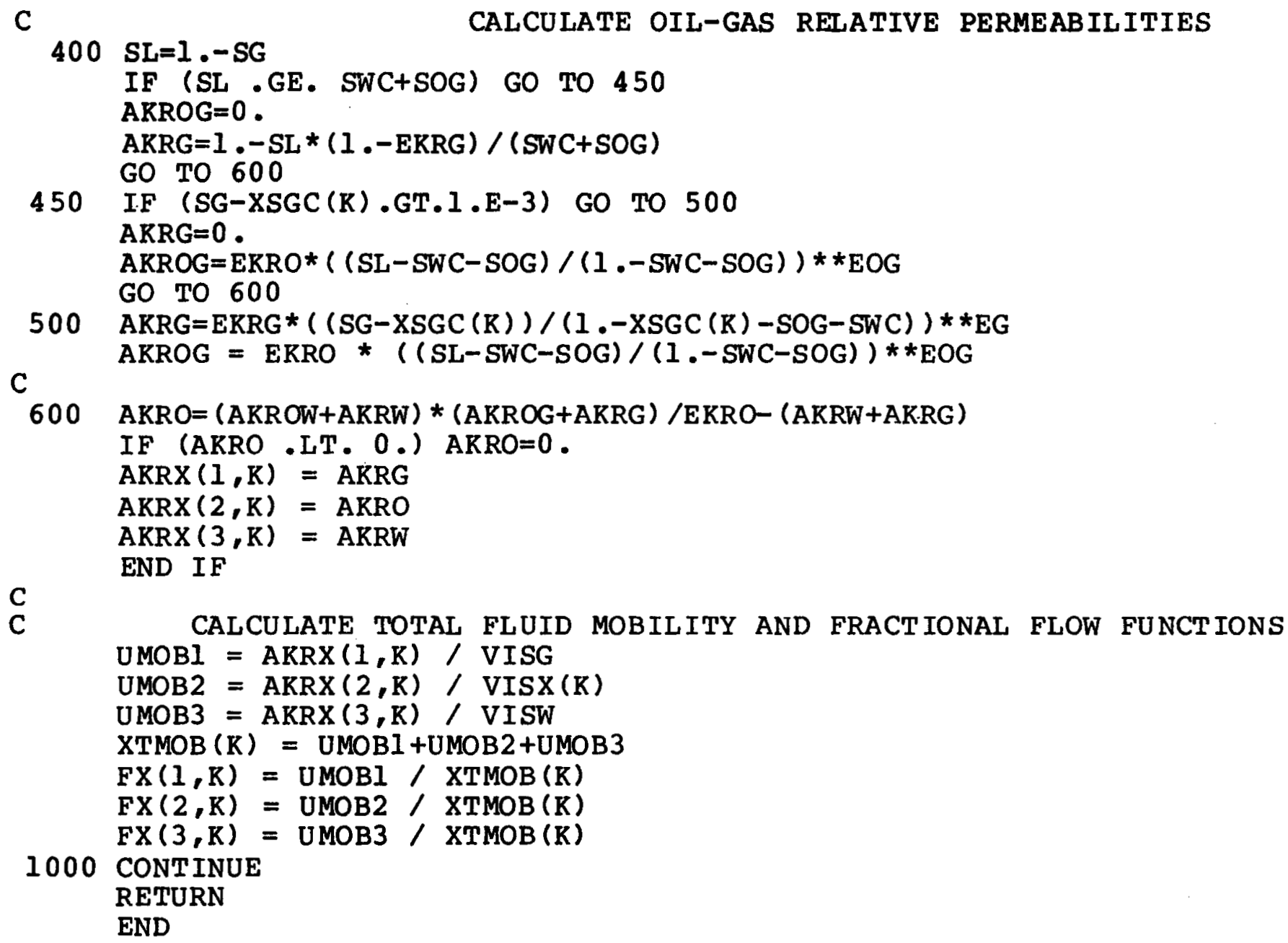


C

\section{SUBROUTINE PRNTS}

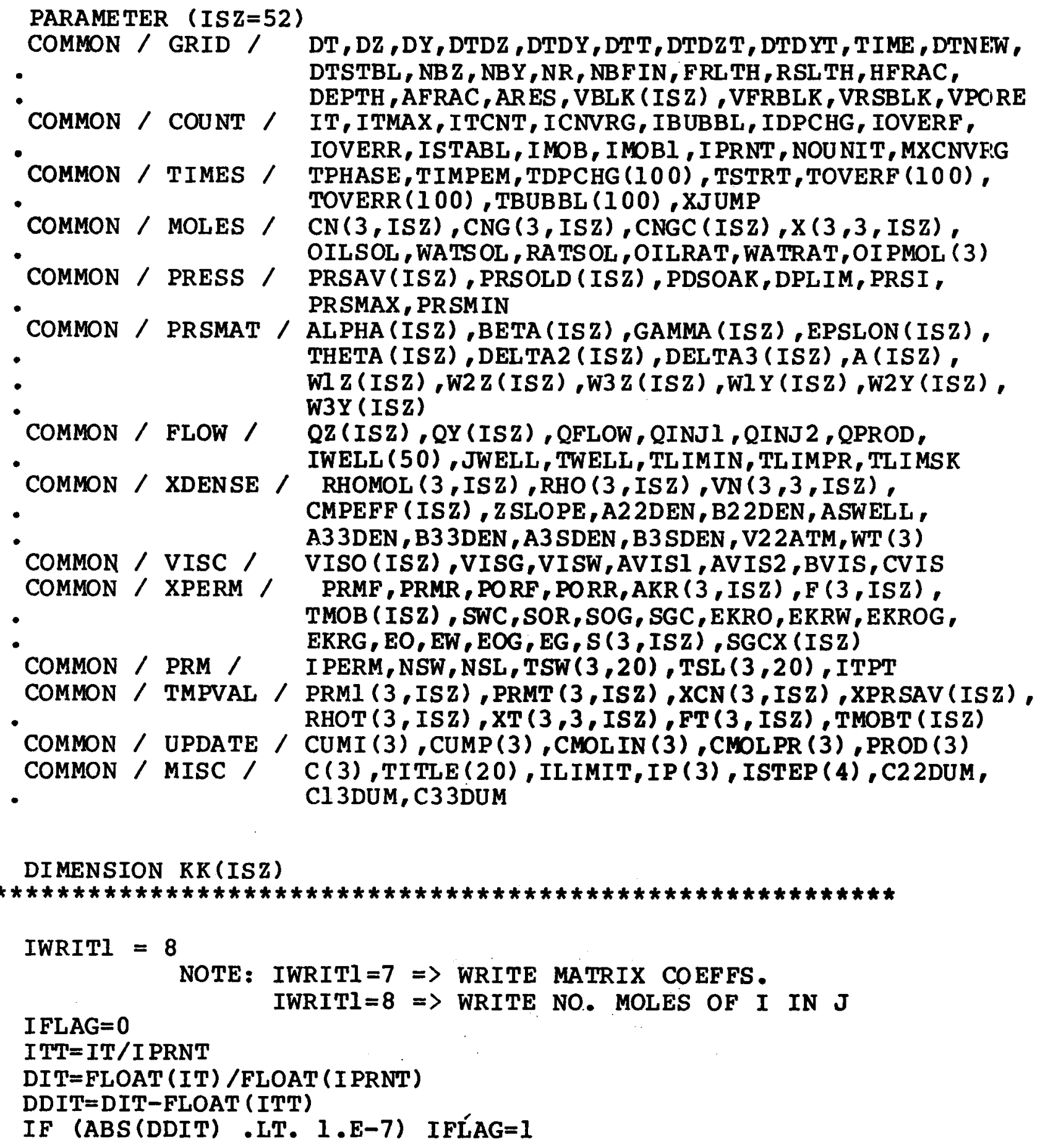




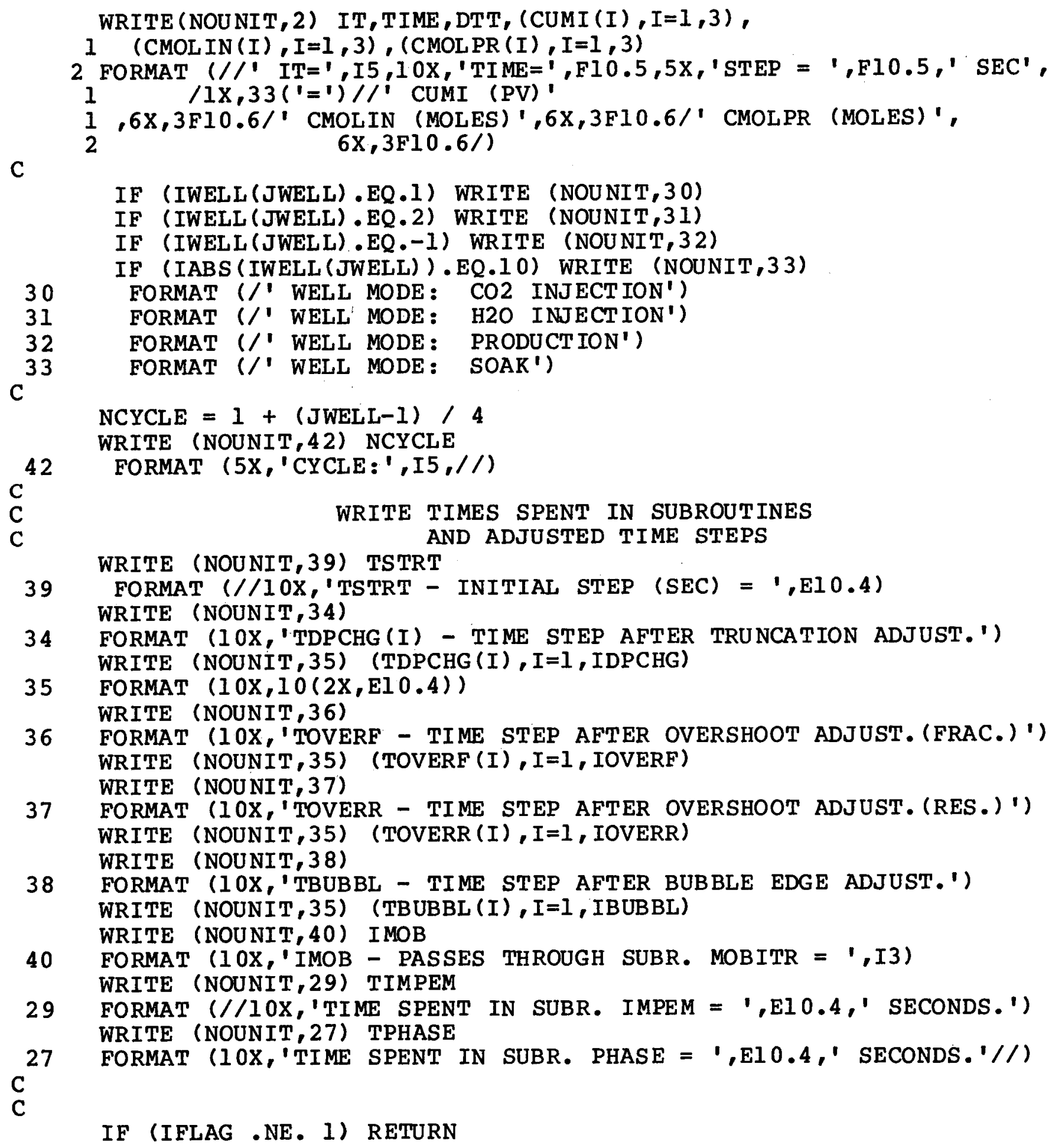


$\mathrm{C}$
$\mathrm{C}$
$\mathrm{C}$
$\mathrm{C}$

PRINT PRESSURES, RELATIVE FLOW RATES, PHASE DENSITIES, AND OVERALL MOLES OF COMPONENT I PER VOL.

WRITE (NOUNIT, 20)

FORMAT (/IX,'PRESSURES',/, $12 \mathrm{X}, '($ FRACTURE - - - $>$ )'

DO $21 \mathrm{KF}=1, \mathrm{NBZ}$

$21 \quad \mathrm{KK}(\mathrm{KF})=2+(\mathrm{KF}-1) * \mathrm{NR}$

WRITE (NOUNIT, 24) $(\mathrm{KK}(\mathrm{I}), I=1, \mathrm{NBZ})$
FORMAT $\left(/ 1 \mathrm{X},{ }^{\prime} \mathrm{K}=1,2 \mathrm{X}, 15(I 2,6 \mathrm{X})\right)$

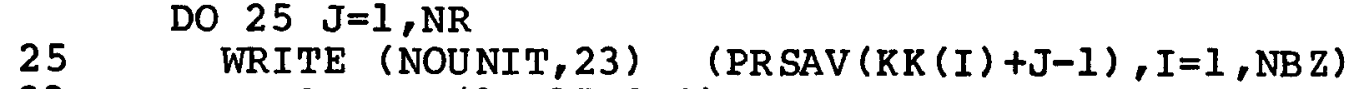

23 FORMAT $(3 \mathrm{X}, 15 \mathrm{~F} 8.3)$

IF (IWRITI.EQ.7) WRITE (NOUNIT, 7)

IF (IWRITI.EQ.8) WRITE (NOUNIT,8)

7

1

2

8

$1 \quad \mathrm{~T} 58,{ }^{\prime} \mathrm{N} 22^{\prime}, \mathrm{T} 70,{ }^{\prime} \mathrm{N} 13^{\prime}, \mathrm{T} 80,{ }^{\prime} \mathrm{N} 33^{\prime}, \mathrm{T} 93^{\prime}, \mathrm{CMMPEF}^{\prime}, \mathrm{Tl} 06$, 'VTOT', $^{\prime}$

2 T120,'VOLERR'/)

26

WRITE (NOUNIT, 26) QZ(1)

FORMAT $(1 \mathrm{X}, 1,2 \mathrm{X}, \mathrm{El0}, 4)$

DO $700 \mathrm{~K}=2$, NBFIN

$\mathrm{VTOT}=\operatorname{CNG}(1, \mathrm{~K}) * \mathrm{VN}(1,1, \mathrm{~K})+\operatorname{CNG}(2, \mathrm{~K}) * \mathrm{VN}(1,2, \mathrm{~K})+$

$\frac{1}{2}$ $\operatorname{CN}(2, K) * V N(2,2, K)+\operatorname{CNG}(3, K) * V N(1,3, K)+$ $\mathrm{CN}(3, \mathrm{~K}) * \mathrm{VN}(3,3, \mathrm{~K})$

VOLERR $=($ VTOT-VBLK $(K)) /$ VBLK $(K)$

CMPDUM $=$ CMPEFF(K) / VTOT

IF (IWRITI.EQ.7) WRITE (NOUNIT,60I) $\mathrm{K}, \mathrm{QZ}(\mathrm{K}), \mathrm{QY}(\mathrm{K})$,

1

ALPHA (K) ,BETA (K) , GAMMA (K) , THETA (K), EPSLON (K), CMPEFF (K)

IF (IWRITI .EQ .8) WRITE (NOUNIT,601) $\mathrm{K}, \mathrm{QZ}(\mathrm{K}), \mathrm{QY}(\mathrm{K}), \mathrm{CNG}(I, \mathrm{~K})$,

1

$\operatorname{CNG}(2, K), C N(2, K), \operatorname{CNG}(3, K), C N(3, K), C M P D U M, V T O T, V O L E R R$

601

700 FORMAT $(1 X, I 2,2(2 X, E 10.4), 8(2 X, E 10.4))$

C CONT INUE

C

C WRITE (NOUNIT,5I)

51 FORMAT (//T3,' 'K',T9,'V1l',T24,'V12!,T39,'V22',T54,'V13',T69, 1

DO $18 \mathrm{~K}=2$, NBFIN 'V33',T95, RHOMOL (J) '/)

18 WRITE (NOUNIT, 12) $\mathrm{K}, \mathrm{VN}(1,1, \mathrm{~K}), \mathrm{VN}(1,2, \mathrm{~K}), \mathrm{VN}(2,2, \mathrm{~K})$,

12

$\operatorname{VN}(1,3, K), \operatorname{VN}(3,3, K), \operatorname{RHOMOL}(1, K), \operatorname{RHOMOL}(2, K), \operatorname{RHOMOL}(3, K)$ FORMAT $(1 X, I 2,3 X, 8(E 10.4,5 X))$ 
C

C

C

C

C

C

C

C

WRITE (NOUNIT, 3)

3 FORMAT $\left(/ 8 \mathrm{x}, ' \mathrm{zl},, 6 \mathrm{x}, \mathrm{z}^{\prime}, 6 \mathrm{x}, \mathrm{z}^{\prime}, 6 \mathrm{X}, \mathrm{Sl}^{\prime}, 6 \mathrm{X}\right.$,

$\mathrm{I}^{\prime} \mathrm{S} 22^{\prime}, 6 \mathrm{X}, \mathrm{S}^{\prime}, 6 \mathrm{X}, \mathrm{Fl}^{\prime}, 6 \mathrm{X}, \mathrm{F}^{\prime}, 6 \mathrm{X}, \mathrm{F}^{\prime}, 5 \mathrm{X}, \mathrm{T}^{\prime} \mathrm{TMOB},, 10 \mathrm{X}, \mathrm{X}^{\prime}(1,2)^{\prime}$,

2

4 FORMAT $(1 X, I 2,10 F 8,5,2(6 X, F 10.6))$

$$
\begin{aligned}
& \mathrm{KB}=2 \\
& \mathrm{DO} 200 \mathrm{KF}=1, \mathrm{NBZ} \\
& \mathrm{KBDUM}=\mathrm{KB}+\mathrm{NBY} \\
& \mathrm{DO} 190 \mathrm{~K}=\mathrm{KB}, \mathrm{KBDUM}
\end{aligned}
$$

$\mathrm{DENOM}=\mathrm{CN}(1, \mathrm{~K})-\mathrm{CNGC}(\mathrm{K})+\mathrm{CN}(2, \mathrm{~K})+\mathrm{CN}(3, \mathrm{~K})$

$\mathrm{Z} 2=\mathrm{CN}(2, \mathrm{~K}) / \mathrm{DENOM}$

$\mathrm{Z3}=\mathrm{CN}(3, \mathrm{~K}) /$ DENOM

$\mathrm{Z1}=1 .-\mathrm{Z} 2-\mathrm{Z} 3$

IF (Zl.LT.1.E-6) $\mathrm{Zl}=0$

FRACT ION DATA 
C

SUBROUTINE IMPEM

PARAMETER (ISZ=52)

COMMON / GRID / DT,DZ,DY,DTDZ ,DTDY,DTT, DTDZT, DTDYT, TIME , DTNEW,

$\bullet$

COMMON / COUNT /

COMMON / TIMES /

COMMON / MOLES /

- OILSOL, WATSOL, RATSOL , OILRAT, WATRAT, OI PMOL (3)

COMMON / PRESS / PRSAV(ISZ),PRSOLD(ISZ),PDSOAK,DPLIM, PRSI,

-

COMMON / PRSMAT / ALPHA (ISZ),BETA (ISZ),GAMMA (ISZ),EPSLON(ISZ),

- THETA (ISZ), DELTA2 (ISZ),DELTA3 (ISZ),A (ISZ),

- WIZ (ISZ),W2Z(ISZ),W3Z(ISZ),W1Y(ISZ),W2Y(ISZ),

- W3Y(ISZ)

COMMON / FLOW / QZ(ISZ), QY(ISZ),QFLOW,QINJ1,QINJ $2, Q P R O D$,

- $\quad$ IWELL (50), JWELL, TWELL, TL IMIN, TL IMPR, TL IMSK

COMMON / XDENSE / RHOMOL $(3, \mathrm{ISZ}), \mathrm{RHO}(3, \mathrm{ISZ}), \mathrm{VN}(3,3, \mathrm{ISZ})$,

-

-

A33DEN,B3 3DEN, A3 SDEN, B3 SDEN, V2 2ATM, WT (3)
COMMON / VISC / VISO (ISZ),VISG,VISW, AVIS1, AVIS2, BVIS, CVI

COMMON / XPERM / PRMF, PRMR, PORF, PORR, AKR $(3, I S Z), F(3, I S Z)$,

-

TMOB (ISZ) , SWC, SOR, SOG, SGC, EKRO, EKRW, EKROG,

-

COMMON / PRM / I PERM, NSW, NSL, TSW $(3,20), \operatorname{TSL}(3,20)$, ITPT

COMMON / TMPVAL / PRMI (3,ISZ),PRMT (3,ISZ),XCN $(3$, ISZ),XPRSAV (ISZ),

RHOT ( 3, ISZ), XT ( 3,3, ISZ), FT ( 3, ISZ), TMOBT ( ISZ)

COMMON / UPDATE / CUMI (3), CUMP (3), CMOLIN (3), CMOLPR (3), PROD (3)

COMMON / MISC / C (3),TITLE(20), ILIMIT,IP(3), ISTEP (4), C22DUM,

C13DUM, C33DUM

C

REAL CTMOL (4)

DATA TDPCHG $/ 100 * 0.0 /$ TOVERF $/ 100 * 0.0 /$ TOVERR $/ 100 * 0.0 /$

DATA TBUBBL/100*0.0/

C

C

C

C

C

INCREMENT TIME STEP COUNTER AND CHANGE INJECTION RATE IF TIME MATCHES INPUT PARAMETERS

$I T=I T+1$

ITCNT $=$ ITCNT +1

C

$\mathrm{DTT}=\mathrm{DT}$

DTDZT $=$ DTDZ

DTDYT $=$ DTDY

DTSTBL = DT 
$\mathrm{C}$ DO $50 \mathrm{~K}=2, \mathrm{NBFIN}$

50

$$
\operatorname{PRSOLD}(K)=\operatorname{PRSAV}(K)
$$

$\mathrm{KPY}=1$

$\mathrm{KNY}=1$

$\mathrm{KPZ}=1$

$\mathrm{KPY}=1$

CALL FLOCHG

IF (ABS (QZ (I)) .LT.1.E-4) THEN

IF (ITCNT.EQ.I) CALL STPCHG (.I,DTT,DTDZT,DTDYT)

IF (ITCNT.GE.3) CALL STPCHG (10.,DTT,DTDZT,DTDYT)

GO TO 90

END IF

C

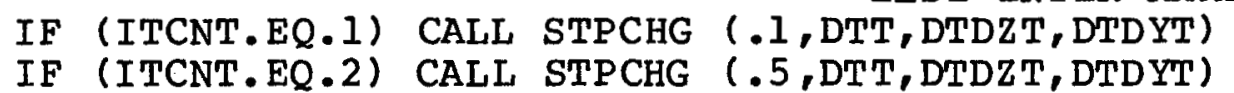

C

C

C

C

C

C

C

90 IDPCHG $=0$

IOVERF $=0$

IOVERR $=0$

TSTRT $=$ DTT

IBUBBL $=0$

$I M O B=0$

C

100 ICNVRG $=0$

RESET VARIABLES AND PRESS. EQN. COEFFS.

IMOBI $=0$

DO $105 \mathrm{~K}=1, \mathrm{NBFIN}$

DO $104 \mathrm{~J}=1,3$

DO $103 \quad I=1,3$

$103 \quad \mathrm{XT}(\mathrm{I}, \mathrm{J}, \mathrm{K})=0$

$X T(I, J, K)=X(I, J, K)$

$\operatorname{RHOT}(J, K)=\operatorname{RHOMOL}(J, K)$

$\operatorname{PRMI}(J, K)=A K R(J, K)$

$104 \quad \mathrm{FT}(\mathrm{J}, \mathrm{K})=\mathrm{F}(\mathrm{J}, \mathrm{K})$

$X T(2,2, K)=X(2,2, K)$

$X T(3,3, K)=X(3,3, K)$

TMOBT (K) $=$ TMOB $(K)$

$W I Y(K)=0$

$W 2 Y(K)=0$

$W 3 Y(K)=0$

$A L P H A(K)=0$

$\operatorname{BETA}(K) \quad=0$

$\operatorname{GAMMA}(\mathrm{K})=0$

THETA (K) $=0$

$105 \quad \operatorname{EPSLON}(K)=0$ 
C CALCULATE RELATIVE MOBILITIES AND FLOW TERMS

C

CALL FLOFN1 (PRMI, VISO, RHOMOL, $X$ )

CALL FLOFN2 (CNG, CN,VN, $X, P R S A V, C M P E F F, S, S G C X)$

C

140 QFLOW =QFLOFN (QZ (1),DTT, RHOMOL $(1,1), \operatorname{RHOMOL}(3,1)$, IWELL (JWELL), $1 \quad \operatorname{RHOMOL}(1,2), \operatorname{RHOMOL}(2,2), \operatorname{RHOMOL}(3,2), \mathrm{F}(1,2)$,

$2 \quad \mathrm{~F}(2,2), \mathrm{F}(3,2), X(2,2,2), X(3,3,2), \mathrm{DELTA} 2(2)$,

$\mathrm{C}$ 3 $\operatorname{DELTA} 3(2), x(1,2,2), x(1,3,2))$

C

150

ENTER PRESSURE/COMPOSITION ITERATIVE CALCULATION LOOF CONTINUE

$$
\mathrm{KB}=2
$$

C

RFRAC $=2$ * * DTDYT

DO $250 \mathrm{KF}=1, \mathrm{NBZ}$

$\mathrm{KBDUM}=\mathrm{KB}+\mathrm{NBY}$

DO $220 \mathrm{~K}=\mathrm{KB}, \mathrm{KBDUM}$

C

C

\section{DEFINE UPSTREAM INDICES BASED ON MOST RECENT FLOW RATES}

C

C

IF (K.EQ.2) THEN

$$
\begin{aligned}
& \text { IF }(\mathrm{QZ}(\mathrm{K}), \mathrm{GE} .0) \quad \mathrm{KPZ}=\mathrm{K} \\
& \text { IF }(\mathrm{QZ}(\mathrm{K}) \cdot \mathrm{LT} \cdot 0) \quad \mathrm{KPZ}=\mathrm{K}+\mathrm{NR} \\
& \text { IF }(\mathrm{QZ}(1), \mathrm{GE}, 0) \quad \mathrm{KNZ}=1 \\
& \text { IF (QZ(1).LT.0) KNZ=K } \\
& \text { IF (NBY.NE.0) THEN } \\
& \text { IF (QY (K) . GE. O) KPY }=K \\
& \text { IF }(\mathrm{QY}(\mathrm{K}) \cdot \mathrm{LT}, 0) \quad \mathrm{KPY}=\mathrm{K}+\mathrm{I}
\end{aligned}
$$
END IF

C

$$
\text { ELSE IF (K,EQ.KB .AND. K.GT.2) THEN }
$$

$$
\begin{aligned}
& \text { IF }(Q Z(K) . G E .0) \quad K P Z=K \\
& \text { IF }(Q Z(K), L T \cdot 0) \quad K P Z=K+N R \\
& \text { IF }(\mathrm{QZ}(\mathrm{K}-\mathrm{NR}), \mathrm{GE}, 0) \quad \mathrm{KNZ}=\mathrm{K}-\mathrm{NR} \\
& \text { IF }(Q Z(K-N R) . L T \cdot 0) \quad K N Z=K \\
& \text { IF (NBY.NE.0) THEN } \\
& \text { IF }(Q Y(K), G E .0) \quad K P Y=K \\
& \text { IF }(Q Y(K), L T \cdot 0) \quad K P Y=K+1
\end{aligned}
$$

END IF

ELSE

GO TO 180

C

$$
\begin{array}{lll}
\text { IF } & (Q Y(K) \cdot G E .0) & K P Y=K \\
\text { IF } & (Q Y(K) \cdot I T \cdot 0) & K P Y=K+I \\
\text { IF } & (Q Y(K-I) \cdot G E \cdot 0) & K N Y=K-1 \\
\text { IF } & (Q Y(K-I) \cdot L T \cdot 0) & K N Y=K \\
\text { GO TO } 200 &
\end{array}
$$

END IF 
C
C
C
C
C

1

$\frac{1}{2}$

1

1

C

C

C

180

1

1

1

2

3

1

C
BRANCH TO APPROPRIATE SYSTEM EQN. AND BUILD COEFFICIENTS

INJECTION B.C. PRESSURE EQN.

ALPHA (2) $=0$

$\operatorname{BETA}(2)=-($ DTDZT * AFRAC * (WI Z (KPZ)

$+\operatorname{DELTA} 2(\mathrm{~K}) * W 2 \mathrm{Z}(\mathrm{KPZ})+\operatorname{DELTA} 3(\mathrm{~K}) * W 3 \mathrm{Z}(\mathrm{KPZ}))$

$+A(K)+$ RFRAC * ARES * (WIY (KPY)

$+\operatorname{DELTA} 2(\mathrm{~K}) *$ W2Y (KPY) + DELTA3 (K)*W3Y (KPY)))

GAMMA $(2)=\operatorname{DTDZT*}(W 1 Z(K P Z)+\operatorname{DELTA2}(K) * W 2 Z(K P Z)+$ DELTA $3(K)$ *W3 Z (KPZ)) * AFRAC

EPSLON (2) $=$ RFRAC* (WIY (KPY) + DELTA2 (K)*W2Y (KPY) + DELTA3 (K) *W3Y (KPY)) * ARES

IF (NBZ.EQ.1) THEN

$\operatorname{BETA}(2)=\operatorname{BETA}(2)+\operatorname{GAMMA}(2)$

GAMMA $(2)=0$

END IF

THETA (2) $=-A(K) * \operatorname{PRSAV}(2)-$ QFLOW

GO TO 220

SET FRACTURE COEFFICIENTS

$\operatorname{ALPHA}(\mathrm{K})=\operatorname{DTDZT} *(\mathrm{WIZ}(\mathrm{KNZ})+\operatorname{DELTA} 2(\mathrm{~K}) * \mathrm{~W} 2 \mathrm{Z}(\mathrm{KNZ})+$ DELTA3 (K) *W3 Z (KNZ)) * AFRAC

BETA $(K)=-($ DTDZT * AFRAC * (WI Z $(\mathrm{KPZ})+W I Z(K N Z)$

$+\operatorname{DELTA} 2(\mathrm{~K}) *(\mathrm{~W} 2 \mathrm{Z}(\mathrm{KPZ})+\mathrm{W} 2 \mathrm{Z}(\mathrm{KNZ}))+\operatorname{DELTA} 3(\mathrm{~K})$ * $(W 3 Z(K P Z)+W 3 Z(K N Z)))+A(K)+$

ARES * RFRAC * (WIY (KPY) +

DELTA2 (K) *W2Y (KPY) + DELTA3 (K)*W3Y (KPY)))

GAMMA $(K)=\operatorname{DTDZT} *(\mathrm{Wl} Z(\mathrm{KPZ})+\operatorname{DELTA} 2(\mathrm{~K}) * \mathrm{~W} 2 \mathrm{Z}(\mathrm{KPZ})+$ $\operatorname{DELTA3}(\mathrm{K}) * W 3 \mathrm{Z}(\mathrm{KPZ}))$ * AFRAC END OF FRACTURE B.C.

IF (R.EQ . 2+(NBZ-1)*NR) THEN

$\operatorname{BETA}(K)=\operatorname{BETA}(K)+\operatorname{GAMMA}(K)$

GAMMA $(K)=0$

END IF

EPSLON $(K)=$ RFRAC * $(W 1 Y(K P Y)+\operatorname{DELTA2}(K) * W 2 Y(K P Y)+$

1

$\operatorname{THETA}(\mathrm{K})=-\mathrm{A}(\mathrm{K}) * \operatorname{PRSAV}(\mathrm{K})$

GO TO 220 


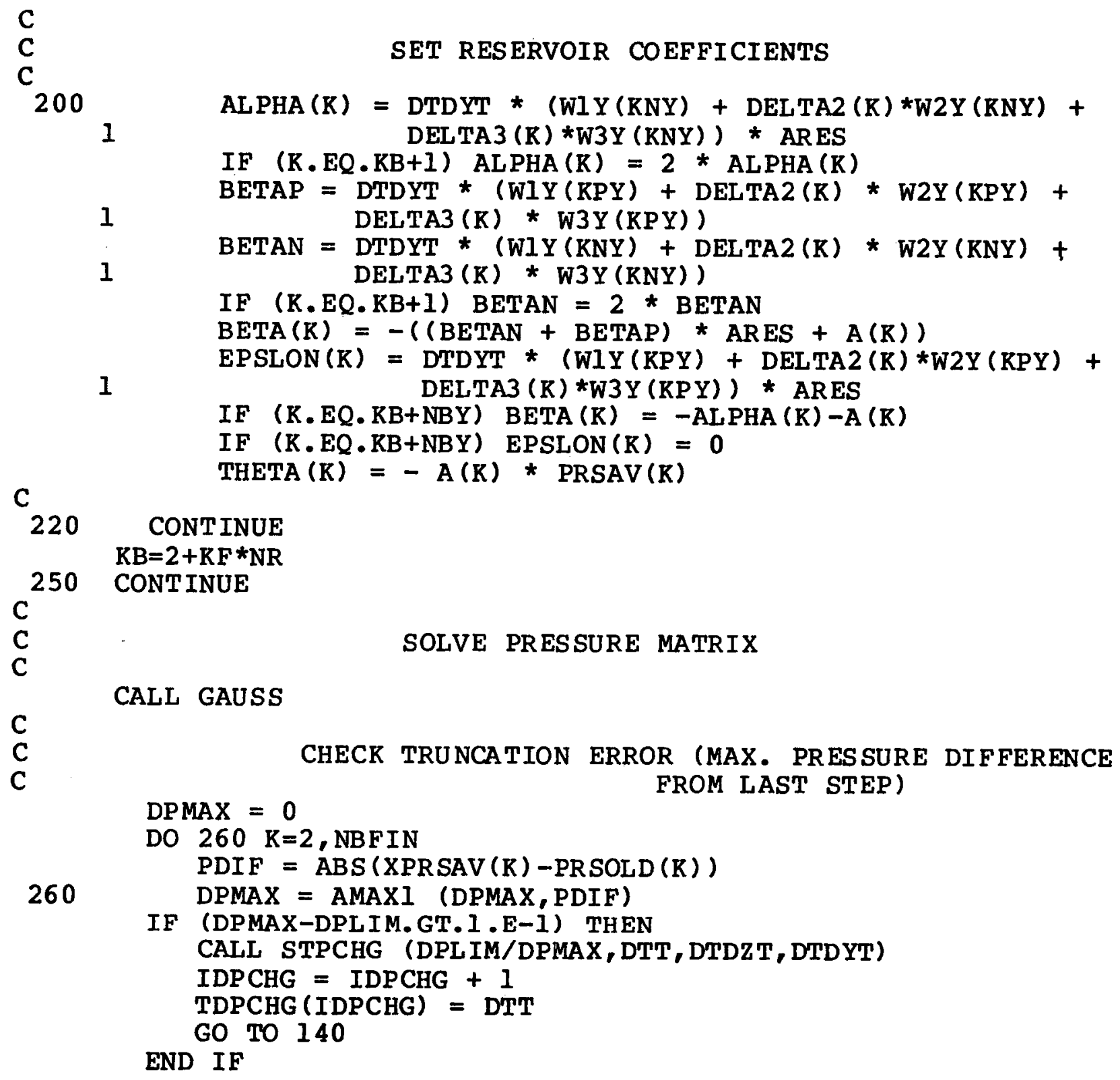


C
C
C
C
C
C
C

$\mathrm{KB}=2$

DO $300 \mathrm{KF}=1, \mathrm{NBZ}$

IF (KB.GE.NBFIN-NBY) GO TO 270

PRSDIF $=$ XPRSAV $(K B)-X P R S A V(K B+N R)$

IF (PRSDIF.GE, O) KBUPZ = KB

IF (PRSDIF.LT.0) KBUPZ $=\mathrm{KB}+\mathrm{NR}$

1 $\mathrm{QZ}(\mathrm{KB})=$ TMOBT $(\mathrm{KBUPZ})$ * PRMF *6.8E-5 * AFRAC * PRSDIF ।

270

1

IF (NBY.EQ.O) GO TO 300

PRSDIF $=(\operatorname{XPRSAV}(\mathrm{KB})-\operatorname{XPRSAV}(\mathrm{KB}+1))$

IF (PRSDIF.GE.O) KBUPY = KB

IF (PRSDIF.LT.O) KBUPY $=\mathrm{KB}+1$

$\mathrm{QY}(\mathrm{KB})=\mathrm{TMOBT}(\mathrm{KBUPY}) *$ PRMR $* 6.8 \mathrm{E}-5$ * ARES * 2 * PRSDIF /

DO $290 \mathrm{~K}=\mathrm{KB}+1, \mathrm{~KB}+\mathrm{NBY}-1$

$\operatorname{PRSDIF}=\operatorname{XPRSAV}(\mathrm{K})-\operatorname{XPRSAV}(\mathrm{K}+1)$

IF (PRSDIF.GE.0) KUP $=K$

IF (PRSDIF.LT.0) KUP $=K+1$

290

1 $\mathrm{QY}(\mathrm{K})=\mathrm{TMOBT}(\mathrm{KUP})$ * PRMR *6.8E-5 * ARES * PRSDIF /

C

$\mathrm{OY}(\mathrm{KB}+\mathrm{NBY})=0$

$\mathrm{KB}=2+\mathrm{KF} * \mathrm{NR}$

C

$Q Z(N B F I N-N B Y)=0$

END OF RESERVOIR B.C.

(RSLTH * DY)

C

C

C

CALCULATE COMPOSITIONS (MOLES I) AT NEW TIME LEVEL

DO $400 \mathrm{KF}=1, \mathrm{NBZ}$

SOLVE COMPOSITION EQUATION IN FRACTURE

$$
\begin{aligned}
& \mathrm{K}=2+(\mathrm{KF}-\mathrm{I}) * \mathrm{NR} \\
& \mathrm{KMI}=\mathrm{K}-\mathrm{NR} \\
& \mathrm{IF}(\mathrm{K} \cdot \mathrm{EQ} \cdot 2) \mathrm{KMI}=1 \\
& \mathrm{IF}(\mathrm{QZ}(\mathrm{KMI}) \cdot \mathrm{GE} \cdot 0) \mathrm{KI}=\mathrm{KMI} \\
& \mathrm{IF}(\mathrm{QZ}(\mathrm{KMI}) \cdot \mathrm{LT} \cdot 0) \mathrm{KI}=\mathrm{K} \\
& \mathrm{IF}(\mathrm{QZ}(\mathrm{K}) \cdot \mathrm{GE} \cdot 0) \mathrm{K} 2 \mathrm{Z}=\mathrm{K} \\
& \mathrm{IF}(\mathrm{QZ}(\mathrm{K}) \cdot \mathrm{L} \cdot \mathrm{T} \cdot 0) \mathrm{K} 2 \mathrm{Z}=\mathrm{K}+\mathrm{NR} \\
& \mathrm{IF}(\mathrm{QY}(\mathrm{K}) \cdot \mathrm{GE} \cdot 0) \mathrm{K} 2 \mathrm{Y}=\mathrm{K} \\
& \mathrm{IF}(\mathrm{QY}(\mathrm{K}) \cdot \mathrm{LT} \cdot 0) \mathrm{K} 2 \mathrm{Y}=\mathrm{K}+1
\end{aligned}
$$




\section{0}

DO $330 \quad I=1,3$

$$
\begin{aligned}
& 330 \\
& 1 \\
& 2 \\
& 3
\end{aligned}
$$

350

C

OVERSHOOT CHECK

IF (CN $(I, K)+C T M O L(I) \cdot L T .-1 . E-6)$ GO TO 410

$\operatorname{XCN}(I, K)=\operatorname{CN}(I, K)+\operatorname{CTMOL}(I)$

GO TO 415

CALL STPCHG $(0.5, D T T, D T D Z T, D T D Y T)$

IOVERF = IOVERF +1

TOVERF (IOVERF) $=\mathrm{DTT}$

\section{IF (DTT.LT.1.E-5) THEN}

PRINT 430, DTT STOP

FORMAT ('STOP: OVERSHOOT. (FRAC.) DTT $=1$, El 0.4) END IF

GO TO 150

\section{IF (NBY.EQ.0) GO TO 550}

$$
\begin{aligned}
& \mathrm{KB}=2 \\
& \mathrm{DO} 500 \mathrm{KF}=1, \mathrm{NBZ} \\
& \mathrm{KBI}=\mathrm{KB}+1 \\
& \mathrm{KBF}=\mathrm{KB}+\mathrm{NBY} \\
& \mathrm{DO} 490 \mathrm{~K}=\mathrm{KBI}, \mathrm{KBF} \\
& \mathrm{KM} 1=\mathrm{K}-1 \\
& \mathrm{IF}(\mathrm{QY}(\mathrm{KMI}) . \mathrm{GE} .0) \mathrm{KI}=\mathrm{KMI} \\
& \mathrm{IF}(\mathrm{QY}(\mathrm{KMI}) \cdot \mathrm{LT} .0) \mathrm{KI}=\mathrm{K} \\
& \mathrm{IF}(\mathrm{QY}(\mathrm{K}) \cdot \mathrm{GE} .0) \mathrm{K} 2=\mathrm{K} \\
& \mathrm{IF}(\mathrm{QY}(\mathrm{K}) \cdot \mathrm{LT} \cdot 0) \mathrm{K} 2=\mathrm{K}+1
\end{aligned}
$$

DO $425 I=1,3$

425

$$
\begin{array}{r}
\text { CTMOL }(I)=0 \\
\text { DO } 450 \mathrm{~J}=1,3
\end{array}
$$

DO $450 \quad I=1,3$

IF (J.EQ.1 .AND. I.NE.1) GO TO 450

IF (J.EQ.2 .AND. I.EQ.3) GO TO 450

IF (J.EQ.3 .AND. I.EQ.2) GO TO 450

1 $\mathrm{CHG}=\mathrm{DTT} *(\mathrm{QY}(\mathrm{KMI}) * \operatorname{RHOT}(\mathrm{J}, \mathrm{KI}) * \mathrm{XT}(\mathrm{I}, \mathrm{J}, \mathrm{KI})$ * $\mathrm{FT}(\mathrm{J}, \mathrm{K} 1)-\mathrm{QY}(\mathrm{K})$ * $\operatorname{RHOT}(\mathrm{J}, \mathrm{K} 2) \star \mathrm{XT}(\mathrm{I}, \mathrm{J}, \mathrm{K} 2)$ * $\operatorname{FT}(J, K 2))$ 


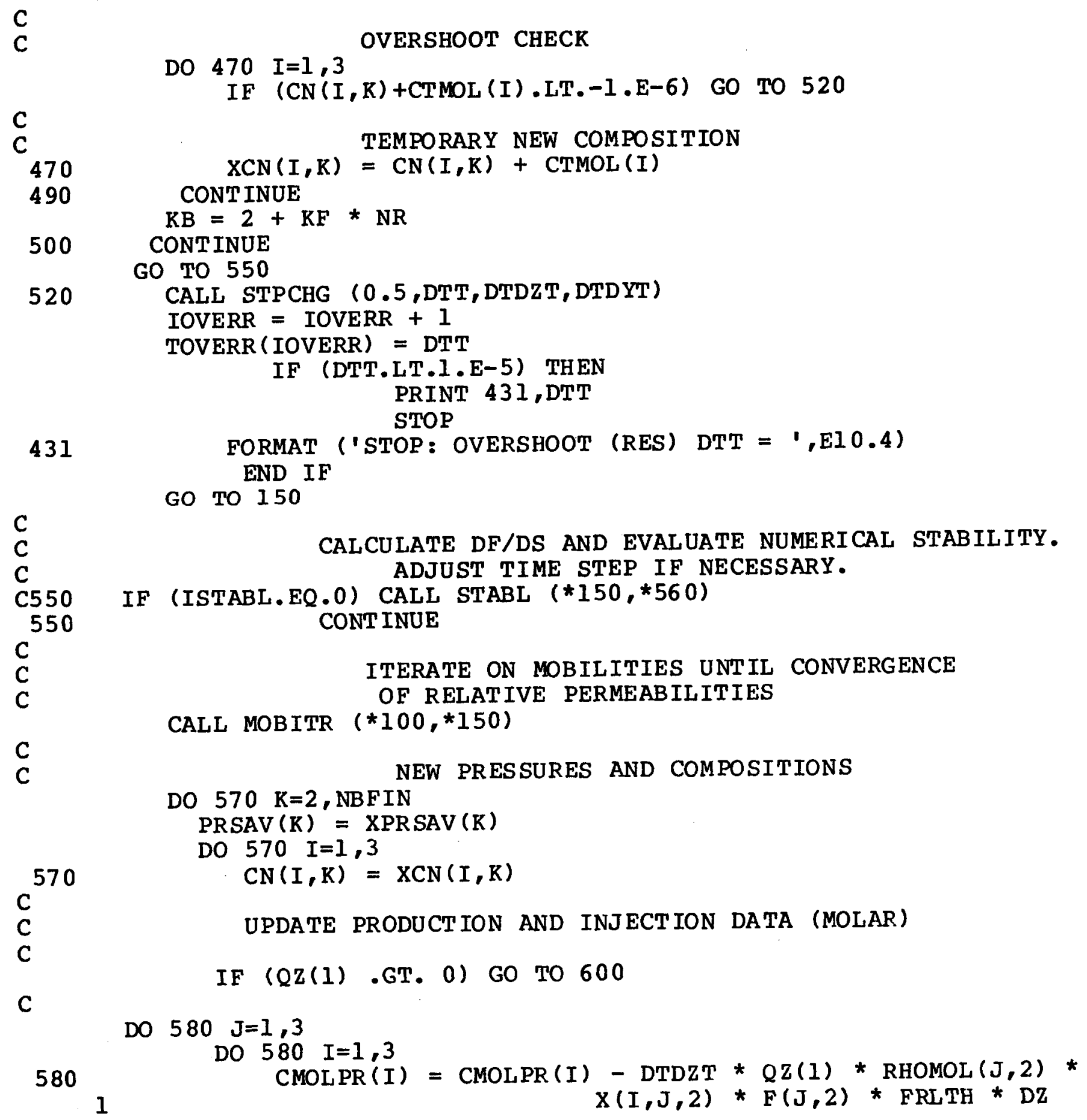


C
C
C
C
C
C
C

CALCULATE APPROXIMATE PORE VOLUMES PRODUCED

$$
\text { RHOOIL }=(3.53 \mathrm{E}-6 * \operatorname{PRSAV}(2)+.945) / \text { WT }(2)
$$

C

C

C

$\operatorname{CUMP}(1)=\operatorname{CMOLPR}(1) /($ RHOMOL $(1,2) * \operatorname{VFRBLK})$

CUMP (2) $=$ CMOLPR (2) $/$ (RHOOIL * VFRBLR)

$\operatorname{CUMP}(3)=$ CMOLPR $(3) * 18 . /$ VFRBLK

CALCULATE FRACTION OF OIP PRODUCED

DO $590 \quad I=1,3$

$\operatorname{PROD}(I)=\operatorname{CMOLPR}(I) / \operatorname{OIPMOL}(I)$

C CONT INUE

GO TO 700

C
C
C
C

MOLES INJECTED (ACCUMULATED) 600 IF (IWELL (JWELL).EQ.1) CMOLIN(1) = CMOLIN(1) + QZ(1) * DTT* 1 RHOMOL $(1,1)$ 3 IF (IWELI (JWELL) $\quad \ldots .2)$ CMOLIN (3) $=$ CMOLIN (3) + QZ (1)

RHOMOL $(3,1)$

C

PORE VOLUMES OF CO2 INJECTED CUMDUM $=Q Z(1) *$ DTT $/(($ VFRBLK+VRSBLK*NBY $) * N B Z)$

IF (IWELL (JWELL).EQ.1) CUMI (I) = CUMI (1) + CUMDUM

IF (IWELL (JWELL) .EQ.2) CUMI (3) = CUMI (3) + CUMDUM

C

C

700 TIME $=$ TIME+DTT

TWELL=TWELL+DTT

C

RETURN

END

C

C

C

C.

$\mathrm{C}$

SUBROUTINE STPCHG ( $\mathrm{X}, \mathrm{DT}, \mathrm{DTDZ}, \mathrm{DTDY})$

THIS SUBR. CHANGES THE TIME STEP ISZE PER THE VALUE OF $X$. REAL X,DT, DTDZ,DTDY

$\mathrm{C}$

$\mathrm{DT}=\mathrm{X} * \mathrm{DT}$

$\mathrm{DTDZ}=\mathrm{X} * \mathrm{DTDZ}$

DTDY $=X *$ DTDY

RETURN

END 
C
C
C
C
C

\section{SUBROUTINE FLOCHG}

THIS SUBROUTINE DETERMINES THE CORRECT WELL FLOW RATE DEPENDING ON THE VALUES INPUT FOR NUMBER OF STEPS PER INJECTION, SOAK, AND PRODUCTION CYCLES.

\section{PARAMETER (ISZ=52) COMMON / GRID /} DT, DZ ,DY, DTDZ ,DTDY, DTT, DTDZT, DTDYT, TIME , DTNEW,

-

$\bullet$

COMMON / COUNT /

C

C

C

$P M A X=0$

PMIN $=1$. E30

DO $10 \mathrm{~K}=2$, NBFIN RETURN

ELSE

RETURN DTSTBL , NBZ, NBY, NR , NBF IN , FRLTH , RSLTH, HFRAC, DEPTH , AFRAC , AR ES , VBLK (ISZ) , VFRBLK , VRSBLK, VPORE IT, ITMAX, ITCNT, I CNVRG , IBUBBL , IDPCHG, IOVERF, IOVERR, ISTABL , I MOB , IMOBI , I PRNT, NOU NIT, MXCNVRG $\mathrm{CN}(3, \operatorname{ISZ}), \operatorname{CNG}(3, \operatorname{ISZ}), \operatorname{CNGC}(\operatorname{ISZ}), X(3,3, \mathrm{ISZ})$, OILSOL, WATS OL, RA TS OL, OILRAT, WATRAT, OI PMOL (3) PRSAV (ISZ) , PRSOID (ISZ), PDSOAK, DPLIM, PRSI , PRSMAX, PR SMIN

$Q Z(I S Z), Q Y(I S Z), Q F L O W, Q I N J 1, Q I N J 2, Q P R O D$, IWELL (50), JWELL, TWELL, TL I MIN , TL I MPR , TL I MS K PRMF , PRMR, PORF, PORR, AKR ( 3 , ISZ) , F ( 3 , ISZ), TMOB (ISZ) , SWC, SOR, SOG, SGC , EKRO, EKRW, EKROG, EKRG, EO, EW, EOG, EG, S (3, ISZ), SGCX (ISZ) C (3), TITLE (20), ILIMIT, IP (3) , ISTEP (4), C2 2DUM, C13DUM, C3 3DUM

\section{HUFF $N^{\prime}$ PUFF WELL-BLOCK FLOW RATE CHANGE}

IFLO $=$ IWELL $($ JWELL $)$

IF (ILIMIT.EQ.1) THEN

$$
\text { PMAX }=\text { AMAXI }(\operatorname{PMAX}, \operatorname{PRSAV}(K))
$$

$\operatorname{PMIN}=\operatorname{AMINI}(\operatorname{PMIN}, \operatorname{PRSAV}(\mathrm{K}))$

IF (IFLO.EQ.1 .OR. IFLO.EQ.2) THEN

IF (PMAX.GE.PRSMAX) GO TO 50

INJECT ION CHECK

ELSE IF (IFLO.EQ.-1) THEN

IF (PMIN.LE.PRSMIN) GO TO 50

SOAK CHECK

IF (PMAX-PMIN.LE.PDSOAK) GO TO 50

RETURN

END IF 


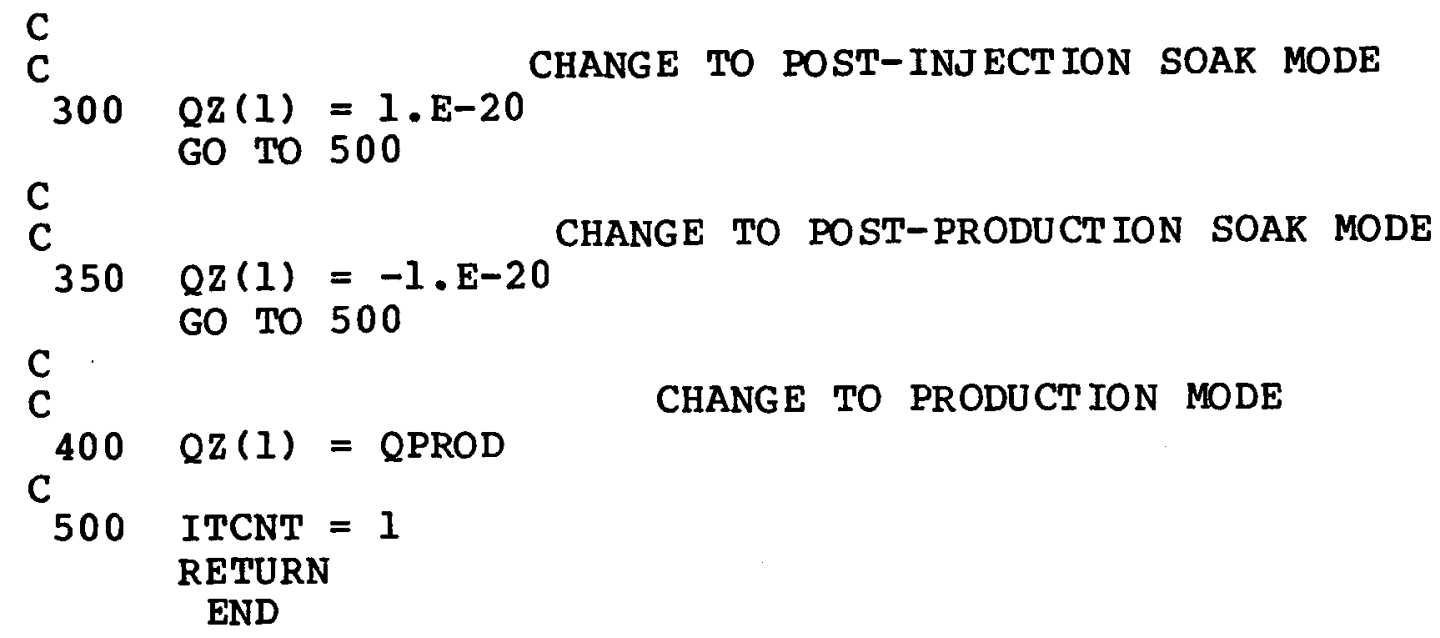


C

\section{SUBROUTINE FLOFNI (PRM,XVISO, XRHO, XX)}

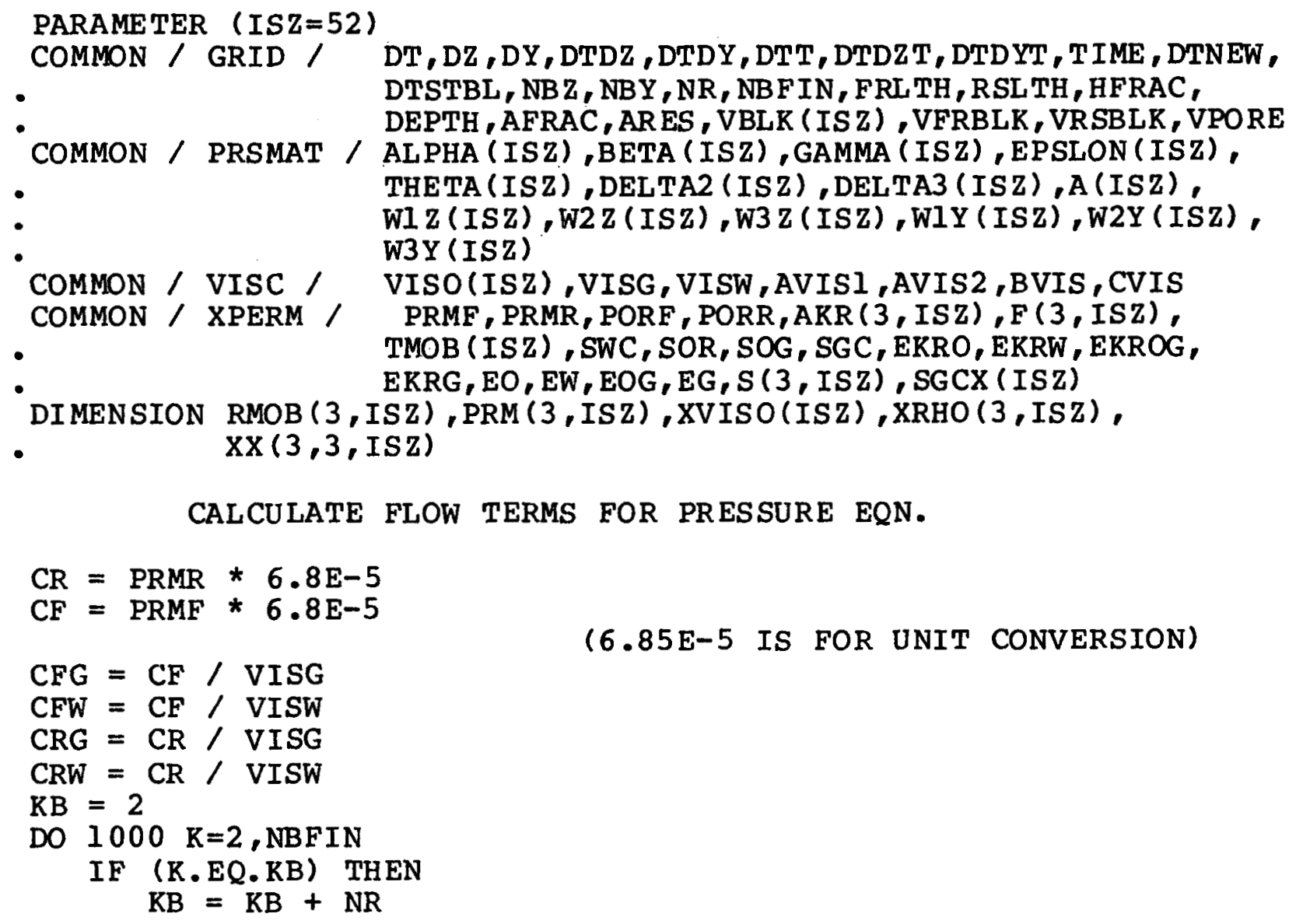
DTSTBL, NBZ, NBY, NR, NBF IN, FRLTH, RSLTH, HFRAC, DEPTH , AERAC , ARES , VBLK (ISZ) , VFRBLK, VRSBLK, VPORE

$\mathrm{C}$ 
C

SUBROUTINE FLOFN2 (XCNG, XCN,XV,XX,XP,XCMP, XS,$X S G C$ )

PARAMETER (ISZ=52)

COMMON / GRID / DT,DZ,DY,DTDZ,DTDY,DTT,DTDZT, DTDYT, TIME, DTNEW,

-

COMMON / MOLES /

- COMMON PRSMAT / AI DTHL, NBZ, NBY, NR, NBFIN, FRLTH, RSLTH, HFRAC, DEPTH , AFRAC, ARES, VBLK (ISZ), VFRBLK, VRSBLK, VPORE $\mathrm{CN}(3, \mathrm{ISZ}), \mathrm{CNG}(3, \mathrm{ISZ}), \operatorname{CNGC}(\mathrm{ISZ}), X(3,3, \mathrm{ISZ})$, OILSOL, WATSOL , RATSOL , OILRAT, WATRAT, OI PMOL (3)

$$
\cdot
$$

-$$
\text { DIMENSION XCNG ( } 3, I S Z), X C N(3, I S Z), X V(3,3, I S Z), X X(3,3, I S Z) \text {, }
$$

C

C

C

C

C

$$
\text { DO } 1000 \mathrm{~K}=2 \text {, NBEIN }
$$

CALCULATE DELTA COEFFICIENTS AND A(K)

$$
\begin{aligned}
& \mathrm{DUM} 3=\mathrm{XCN}(3, \mathrm{~K})+\mathrm{XCNG}(3, \mathrm{~K}) \\
& \mathrm{DUM} 2=\mathrm{XCN}(2, \mathrm{~K})+\mathrm{XCNG}(2, \mathrm{~K})
\end{aligned}
$$

IF (XS $(I, K)-X S G C(K) . L E .1 . E-4)$ THEN

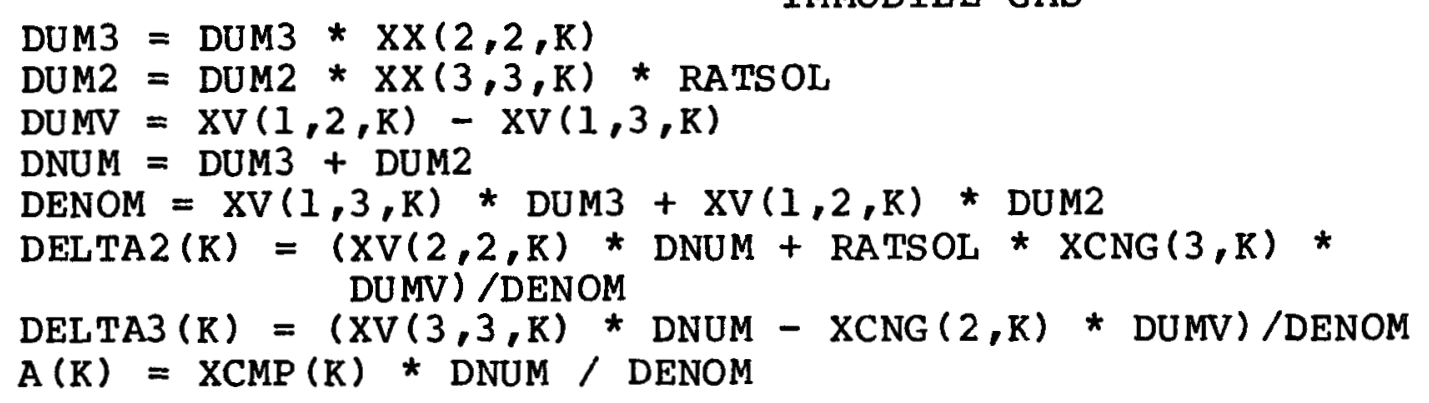

ELSE

C

$$
\begin{aligned}
& \mathrm{DUMV} 2=\mathrm{XV}(1,1, \mathrm{~K})-\mathrm{XV}(1,2, \mathrm{~K}) \\
& \text { MOBILE GAS } \\
& \text { DUMV3 }=X V(1,1, K)-X V(1,3, K) \\
& \text { SOL2 }=\text { OILSOL } * \mathrm{XP}(\mathrm{K}) \\
& \text { SOL } 3=\text { WATSOL } * \mathrm{XP}(\mathrm{K}) \\
& \text { SOL2M }=1 .- \text { SOL } 2 \\
& \text { SOL } 3 M=1 .- \text { SOL } 3 \\
& \operatorname{DELTA} 2(\mathrm{~K})=(\mathrm{XV}(2,2, \mathrm{~K}) * \text { SOL } 2 M-\mathrm{DUMV} 2 * \text { SOL } 2) / \\
& (\mathrm{XV}(1,1, K) * \mathrm{SOL} 2 \mathrm{M})
\end{aligned}
$$

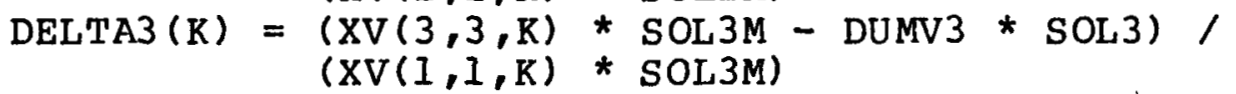

$$
\begin{aligned}
& \text { CMPMOB }=\text { DUMV2 * DUM2 * OILSOL } / \text { SOL2M }+ \text { DUMV3 * DUM3 * } \\
& \text { WATSOL / SOL3M } \\
& A(K)=(X C M P(K)+C M P M O B) / X V(1,1, K)
\end{aligned}
$$

1000 CONT INUE

RETURN

END 
$\mathrm{C}$ SUBROUTINE GAUSS

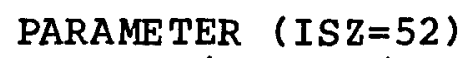

$$
\text { - }
$$
DTSTBL , NBZ , NBY , NR, NBFIN, FRLTH, RSLTH , HFRAC, DEPTH, AFRAC, ARES, VBLK (ISZ) , VFRBLK, VRSBLK, VPORE COMMON / PRSMAT / ALPHA (ISZ),BETA (ISZ), GAMMA (ISZ), EPSLON (ISZ), THETA (ISZ), DELTA2 (ISZ), DELTA3 (ISZ), A (ISZ), W1 Z (ISZ),W2Z(ISZ),W3 Z (ISZ),WIY (ISZ), W2Y (ISZ), W3Y (ISZ)

COMMON / TMPVAL / PRMI $(3$, ISZ), PRMT $(3$, ISZ), XCN $(3$, ISZ), XPRSAV (ISZ),

C

C

C

C

C

C

C

$\mathrm{C}$

REAL XALPHA (ISZ), XBETA (ISZ), XTHETA(ISZ), XGAMMA (ISZ), XEPSLN(ISZ)

THIS SUBROUTINE WILL SOLVE THE PRESSURE MATRIX ARISING OUT OF THE QUASI-TWO DIMENSIONAL CHARACTERIZATION OF A FRACTURED RESERVOIR.

$\mathrm{C}$ $X T H E T A(1)=0$ $\operatorname{XPRSAV}(\mathrm{NBFIN}+1)=0$

DO $100 \mathrm{~K}=2$, NBFIN $\operatorname{XPRSAV}(K)=0$ XALPHA $(K)=\operatorname{ALPHA}(K)$ $\operatorname{XBETA}(K)=\operatorname{BETA}(K)$ XGAMMA $(K)=$ GAMMA $(K)$

$X \operatorname{THETA}(K)=$ THETA $(K)$

$\operatorname{XEPSLN}(K)=\operatorname{EPSLON}(K)$ 


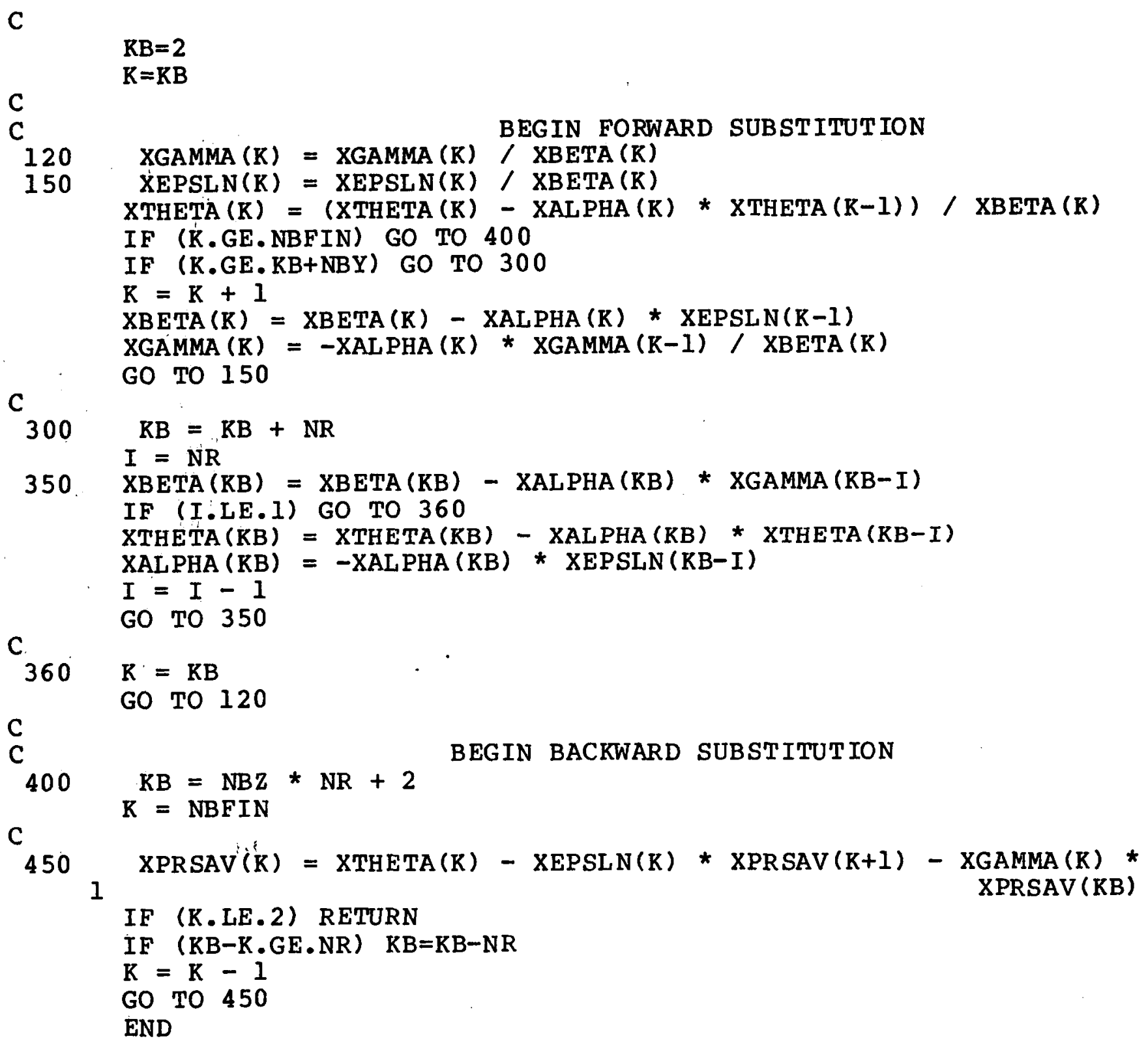

C

C

C

C

$400 \quad \mathrm{~KB}=\mathrm{NBZ} * \mathrm{NR}+2$

$\mathrm{K}=\mathrm{NBFIN}$

C

$450 \quad \operatorname{XPRSAV}(\mathrm{K})=\operatorname{XTHETA}(\mathrm{K})-\operatorname{XEPSLN}(\mathrm{K}) * \operatorname{XPRSAV}(\mathrm{K}+1)-\underset{\operatorname{XPAMMA}(\mathrm{K})}{\operatorname{XPSAV}(\mathrm{KB})}$

IF (K.LE. 2) RETURN

BEGIN BACKWARD SUBSTITUTION

IF (KB-K.GE.NR) $\quad \mathrm{KB}=\mathrm{KB}-\mathrm{NR}$

$\mathrm{K}=\mathrm{K}-\mathrm{I}$

GO TO 450

END 
C

SUBROUTINE MOBITR $(*, *)$

PARAMETER (ISZ $=52$ )

COMMON / GRID / DT, DZ,DY,DTDZ,DTDY,DTT,DTDZT, DTDYT, TIME, DTNEW,

-

COMMON / COUNT /

COMMON / MOLES / PRSMAX, PRSMIN

-

COMMON / FLOW /

-

COMMON / XDENSE /

-

COMMON /. VISC / COMMON / XPERM /

COMMON / PRM /

COMMON / TMPVAL /

COMMON / UPDATE /

COMMON / MISC / W3Y (ISZ)
COMMON / TIMES /

COMMON / PRESS /

COMMON / PRSMAT /

DTSTBL , NBZ, NBY, NR, NBFIN, FRLTH, RSLTH, HFRAC, DEPTH , AFRAC, ARES, VBLK (ISZ) , VFRBLK, VR SBLK, VPORE IT, ITMAX, ITCNT, ICNVRG, IBUBBL, IDPCHG , IOVERF, IOVERR, ISTABL, IMOB, IMOB1 , I PRNT, NOU NIT, MXCNVRG TPHASE, TIMPEM, TDPCHG (100), TSTRT, TOVERF (100), TOVERR $(100)$, TBUBBL $(100)$, XJ UMP

$\mathrm{CN}(3, \operatorname{ISZ}), \mathrm{CNG}(3, \operatorname{ISZ}), \mathrm{CNGC}(\mathrm{ISZ}), x(3,3, \mathrm{ISZ})$, OILSOL, WATSOL, RATSOL, OILRAT, WATRAT, OI PMOL (3) PRSAV (ISZ) , PRSOLD (ISZ), PDSOAK, DPLIM, PRSI,

ALPHA (ISZ), BETA (ISZ), GAMMA (ISZ), EPSLON (ISZ), THETA (ISZ), DELTA2 (ISZ), DELTA3 (ISZ) ,A (ISZ) , W1 Z(ISZ), W2Z(ISZ), W3Z(ISZ),WIY(ISZ),W2Y(ISZ), QZ(ISZ), QY (ISZ), QFLOW, QINJ 1, QINJ 2, QPROD, IWELL (50), JWELL, TWELL, TL IMIN, TL IMPR, TL I MSK RHOMOL ( $3, I S Z), R H O(3, I S Z), V N(3,3, I S Z)$, CMPEFF (ISZ) , ZSLOPE, A2 2DEN, B2 2DEN, ASWELL, A3 3DEN, B3 3DEN, A3 SDEN, B3 SDEN, V2 2ATM, WT (3) VISO (ISZ) ,VISG,VISW, AVIS1, AVIS2, BVIS, CVIS PRMF, PRMR, PORF, PORR, ARR (3,ISZ), F (3, ISZ), TMOB (ISZ) , SWC , SOR, SOG, SGC, EKRO, EKRW, EKROG, EKRG, EO, EW, EOG, EG, S ( 3 , ISZ), SGCX (ISZ) I PERM , NSW, NSL, TSW $(3,20), T S L(3,20)$, ITPT PRMI $(3, I S Z), \operatorname{PRMT}(3, \operatorname{ISZ}), X C N(3, I S Z), X P R S A V(I S Z)$, RHOT ( 3, ISZ), XT $(3,3$, ISZ), FT ( 3, ISZ) , TMOBT (ISZ)

CUMI (3), CUMP (3), CMOL IN (3), CMOLPR (3), PROD (3) C (3), TITLE (20), ILIMIT, IP (3), ISTEP (4), C2 2DUM, C13DUM, C33DUM

DIMENS ION XCNG (3, ISZ), RHOGMT ( $3, \operatorname{ISZ),VNT}(3,3, \operatorname{ISZ}), X V I S O$ (ISZ), $X S G C(I S Z), C M P E F T(I S Z), S T(3, I S Z), X 10(I S Z)$

LOGICAL XI, X2, X3,X4,XX1,XX2,XX3

C

IMOB $=$ IMOB + 1

$I M O B I=I M O B I+1$

IF (IMOBI.LE.I) THEN

DO $40 \mathrm{~K}=2$, NBF IN

DO $40 \mathrm{~J}=1,3$

40

ELSE $\operatorname{PRM} 1(J, K)=\operatorname{AKR}(J, K)$

DO $4.5 \mathrm{~K}=2$, NBEIN

DO $45 \mathrm{~J}=1,3$

45

END IF $\operatorname{PRMI}(J, K)=\operatorname{PRMT}(J, K)$ 
C

C CALCULATE NEW PHASE COMPOSITIONS

CALL EQULIB (CNGC, XCN, XPRSAV, XCNG, XT, XIO)

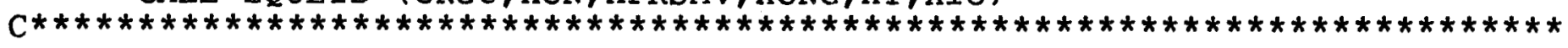

C

C

C

\section{CHECK FOR APPEARANCE/DISAPPEARANCE OF GAS IN A BLOCK AND ADJUST TIME STEP FOR MINIMUM CROSS-OVER AT BUBBLE POINT}

$\mathrm{KMAX}=0$

TCHGMX $=1 . \mathrm{E} 6$

DO $80 \mathrm{~K}=2$, NBFIN

$\mathrm{CO}=$ OILSOL $*$ PRSOLD $(\mathrm{K})$

$\mathrm{Cl}=\mathrm{X}(1,2, \mathrm{~K})-\mathrm{CO}$

$\mathrm{C} 2=\mathrm{XIO}(\mathrm{K})-$ OILSOL $* \mathrm{XPRSAV}(\mathrm{K})$

$\mathrm{XI}=\mathrm{ABS}(\mathrm{Cl})$.LE. $1 \cdot \mathrm{E}-05$

$X 2=C 2 \cdot L E \cdot-X J U M P$

$\mathrm{X} 3=\mathrm{Cl} \cdot \mathrm{LE} \cdot-\mathrm{I} \cdot \mathrm{E}-5$

$\mathrm{X} 4=\mathrm{C} 2 \cdot \mathrm{GE}$. XJUMP

$\mathrm{XX1}=\mathrm{X} 1$. AND. $\mathrm{X} 2$

$\mathrm{XX} 2=\mathrm{X} 3$. AND. $\mathrm{X} 4$

$\mathrm{XX} 3=\mathrm{XX1} \cdot \mathrm{OR} \cdot \mathrm{XX} 2$

IF $(X \times 3)$ THEN

IF (XXI) THEN

C

SATURATEd to unSATURATEd CASE

$$
\text { TCHG }=(\text { OILSOL } *(\operatorname{XPRSAV}(K)-\text { PRSOLD }(K))) /
$$

$$
(X 10(K)-X(1,2, K))
$$

TCHGMX = AMINI (TCHGMX, ABS (TCHG))

IF (ABS (TCHGMX-TCHG) . LE.I.E-6) KMAX $=\mathrm{K}$

ELSE IF (XX2) THEN

C

UNSATURATED TO SATURATED CASE

DUM $=(X 10(K)-X(1,2, K)) /(X P R S A V(K)-\operatorname{PRSOLD}(K))$

$\mathrm{PX}=(\mathrm{X} 10(\mathrm{~K})-\mathrm{DUM} * \mathrm{XPRSAV}(\mathrm{K})) /(\mathrm{OILSOL}-\mathrm{DUM})$

TCHG $=($ PX-PRSOLD $(K)) /(\operatorname{XPRSAV}(K)-\operatorname{PRSOLD}(K))$

$\mathrm{C} \quad \mathrm{TCHG}=($ OILSOL $* \operatorname{XPRSAV}(\mathrm{K})-\mathrm{X}(1,2, \mathrm{~K}))$
C -
TCHGMX = AMINI (TCHGMX, ABS (TCHG)) $(X 10(K)-X(1,2, K))$

IF (ABS (TCHGMX-TCHG) . LE.1.E-6) KMAX $=\mathrm{K}$

END IF

END IF

80 CONTINUE

IF (KMAX.GT.O) THEN

CALI STPCHG (TCHGMX,DTT,DTDZT, DTDYT)

IBUBBL $=$ IBUBBL +1

TBUBBL $($ IBUBBL $)=\mathrm{DTT}$

END IF RETURN 1 
CALCULATE PHASE DENSITIES

CALL DENSE (XPRSAV, XT, RHOGMT, RHOT, VNT)

C

C

DO $60 \mathrm{~K}=2$, NBFIN

CALCULATE OIL VISCOSITY

60

C

C

$\mathrm{C}$

C

$\mathrm{C}$

C

C

C

C

$\operatorname{XVISO}(K)=\operatorname{VISOIL}(\operatorname{XPRSAV}(K), X T(I, 2, K))$

C

CALL CMPRES (XCNG, XCN, XPRSAV, CMPEFT, VNT)

CALCULATE AVERAGE COMPRESSIBILITY

CALCULATE PHASE SATURATIONS

CALL SCALC (XCNG, XCN,VNT, XSGC, ST, CNGC)

CALCULATE RELATIVE PERMEABILITIES

CALL PERM (ST,XVISO, XSGC, PRMT, FT, TMOBT)

C CALCULATE FLOW COEFFICIENTS FOR PRES. EQN.

CALL FLOFNI (PRMT, XVISO, RHOT, XT)

CALL FLOFN2 (XCNG, XCN, VNT, XT, XPRSAV, CMPEFT, ST, XSGC)

C

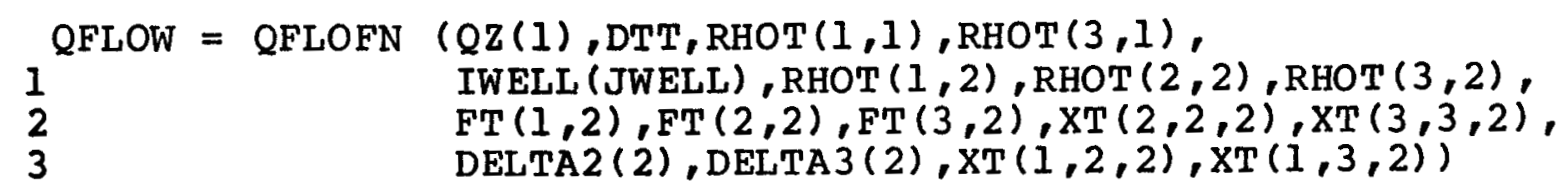
$\operatorname{DELTA} 2(2), \operatorname{DELTA} 3(2), \operatorname{XT}(1,2,2), X T(1,3,2))$

C

C

IF (IMOBI.LE.I) RETURN 2

DO $140 \mathrm{~K}=2$, NBFIN

CHECK PERMEABILITY CONVERGENCE

DO $140 \mathrm{~J}=1,3$

$\operatorname{PRMDIF}=\operatorname{PRMI}(J, K)-\operatorname{PRMT}(J, K)$

IF (PRMDIF.EQ.O..OR. PRMI $(J, K) . E Q .0$.$) GO TO 140$ PERDIF $=$ ABS (PRMDIF) $/ \operatorname{PRMI~}(\mathrm{J}, \mathrm{K})$

140 CONTINUE

C RETURN

150 IF (ICNVRG.LE. MXCNVRG) THEN

ICNVRG $=$ ICNVRG +1

C PRINT 200, $K, J, A K R(J, K), \operatorname{PRMT}(J, K), \operatorname{PRMI}(J, K), \operatorname{PERDI} F, I C N V R G$

200 FORMAT $(20 \mathrm{X}, ' \mathrm{~K}, \mathrm{~J}, \mathrm{AKR}$, PRMT, PRMI, PERDIF, ICNVRG : ',2I3,

RETURN 2

ELSE

RETURN

END IF

END 
C

FUNCTION VISOIL $(P, X 12)$

\section{PARAMETER (ISZ=52)}

COMMON / VISC / VISO(ISZ), VISG,VISW, AVIS1, AVIS2, BVIS, CVIS

C

C

VISOIL $=10 * *$ (AVISI *P+BVIS *X12+CVIS)

RETURN

END

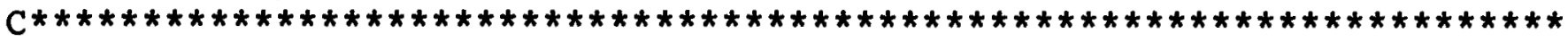
1

FUNCTION QFLOFN (Q,DT,RO11,RO31, IW,RO12,RO22,RO32,F1,F2,F3, X22,

C X33,DEL2,DEL3, XI2, X13)

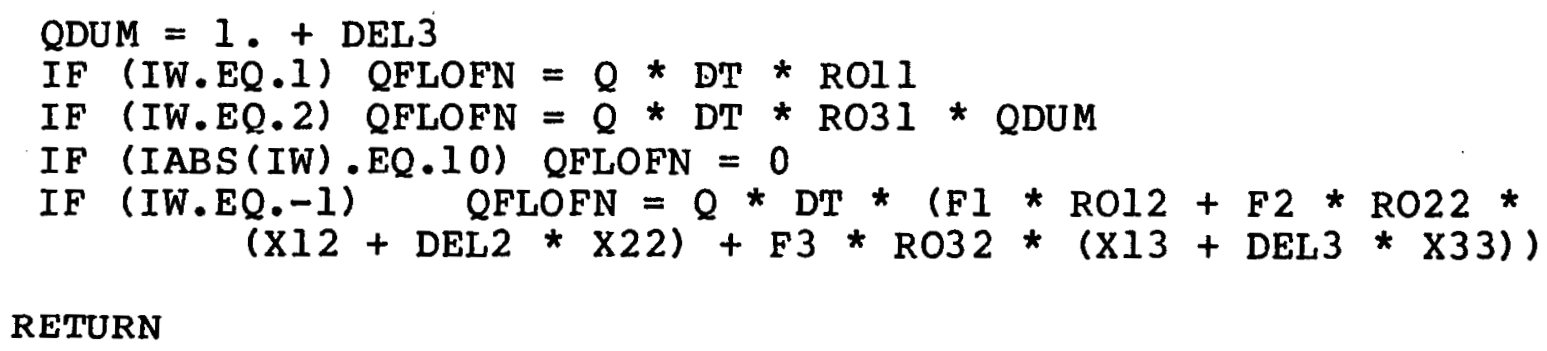

RETURN

C

END 